\title{
Estudos de Técnicas de Texturização e Biolização, e Desempenho Biológico In Vitro e In Vivo em Membrana para um Dispositivo de Assistência Ventricular e Coração Artificial Totalmente Implantáveis
}

\section{Daniel Formariz Legendre}

Dissertação apresentada ao Programa de PósGraduação Interunidades em Bioengenharia / Escola de Engenharia de São Carlos / Faculdade de Medicina de Ribeirão Preto / Instituto de Química de São Carlos, da Universidade de São Paulo para obtenção do título de Mestre em Bioengenharia.

Orientador: Prof. Dr. Orivaldo Lopes da Silva

São Carlos 


\section{Dedicatória}

Aos meus pais com amor e gratidão. 


\section{Agradecimentos}

Este trabalho foi um dos maiores desafios de minha vida e sua realização só foi possível devido à contribuição de pessoas diretamente ou indiretamente envolvidas na pesquisa.

Gostaria de agradecer ao professor e amigo Orivaldo Lopes da Silva da Escola de Engenharia de São Carlos da Universidade de São Paulo pela sua excepcional orientação para a realização desta pesquisa.

Gostaria de agradecer ao professor e amigo Aron José Pazin de Andrade por sua brilhante orientação e apoio no desenvolvimento deste trabalho.

Gostaria de agradecer ao Dr. Paulo Valente do Departamento de Cirurgia Experimental e a Dra. Lílian Mary da Silva do Departamento de Patologia, ambos do Instituto "Dante Pazzanese" de Cardiologia, pela enorme contribuição, ensinamentos e amizade.

Gostaria de agradecer ao colega Eduardo Miola do Laboratório de Interações Hiperfinas do Departamento de Física da Universidade Federal de São Carlos pela sua ajuda.

Gostaria de agradecer a professora Dra. Lauralice de Campos Franceschini Canale, pela sua ajuda no momento em que ingressei nesta instituição de ensino e durante toda a duração da pesquisa.

Gostaria de agradecer ao amigo André Paschoal por toda a sua ajuda nos momentos mais difíceis.

Gostaria de agradecer a toda equipe médica do grupo de pesquisa do Coração Artificial Total do Instituto "Dante Pazzanese" de Cardiologia pela valorosa participação neste projeto.

Gostaria de agradecer aos companheiros do Departamento de Biomecânica do Instituto "Dante Pazzanese" de Cardiologia por todo apoio e colaboração.

Gostaria de agradecer aos meus colegas e amigos do Instituto "Dante Pazzanese" de Cardiologia. 
Gostaria de agradecer a todos, que de alguma maneira me ajudaram a realizar este trabalho.

Finalmente, gostaria de agradecer à minha família e amigos por todo o apoio e compreensão, o que tornou viável a realização deste trabalho. 


\section{Lista de Figuras}

Figura I.1-1 Percentual de Óbitos por Doenças Cardiovasculares. 2

Figura I.2.1-1 Modelo da bomba de sangue desenvolvida por DeBakey. 5

Figura I.2.1-2 Coração artificial implantado em animal por Akutsu e Kolf. 6

Figura I.2.1-3 Primeiro implante clínico de um DAV pulsátil. 6

Figura I.2.1-4 Posicionamento do balão intra-aórtico dentro da artéria. $\quad 7$

Figura I.2.1-5 "Jarvik 7" Coração artificial total implantado por 112 dias. 7

Figura I.2.1-6 Coração artificial total "AbioCor". 8

Figura I.2.3-1 Desenho esquemático da montagem dos componentes do Coração Artificial Auxiliar.

Figura I.5.1-1 Representação esquemática da orientação das fibras de tropocolágeno no colágeno e após separação e quebra as cadeias em segmentos, produzindo moléculas de gelatina.

Figura II.1.1-1 Desenho esquemático do circuito de teste.

Figura II.1.1-2 Mock Loop System utilizado no teste de resistência do diafragma texturizado.

Figura II.2.1-1 Fluxograma do processo de experimento em animal com implante de patch.

Figura II.2.1-2 Secção da parede arterial. 26

Figura II.2.1-3 Laparotomia mediana permitindo o acesso à aorta abdominal. 29

Figura II.2.1-4 Clampeamento parcial e remoção de parte da parede da artéria. 29

Figura II.2.1-5 Sutura dos patches na parede da aorta e verificação de qualquer tipo de vazamento.

Figura II.2.2-1 Fluxograma do processo de experimento em animal com implante de DAV.

Figura II.2.2-2 Toracotomia lateral direita.

Figura II.2.2-3 Incisão na altura da $12^{\mathrm{a}}$ ou $13^{\mathrm{a}}$ costela para acomodação dos cabos de alimentação/sensores e de comunicação de ar com a antecâmara.

Figura II.2.2-4 Os enxertos de entrada e saída do DAV são suturados ao ápice do ventrículo esquerdo e à aorta ascendente. Também são feitos ajustes em relação ao comprimento dos enxertos.

Figura II.2.2-5 O dispositivo vazador de ventrículo é utilizado para produzir um orifício no ápice do ventrículo esquerdo. 
Figura II.2.2-6 Sutura do bordelete que é ligado ao enxerto de entrada do DAV. 38 Figura II.2.2-7 Nas primeiras 24 horas do pós-cirúrgico, o animal é mantido na mesa cirúrgica sob constante observação. 38

Figura III.1.1-1 Diafragma texturizado após término do experimento In Vitro. 41 Figura III.1.2.1-1 MEV (A) Apesar de aparentemente lisa, a superfície do material se mostrou rugosa (aumento de 3.000x);

(B) Base de poliéster com cobertura de poliuretana (superfície lisa sem gelatina) (aumento de 65x).

Figura III.1.2.1-2 MEV (A) A superfície de contato tem um aspecto extremamente poroso, servindo como base para deposições de elementos constituintes do sangue (aumento de 40x);

(B) Base de poliéster com cobertura de poliuretana (superfície texturizada sem gelatina) (aumento de 55x).

Figura III.1.2.1-3 MEV (A) A superfície do patch é constituída por uma camada protéica que isola totalmente a poliuretana, evitando o seu contato com o meio biológico (aumento de 150x);

(B) Base de poliéster com cobertura de poliuretana biolizada (superfície texturizada e com cobertura de gelatina) (aumento de 50x).

Figura III.1.2.1-4 (A) Definitivamente foi rompida a parede do va so para a colocação do implante;

(B) Íntima em formação, ainda com grande quantidade de células inflamatórias. 46

Figura III.1.2.1-5 Rotura da lâmina elástica interna e da média.

Figura III.1.2.1-6 (A) Íntima neo-formada, com células endoteliais e células musculares lisas bem evidentes;

(B) Íntima neo-formada cicatricial e espessa.

48

Figura III.1.2.1-7 (A) A neo-vascularização ocorre a partir da parede não lesada do vaso;

(B) Ocorrência de uma possível calcificação distrófica;

(C) Proliferação vascular concomitante no bordo da lesão devido à necessidade de uma cicatrização;

(D) Presença de processo inflamatório;

(E) Presença de um tecido mais maduro, pois existe um número menor de núcleos, o que demonstra uma fase mais cicatricial;

(F) Grande quantidade de células histiocitárias de corpo estranho. 
Figura III.1.2.1-8 Íntima neo-formada, células musculares e tecido conjuntivo. 51

Figura III.1.2.1-9 (A) Células endoteliais mostrando a completa recuperação do tecido lesado;

(B) Íntima neo-formada bastante espessa, com a presença de células musculares lisas e de tecido conjuntivo;

(C) Resposta do hospedeiro e resposta inflamatória ao material que é implantado. 52

Figura III.1.2.2-1 As curvas superiores de eletrocardiograma e de pressão arterial registram o momento em que o dispositivo é desligado e ligado novamente. As curvas inferiores mostram o coração natural em sincronismo com o DAV.

Figura III.1.2.2-2 As curvas indicam freqüência cardíaca de 78 bpm, pressões arteriais máxima, média e mínima de respectivamente 151, 119 e 108 mmHg. O dispositivo foi colocado em modo de funcionamento com taxa variável de ejeção e velocidade do motor de $61 \mathrm{bpm}$.

Figura III.1.2.2-3 A freqüência cardíaca é de 56 bpm, e as pressões arteriais máxima, média e mínima são de respectivamente 112, 86 e 69 mmHg. Foi utilizada derivação I com filtro e velocidade do papel de $25 \mathrm{~mm} / \mathrm{s}$. O dispositivo foi colocado em modo de funcionamento com taxa fixa de ejeção e velocidade do motor de $60 \mathrm{bpm}$.

Figura III.1.2.2-4 (A) Diafragma do dispositivo de assistência após explante parcialmente coberto por trombo;

(B) Câmara de bombeamento após explante com oclusão parcial do orifício de saída devido à formação de um trombo;

(C) Porção do trombo recente, intracavitário, constituído por uma rede de fibrina, hemácias e alguns elementos celulares. 
Lista de Tabelas

Tabela III.1.2.1-1 Dados referentes aos implantes de patch em animal 


\section{Lista de Abreviaturas e Siglas}

DAV - Dispositivo de Assistência Ventricular

CAA - Coração Artificial Auxiliar

SUS - Sistema Único de Saúde

FAJ - Fundação Adib Jatene

IDPC - Instituto "Dante Pazzanese" de Cardiologia

Incor - Instituto do Coração

NI - Neo-íntima

MEV - Microscopia Eletrônica de Varredura

$\mathrm{CC} \quad$ - $\quad$ Corrente Contínua

ASTM - $\quad$ American Society for Testing and Materials

HEPA - $\quad H i g h$ Efficiency Particulate Air filter

DMAc - $\quad$ N,N Dimetilacetamida

CEPE - Comitê de Ética em Pesquisa Experimental

TCA - Tempo de Coagulação Ativada

PVC - Pressão Venosa Central

UTI - Unidade de Terapia Intensiva

PA - Pressão Arterial

ECG - Eletrocardiograma

TP - Tempo de Protrombina

HE - Hematoxilina e Eosina 


\section{Sumário}

Lista de Figuras

Lista de Tabelas

Lista de Abreviaturas e Siglas $\quad$ v

Resumo viii

Abstract $\quad$ ix

Introdução 1

I.1 Motivação para o Desenvolvimento da Tecnologia 1

I.2 Bombas de Sangue 4

I.2.1 Evolução das Bombas de Sangue 5

I.2.2 Classificação dos Dispositivos de Assistência 8

I.2.3 Breve Descrição do Dispositivo de Assistência Ventricular Esquerda 11

$\begin{array}{lll}\text { I.2.4 Problemas Associados ao Bombeamento de Sangue } & 13\end{array}$

$\begin{array}{ll}\text { I.3 Diafragma } & 14\end{array}$

$\begin{array}{ll}\text { I.4 Adsorção de Proteínas } & 16\end{array}$

$\begin{array}{ll}\text { I.5 Biolização } & 17\end{array}$

$\begin{array}{llr}\text { I.5.1 Gelatina } & 18\end{array}$

$\begin{array}{lll}\text { I.5.2 Processo de Biolização } & 19\end{array}$

$\begin{array}{ll}\text { I.6 Endotelização } & 20\end{array}$

II.1 Teste In Vitro 22

II.1.1 Descrição do Sistema Mecânico 22

II. 2 Testes In Vivo $\quad 25$

II.2.1 Implante de Patch 25

II.2.2 Implante do Dispositivo 31

III.1 Resultados 41

III.1.1 Teste In Vitro 41

III.1.2 Testes In Vivo $\quad 42$

III.1.2.1 Implante de Patch 42

III.1.2.2 Implante do Dispositivo 52

IV.1 Discussão $\quad 58$

IV.1.1 Teste In Vitro $\quad 58$

IV.1.2 Implante de Patch $\quad 58$

IV.1.3 Implante do DAV 59 
IV.2 Conclusões

IV.2.1 Teste Mecânico $\quad 60$

IV.2.2 Estudo Morfológico e Histológico 60

$\begin{array}{ll}\text { IV.2.3 Implante do Dispositivo } & 61\end{array}$

Referências Bibliográficas $\quad 62$

Apêndice A $\quad 65$

$\begin{array}{ll}\text { Apêndice B } & 82\end{array}$

Apêndice C 93

$\begin{array}{ll}\text { Anexo A } & 98\end{array}$

$\begin{array}{ll}\text { Anexo B } & 103\end{array}$ 


\section{Resumo}

LEGENDRE, D. F. (2003). Estudos de Técnicas de Texturização e Biolização, e Desempenho Biológico In Vitro e In Vivo em Membrana para um Dispositivo de Assistência Ventricular e Coração Artificial Totalmente Implantáveis. São Carlos, 2003. 103p. Dissertação (Mestrado) - Escola de Engenharia de São Carlos, Universidade de São Paulo.

Foi desenvolvido um diafragma de elevada vida útil e biocompatibilidade a ser utilizado em um dispositivo de assistência ventricular esquerda (DAV) eletromecânico de dimensões reduzidas e totalmente implantável. Foi realizado teste de resistência do diafragma de poliuretana com superfície texturizada. O teste avaliou sua resistência para experimentos In Vivo de até quinze dias com o DAV implantado em bezerro. Uma superfície de endotélio natural tem excelente tromboresistência. A quantidade e as características da neointima formada em um DAV são determinadas pela superfície do material, hemodinâmica e condições fisico-patológicas. O implante de patch na aorta abdominal de porco isola as variáveis que normalmente estão presentes durante a utilização do DAV e que interferem na hemocompatibilidade do material. A avaliação das características do material foi obtida com o seu implante na parede da aorta descendente em contato com o fluxo sanguíneo. Diferentes tipos de superfície de contato foram avaliadas em sete experimentos In Vivo. Este estudo está voltado para as reações de interface sangue / material. Um estudo histológico foi realizado ao final de cada experimento para analisar as interações entre o sangue e o material, quantificando e qualificando a intima neo formada sobre a superfície de contato, calcificação e deposições de elementos constituintes do sangue.

\section{Palavras-chave:}

Dispositivo de Assistência Ventricular, Teste de Resistência, Hemocompatibilidade, Endotelização. 


\begin{abstract}
LEGENDRE, D. F. (2003). Studies of Techniques Applied to Make a Textured and Biolized Surface Diaphragm, and Biological Performance In Vitro and In Vivo in a Membrane of a Ventricle Assist Device and Total Artificial Heart Fully Implantable. São Carlos, 2003. 103p. Dissertação (Mestrado) - Escola de Engenharia de São Carlos, Universidade de São Paulo.

It has been developed a high lifetime and biocompatible diaphragm to be used in a Left Ventricle Assist Device (LVAD) that is a reduced dimension totally implantable electromechanical device. It has been performed an endurance test on a textured diaphragm made of polyurethane. This test has evaluated the diaphragm resistance to be used in In Vivo tests with the LVAD implanted for fifteen days in calves. A natural endothelial cell surface has excellent thromboresistant characteristics. The quantity and the characteristics of the neointima formed into LVAD are determined by the material surface, hemodynamics of the blood through the device, and the physico-pathological conditions. The patch implantation into the abdominal aorta of pigs has isolated some normal variables that usually are present during LVAD utilization and that may interfere on the material biocompatibility. The evaluation of the material's characteristics has been enhanced through its implantation at the descending aorta wall in contact with blood flow. Different kinds of contact surfaces of specific polyurethane are tested in seven In Vivo experiments. This study is totally focused in the reaction of the bloodmaterial interface. A histogical study is performed in the end of every animal experiment to analyze the interactions between blood and biomaterial. It's emphasized the quantification and qualification of the neointima over the blood contact surface, calcification, and blood depositions.
\end{abstract}

\title{
Keywords :
}

Left Ventricle Assist Device, Endurance Test, Bloodcompatibility, Endothelization. 


\section{Capítulo I}

Introdução

\section{I.1 Motivação para o Desenvolvimento da Tecnologia}

Devido ao grande desenvolvimento da tecnologia médica ocorrida nos últimos quarenta anos, houve um expressivo aumento na expectativa de vida da população humana. No Brasil, desde a década de quarenta vem ocorrendo um processo de inversão das curvas de mortalidade, gerando um declínio desta taxa devido a doenças infecciosas e um significativo aumento desta taxa por doenças crônicas não transmissíveis e causas externas. Esse fenômeno é conhecido como transição epidemiológica e ocorreu em todos os países desenvolvidos onde a população de idosos está cada vez mais expressiva.

Em 1930 em nosso país, as doenças cardiovasculares representavam aproximadamente $11,8 \%$ do total de óbitos das capitais, no entanto em 1996 este percentual cresceu drasticamente chegando a 27,4\% (Figura I.1-1). A taxa de mortalidade devido a doenças cardiovasculares é considerada alta em nosso país, mesmo com todo o desenvolvimento tecnológico aplicado em diagnóstico e tratamento deste tipo de doença (Ministério da Saúde, 2002). 


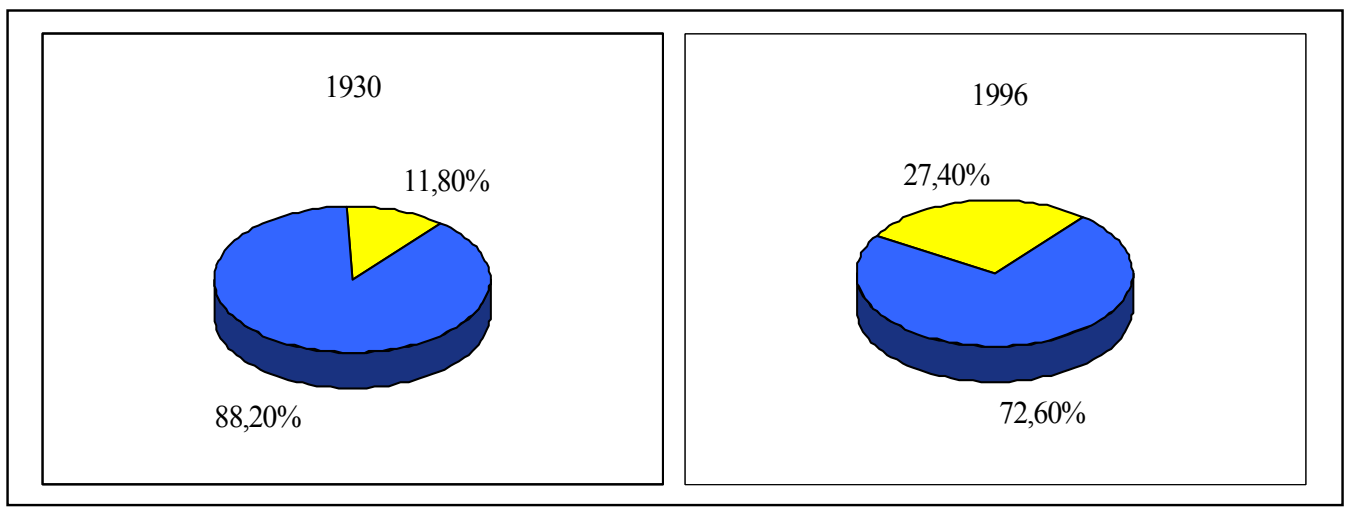

Figura I.1-1 Percentual de Óbitos por Doenças Cardiovasculares.

O transplante de órgão é considerado como uma das principais alternativas cirúrgicas em casos de doenças onde terapias médicas e/ou cirurgias convencionais já não apresentam resultado eficiente como alternativa de tratamento. Transplante é um procedimento cirúrgico onde ocorre à substituição de um órgão ou tecido comprometido de uma pessoa (receptor), por outro órgão ou tecido sadio de outra pessoa (doador). O doador e o receptor devem compartilhar uma série de características biológicas comuns. Esse procedimento é aplicado com o intuito de salvar e melhorar a qualidade de vida do paciente (receptor).

A maior parte dos transplantes, cerca de noventa por cento são financiados pelo Sistema Único de Saúde (SUS), isso porque a maioria dos planos de saúde não custeia esse tipo de procedimento.

Nos dias atuais, em todo o mundo mais de seiscentas mil pessoas estão cadastradas nas filas de espera de transplante de órgão ou tecido, sendo que no Brasil a fila de espera é de mais de quarenta e duas mil pessoas. A lista de espera para transplante de um coração é a menor delas, pois a maioria dos candidatos morre antes mesmo de conseguir um órgão (Aliança Brasileira pela Doação de Órgãos e Tecidos, 2002).

O número de doadores efetivos é relativamente baixo devido à contra-indicação médica e à resistência familiar. $\mathrm{O}$ fator determinante para a utilização de um órgão em transplante é o estado no qual ele se encontra. Em geral, existe um limite de idade para um doador de órgão, que no caso de um coração é de cinqüenta e cinco anos.

Assim que o coração de um doador é retirado, este órgão pode permanecer sem circulação sanguínea por um período máximo de seis horas. Após o recebimento do 
novo órgão, o paciente deve tomar diversas drogas pelo resto de sua vida a fim de se evitar a rejeição ao mesmo.

Evidentemente, existe a necessidade da implementação de uma terapia alternativa, que possa ser empregada em casos de pacientes portadores de insuficiência cardíaca grave, e que sejam candidatos à substituição cardíaca. Com esse propósito vem sendo estudada em diversas instituições a utilização de dispositivos de assistência, sejam eles univentriculares ou biventriculares, que possam assistir ou substituir o coração natural do candidato ao transplante.

No Instituto do Coração de São Paulo (Incor) está em desenvolvimento um dispositivo de assistência ventricular paracorpóreo com princípio de funcionamento pneumático (Oshiro, 1995). A unidade de bombeamento constituída por câmara e antecâmara, ambas confeccionadas de resina epoxy, são separadas por uma membrana de poliuretana. Essa membrana é reforçada com uma malha de algodão que lhe proporciona aumento de resistência, evitando assim estiramento excessivo. A câmara de bombeamento é revestida pela poliuretana, evitando o contato de sangue com materiais distintos (resina e poliuretana), o que propiciaria a formação de trombo. Na entrada e na saída da câmara de bombeamento são posicionadas duas próteses valvares de pericárdio bovino.

O Instituto "Dante Pazzanese" de Cardiologia (IDPC) e a Fundação Adib Jatene (FAJ) vêm desenvolvendo um modelo de ventrículo de assistência esquerda, com princípio de funcionamento eletromecânico. O dispositivo de assistência ventricular (DAV), totalmente implantável devido a sua dimensão reduzida, pode permanecer implantado por um período prolongado, servindo assim como "ponte para transplante" e estendendo a sobrevida do paciente até que um órgão sadio esteja disponível para transplante. No projeto de uma bomba de sangue eletromecânica pulsátil (ventrículo ou coração artificial auxiliar), faz-se necessária à utilização de um diafragma com elevada vida útil e hemocompatibilidade. Inicialmente era utilizado um diafragma de silicone que apesar da facilidade de confecção, se mostrou inviável devido à falta de resistência mecânica. Aliado a isso, havia a dificuldade de se obter uma superfície apropriada que possibilitasse o processo de deposição de uma camada protéica. A utilização de poliuretana na confecção de uma membrana se mostrou como uma alternativa viável devido à excelente resistência mecânica, sendo também possível a obtenção de uma superfície texturizada, que não comprometesse a sua vida útil, e que possibilitaria a 
deposição de uma camada protéica. Através de teste In Vitro, onde são simuladas as condições fisiológicas normais do ser humano, foi possível avaliar a resistência da membrana texturizada sem que fosse necessário o implante do dispositivo.

No processo de biolização, uma gelatina composta de colágeno de pele bovina (tipo I) tem como função criar uma neo-interface entre a poliuretana (material não orgânico) e o sangue, servindo como uma superfície geradora de neo-íntima (NI). Diante da necessidade de caracterização da superfície de contato, foi proposta a realização de testes para avaliação das interações entre biomaterial e sangue, possibilitando uma análise comparativa entre a utilização de poliuretana com superfície texturizada com e sem cobertura protéica e superfície lisa sem cobertura protéica.

Esta pesquisa tem como objetivo o estudo e a aplicação de técnicas para a texturização e biolização de uma membrana utilizada em um ventrículo de assistência pulsátil e também a análise quantitativa e qualitativa de crescimento de uma neo-íntima sobre os materiais utilizados nas superfícies internas do DAV em desenvolvimento no IDPC/FAJ. Assim, foram feitos:

- Estudo e aplicação de técnicas para a texturização e biolização de uma membrana utilizada em um ventrículo de assistência esquerda pulsátil;

- Realização de testes In Vitro simulando as condições fisiológicas normais de um humano adulto com o intuito de testar a resistência mecânica do diafragma texturizado;

- Testes In Vivo com implante de patch (amostra de poliuretana texturizada com e sem cobertura protéica e lisa sem cobertura protéica) na aorta abdominal de suínos para a confirmação da formação de uma camada neo-íntima na interface de contato sangue/biomaterial;

- Microscopia Eletrônica de Varredura do material a ser implantado;

- Microscopia Óptica do material implantado.

- Realização de testes In Vivo conforme estudos anteriores para a constatação da formação de uma neo-íntima na interface de contato sangue/biomaterial, considerando as variáveis intrínsecas em condições normais de funcionamento de um ventrículo de assistência.

I. 2 Bombas de Sangue 


\section{I.2.1 Evolução das Bombas de Sangue}

Os dispositivos de assistência circulatória sofreram grande evolução desde os primórdios do século vinte, em conseqüência do desenvolvimento de técnicas cirúrgicas.

Em 1934, foi desenvolvida pelo Dr. Michael DeBakey a primeira bomba sanguínea de fluxo contínuo para transfusão (Figura I.2.1-1). Conhecida como bomba de roletes porque utiliza o princípio conhecido como "tubo de ordenhar", onde girando uma manivela no sentido horário os cilindros comprimem sucessivamente o tubo de borracha, produzindo um efeito de "ordenha", que força o sangue a deslocar-se no sentido horário (DeBakey, 1934).

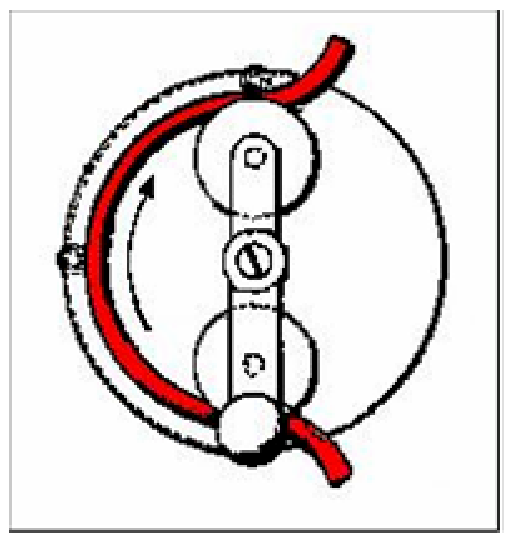

Figura I.2.1-1 Modelo da bomba de sangue desenvolvida por DeBakey.

Em 1953, J. H. Gibbon e C. W. Lillehei utilizaram pela primeira vez uma máquina de circulação extracorpórea com bomba de roletes em cirurgia com coração aberto em paciente (Allen e Lillehei, 1957). O equipamento consistia de uma bomba e um oxigenador de sangue, o que permitia a manutenção do fluxo e da troca de gases sangüíneos durante o ato cirúrgico, enquanto o coração e os pulmões eram mantidos fora da circulação.

Em 1957, Akutsu e Kolff implantaram um coração artificial com princípio de funcionamento pneumático em um cão (Figura I.2.1-2), mantendo o animal vivo por aproximadamente noventa minutos (Akutsu e Kolff, 1958). 


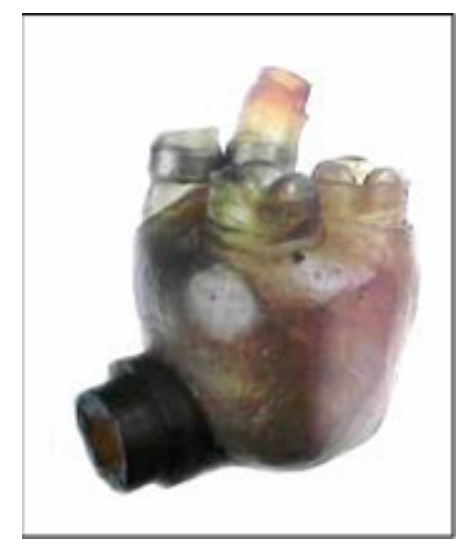

Figura I.2.1-2 Coração artificial implantado em animal por Akutsu e Kolf.

Em 1961, Liotta realizou o primeiro implante clínico de um dispositivo de assistência ventricular pulsátil (Liota, 1963) (Figura I.2.1-3). Com o aperfeiçoamento das técnicas cirúrgicas e o desenvolvimento da tecnologia mecânica e eletrônica, esforços foram realizados na tentativa de substituir totalmente o coração natural.

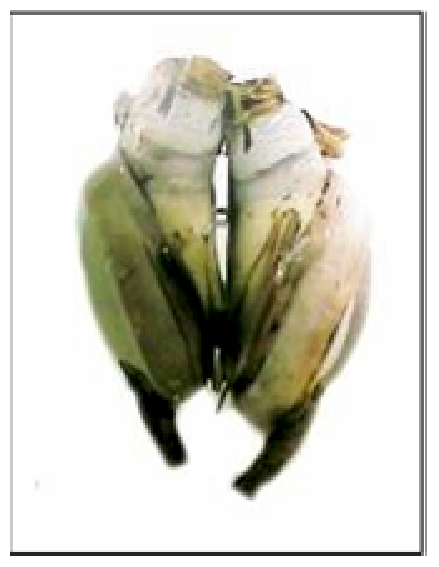

Figura I.2.1-3 Primeiro implante clínico de um DAV pulsátil.

Em 1962, Moulopoulos e colaboradores desenvolveram o balão intra-aórtico (Moulopoulos et al., 1962) (Figura I.2.1-4). 


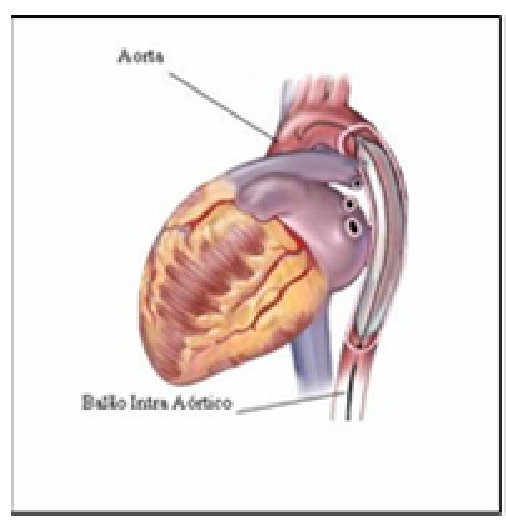

Figura I.2.1-4 Posicionamento do balão intra-aórtico dentro da artéria.

Em 1969, Denton A Coolley implantou pela primeira vez em ser humano um coração artificial como "ponte para transplante", tendo o dispositivo permanecido no paciente por 64 horas (Bronzino, 1986).

Em 1982, DeVries implantou o primeiro coração artificial total conhecido como Jarvik-7 (Figura I.2.1-5), com princípio de funcionamento pneumático, tendo o paciente sobrevivido por um período de 112 dias (DeVries, 1984).

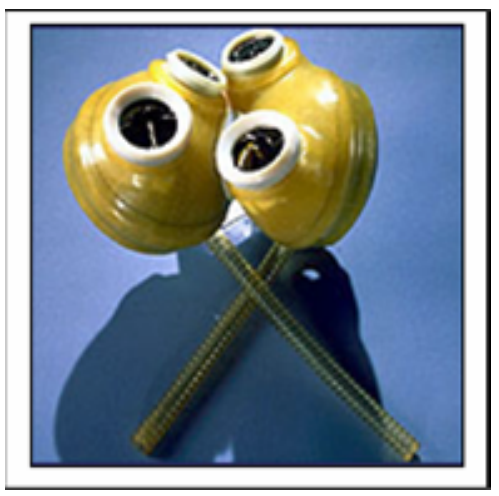

Figura I.2.1-5 "Jarvik 7" Coração artificial total implantado por 112 dias.

Em julho de 2001, cirurgiões do "Jewish Hospital” em Louisville, Kentucky, executaram o primeiro implante em um paciente do AbioCor (Figura I.2.1-6), uma bomba com princípio de funcionamento eletro-hidráulico (Newsweek, 2001). 


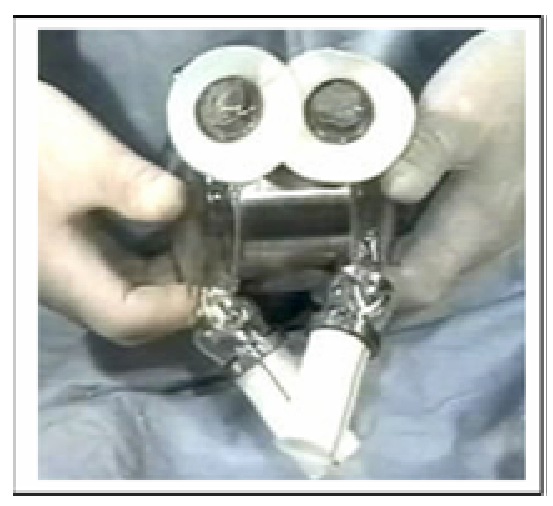

Figura I.2.1-6 Coração artificial total "AbioCor".

\section{I.2.2 Classificação dos Dispositivos de Assistência}

Os dispositivos de assistência podem ser classificados quanto ao tipo de bombeamento, quanto à sua localização em relação à anatomia do receptor, quanto ao modo de acionamento do atuador, quanto à assistência promovida, e quanto à sua aplicabilidade.

Tipo de Bombeamento:

Bombeamento não-pulsátil com fluxo radial:

Nesse tipo de bombeamento os dispositivos têm fluxo contínuo e o sangue se movimenta perpendicular ao eixo de rotação da bomba. A admissão é realizada pelo conector de entrada e o sangue é forçado, pelo efeito centrífugo, em direção à base, saindo da bomba sob pressão.

Bombeamento não-pulsátil com fluxo axial:

Nesse tipo de bombeamento o fluxo de sangue é paralelo ao eixo de rotação do dispositivo.

Bombeamento pulsátil:

Nesse tipo de bombeamento o fluxo de sangue ocorre devido à movimentação de um ou dois diafragmas (univentricular ou biventricular), dependendo do tipo de assistência. São utilizadas valvas mecânicas ou bioprótese (tecido natural), as quais permitem a passagem unidirecional do sangue. 
Modo de Acionamento:

Eletromecânico:

Esse tipo de acionamento tem como princípio a transformação do movimento de rotação de um motor elétrico em movimento linear através de um parafuso de roletes que empurra uma placa propulsora, deslocando um diafragma. Este tipo de dispositivo promove a ejeção alternada das câmaras direita e esquerda.

Eletro-hidráulico:

Um exemplo deste tipo de dispositivo utiliza uma ou duas câmaras de sangue que são separadas das antecâmaras por diafragmas. Uma bomba de alta rotação é utilizada para bombear óleo de uma antecâmara para a outra, movendo os diafragmas e ejetando o sangue dos ventrículos de forma alternada.

Pneumático:

Este tipo de acionamento utiliza basicamente o mesmo princípio do acionamento eletro-hidráulico. No entanto é utilizado um compressor ao invés de uma bomba de alta rotação, que movimentará os diafragmas pela injeção de ar comprimido nas antecâmaras.

Eletromagnético:

Este tipo de dispositivo é composto por um eletroímã posicionado entre placas metálicas, que com sua atração comprimem uma bolsa de poliuretana, onde é armazenado o sangue.

Localização do Dispositivo:

Paracorpóreo:

O dispositivo é colocado externamente ao corpo do paciente.

Implantável:

O dispositivo é colocado dentro do corpo do paciente.

Assistência Promovida: 
Contrapulsação:

Este tipo de assistência promovida, por exemplo, pelo balão intra-aórtico é baseada no princípio da contrapulsação. O balão intra-aórtico é posicionado por meio de um cateter na aorta torácica descendente. Ele é rapidamente inflado na diástole, simultaneamente com o fechamento da valva aórtica, aumentando assim a pressão diastólica de pico na porção proximal da aorta ascendente, melhorando as perfusões coronariana e sistêmica. No início da sístole, o balão é rapidamente esvaziado, permitindo que o volume sistólico seja ejetado na aorta sem obstáculos.

Assistência em série:

Neste tipo de assistência, o dispositivo é posicionado de forma a substituir as atividades do ventrículo, que foi totalmente extraído, bombeando sangue para a aorta.

Assistência em paralelo:

Normalmente, um dispositivo de assistência ventricular em paralelo é posicionado junto ao coração natural. Ele recebe sangue dos átrios ou dos ventrículos e retorna aos grandes vasos (aorta ou tronco pulmonar), podendo a assistência ser dada à circulação sistêmica e pulmonar de forma individual (assistência univentricular) ou simultânea (assistência biventricular). Na assistência ventricular direita, a configuração geralmente utilizada neste tipo de procedimento é a canulação do átrio direito e do tronco pulmonar. $\mathrm{Na}$ assistência ventricular esquerda, a disposição mais utilizada é a drenagem pelo ápice do ventrículo esquerdo ou pelo átrio esquerdo ejetando na aorta torácica ascendente ou descendente. Na assistência biventricular é utilizada uma combinação das assistências direita e esquerda.

Total:

No implante ortotópico os ventrículos do paciente são extraídos e substituídos por um coração artificial total. Dessa forma o coração artificial total substitui totalmente as funções do coração natural. Mesmo assim, o coração artificial total não serve de substituto permanente para o coração natural, o paciente deverá sofrer transplante.

Compressão extrínseca: 
É realizada por dispositivos que aplicam pressão sobre o coração de forma a realizar uma massagem cardíaca interna. O tipo de assistência que utiliza esse princípio é a cardiomioplastia, onde o músculo grande dorsal da parede do tórax do próprio paciente é deslocado de sua inserção normal e colocado de modo a envolver o coração. Esse procedimento proporciona uma melhora no bombeamento de sangue exercido pelo coração quando as paredes musculares de seus ventrículos estão com sua capacidade contrátil muito diminuída.

Aplicabilidade:

Substituição temporária:

Em substituição temporária o equipamento é utilizado apenas durante o ato cirúrgico, como, por exemplo, na circulação extracorpórea, onde existe a necessidade de substituição momentânea das funções do coração e dos pulmões.

Suporte para recuperação:

O suporte para a recuperação é utilizado quando existe a necessidade de auxílio à função cardíaca facilitando a recuperação do coração, podendo ser realizada através de balão intra-aórtico ou bombas centrífugas.

Suporte Prolongado ou "Ponte para transplante":

A assistência ventricular prolongada como "ponte para transplante" é utilizada quando o paciente necessita de um transplante cardíaco imediato, porém não há nenhum doador disponível. O equipamento mantém o paciente vivo, até a obtenção de um órgão para o transplante. Este tipo de procedimento pode ser realizado com a utilização de bomba axial ou dispositivo de assistência ventricular implantáveis.

\section{I.2.3 Breve Descrição do Dispositivo de Assistência Ventricular Esquerda (DAV)}

O DAV é um dispositivo com princípio de acionamento eletromecânico e controlado eletronicamente. O dispositivo é composto por um corpo central de alumínio, utilizado como base de fixação para um parafuso planetário de roletes, que transforma o movimento de rotação de um motor elétrico de corrente contínua (CC) sem escovas em movimento linear do parafuso de roletes (Figura I.2.3-1). O parafuso de 
roletes avança e empurra uma placa propulsora, deslocando um diafragma de poliuretana $\left(\right.$ BioSpan $\left.{ }^{\circledR}\right)$.

Este dispositivo ajuda o coração natural a obter o fluxo sangüíneo necessário ao organismo e sua freqüência de funcionamento varia conforme ocorrem mudanças na pré-carga ou pressão de enchimento ventricular.

Sensores magnéticos de efeito Hall são instalados no corpo central do DAV, para detecção e controle do posicionamento das suas partes móveis. A fase de ejeção é iniciada quando um dos sensores detecta o enchimento completo do ventrículo esquerdo. Dessa forma, a freqüência de funcionamento do DAV depende do tempo de enchimento do ventrículo esquerdo.

O sistema de controle obtém as informações a partir do movimento da placa propulsora esquerda, a qual, por sua vez, responde à pressão atrial esquerda.

Seu princípio de funcionamento é baseado na lei de Frank-Starling, onde o retorno venoso controla o débito cardíaco. Assim, se o retorno venoso aumentar, o enchimento esquerdo ocorrerá mais rapidamente, e a freqüência de batimento aumentará. Se o retorno venoso diminuir, o enchimento esquerdo é mais demorado, e um novo ciclo só terá início após o enchimento total do ventrículo esquerdo, desse modo o sistema irá desacelerar.

O controlador pode ser configurado para atuar em taxa fixa ou em taxa variada. No modo taxa fixa, o controlador irá ejetar o volume de sangue de acordo com a freqüência de batimento previamente ajustada, independente da resposta do sensor de posicionamento do diafragma. Já no modo de taxa variada, a ejeção ocorrerá de acordo com a resposta do sensor de posicionamento do diafragma.

Duas próteses valvares cardíacas de pericárdio bovino são utilizadas na entrada e saída da câmara de bombeamento, o que faz com que o fluxo sanguíneo seja direcionado em apenas um sentido.

Os componentes e subsistemas que compõem o DAV são também adaptáveis a um Coração Artificial Auxiliar (CAA), através de acoplamento de uma câmara de bombeamento direita, placa propulsora e diafragma. 


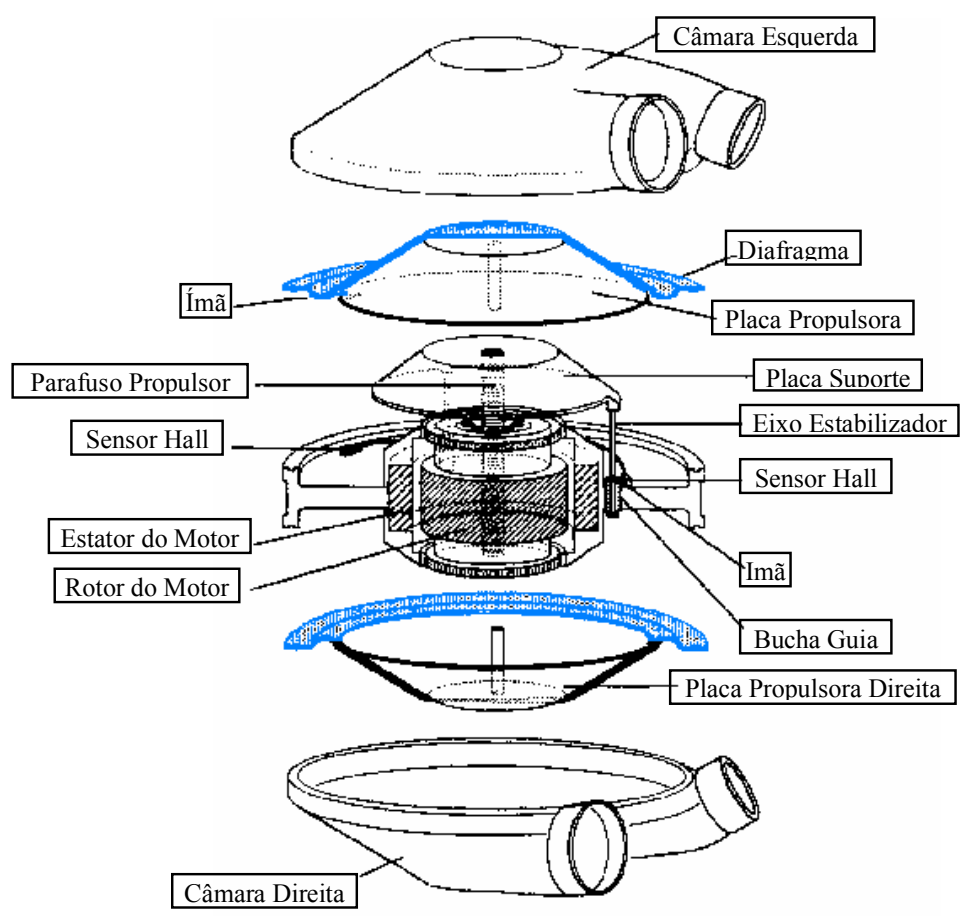

Figura I.2.3-1 Desenho esquemático da montagem dos componentes do Coração Artificial Auxiliar.

\section{I.2.4 Problemas Associados ao Bombeamento de Sangue}

O bombeamento artificial de sangue requer certa cautela devido aos problemas gerados por este tipo de procedimento. Inconvenientes relacionados ao bombeamento de sangue dizem respeito à formação de coágulos ou trombos, traumatismo das células sanguíneas e pela formação de bolhas dentro do dispositivo (Nosé, 1971-a). É fundamental que estes problemas sejam minimizados a níveis aceitáveis sob o ponto de vista fisiológico.

Um dos principais problemas em bombeamento de sangue está associado à formação de coágulos ou trombos (Nosé, 1967-a). Um coágulo que se desenvolva dentro de um dispositivo de bombeamento, provavelmente será deslocado devido ao fluxo contínuo de sangue. Coágulos que fluem livremente dentro do sistema circulatório, também chamados de êmbolos, se deslocam até que cheguem em artérias ou arteríolas de pequeno calibre, podendo causar trombose. Dependendo do tamanho do coágulo, ele poderá diminuir a eficiência da bomba. Uma maneira bastante usual para evitar condições tromboembólicas é a administração de anticoagulantes como a 
heparina ao paciente (Guyton, 1977). Outra maneira é a utilização de materiais hemocompatíveis nas superfícies de contato com o sangue (Nosé, 1967-b). Se o fluxo sanguíneo estiver excessivamente lento, também favorecerá a formação de coágulos, pois pequenas quantidades de procoagulantes estão sempre sendo formadas pelo sangue e, o fluxo lento permitirá aumentar as concentrações de procoagulantes o suficiente para iniciar o processo de coagulação sanguínea. Ao contrário do que ocorre quando há um fluxo eficiente de sangue, pois dessa forma os procoagulantes do sangue são rapidamente misturados em grandes quantidades de sangue (Guyton, 1977).

Outro problema comumente associado ao bombeamento de sangue é a ocorrência de hemólise. Ou seja, ocorre a rotura da membrana das hemácias permitindo a liberação da hemoglobina para o plasma, constituindo a hemoglobina livre. O fenômeno gerado pelo aumento de hemoglobina livre no plasma em conseqüência da hemólise é a hemoglobinemia. O grau de hemólise depende dos níveis de tensões as quais as células estão submetidas e do tempo de exposição destas células aos agentes causadores do trauma. A quantidade de hemoglobina livre no plasma depende da capacidade e da velocidade de remoção do pigmento pelo organismo de cada indivíduo. O excesso de hemoglobina livre no plasma é filtrado pelos rins, e dessa forma, a urina que contém hemoglobina adquire a coloração avermelhada. A ocorrência de hemólise em níveis superiores aos aceitáveis pelo organismo irá resultar em uma série de problemas como a anemia. No bombeamento de sangue também é indesejável o surgimento de bolhas dentro do sistema. Caso estas bolhas entrem no sistema circulatório, isso resultaria em um risco de embolia.

\section{I.3 Diafragma}

Um dispositivo de assistência ventricular com princípio de funcionamento eletromecânico requer a utilização de um elemento flexível como um diafragma ou uma bolsa. Esse elemento flexível isola o sangue dentro de um compartimento ou câmara, evitando o contato do sangue com os demais componentes do dispositivo.

Nesse tipo de aplicação, o diafragma deve possuir características como antitrombogenicidade, mínima rejeição pelo corpo, e também elevada vida útil. A utilização de um componente flexível em um dispositivo de assistência de uso 
prolongado, requer do mesmo uma performance de aproximadamente quarenta milhões de ciclos por ano (Graham, 1990).

O uso de poliuretana em dispositivos de assistência já é bastante difundido. Em 1967, Boretos e Pierce (Lelah e Cooper, 1986) propuseram a utilização de uma poliuretana chamada Biomer $^{\mathrm{TM}}$ para uso em coração artificial. Verificaram que o material tinha boa hemocompatibilidade, e ainda apresentava boa estabilidade física. Essa poliuretana foi amplamente utilizada em dispositivos de assistência e corações artificiais, incluindo o Jarvik. Apesar dos bons resultados obtidos com o Biomer ${ }^{\mathrm{TM}}$, ele foi pouco utilizado clinicamente e, portanto descontinuado na década de 80. Uma poliuretana conhecida como BioSpan ${ }^{\circledR}$ foi desenvolvida com o objetivo de substituir diretamente o Biomer $^{\mathrm{TM}}$. O BioSpan ${ }^{\circledR}$ tem como característica alta resistência, flexibilidade, resistência à fadiga, biocompatibilidade, bioestabilidade, e elevada vida útil. As propriedades mecânicas dessa poliuretana foram testadas pelo fabricante segundo as normas ASTM. A durabilidade do diafragma é um fator limitante para a utilização de dispositivos de assistência.

De acordo com estudos realizados por Nosé e colaboradores (1967-b), foi constatado que para se evitar a coagulação de sangue dentro de próteses cardíacas, deveriam ser levados em consideração alguns fatores como geometria da prótese cardíaca para se evitar estagnação de sangue, fluxo apropriado de sangue para lavagem efetiva das paredes da câmara, acabamento das superfícies em contato com sangue, limpeza apropriada das superfícies em contato com sangue, para se evitar contaminação no processo, e evitar junção de dois materiais diferentes.

Dessa forma verificou-se a dificuldade de uma bomba de superfície lisa em atender estes requisitos. Assim, foram estudadas bombas com diferentes superfícies, demonstrando significativa melhoria na biocompatibilidade de bombas com superfície texturizada e com cobertura protéica. A utilização de um componente biológico como gelatina sobre um polímero como a poliuretana e posteriormente tratado com aldeídos, torna o material compatível com o sangue (Kambic, 1976 e 1978).

\section{Confecção do Diafragma}

Algumas condições especiais são necessárias para a confecção de um diafragma de BioSpan®. É necessária a utilização de câmara de fluxo laminar com filtro HEPA, diminuindo a contaminação por partículas. A temperatura de trabalho deve ser mantida 
entre 30 e $35^{\circ} \mathrm{C}$, pois o solvente $\mathrm{N}, \mathrm{N}$ dimetilacetamida (DMAc) é um material higroscópico e, portanto retém umidade à temperatura ambiente. O molde do diafragma é confeccionado em Delrin devido ao seu baixo coeficiente de atrito e sua resistência à temperatura. Para a obtenção da espessura necessária $(0,5 \mathrm{~mm})$ são depositadas aproximadamente oito camadas, sendo que na última será produzida uma superfície texturizada. A texturização é necessária para que a cobertura de proteína fique bem ancorada na superfície do diafragma.

O processo de confecção do diafragma texturizado inicia-se com a diluição do BioSpan ${ }^{\circledR}$ em solvente DMAc para a concentração de 18,75\%. A superfície do molde é pintada com BioSpan ${ }^{\circledR}$ e mantida em ambiente com temperatura controlada entre 30 e $35^{\circ} \mathrm{C}$ de 20 a 60 minutos. Após isso, o diafragma é colocado em estufa a uma temperatura de $60^{\circ} \mathrm{C}$ por um período de 60 a 120 minutos. Essa primeira etapa do processo de confecção do diafragma é repetida até que o mesmo atinja a espessura de $0,5 \mathrm{~mm}$.

A qualidade do diafragma deve ser checada por meio de radiografia, a qual identifica a presença de partículas contaminantes, bolhas e orifícios no material. Para a formação de uma superfície texturizada, a última camada do diafragma recebe um tratamento específico. Dessa forma, é depositada sobre a superfície do diafragma mais uma camada de BioSpan ${ }^{\circledR}$ e totalmente coberta com polissacarídeo (açúcar refinado). O molde é mantido em estufa a $60^{\circ} \mathrm{C}$ por 24 horas para a remoção total de qualquer resquício de solvente. Após esse período, ele é submerso em água fervendo por 60 minutos para a remoção do polissacarídeo. Ao final do processo é feita a secagem e a inspeção do diafragma.

\section{I.4 Adsorção de Proteínas}

Quando o sangue entra em contato com uma superfície artificial, ocorre a adsorção de uma camada de proteína na interface. A natureza química e física da superfície de contato de um biomaterial, tais como: grupo de superfície específico, carga da superfície e reatividade química, são fatores importantes que determinam as proteínas do plasma adsorvidas na interface (Vašku e Urbánek, 1995). 
A compatibilidade sanguínea de qualquer material depende da habilidade da superfície de contato de interagir com proteínas do plasma e ainda demonstrar a capacidade de permanecer livre de trombo.

A adsorção de uma camada protéica é hipotetizada como precursora para a adesão de plaquetas, ativação do mecanismo intrínseco de coagulação e resultando na formação de trombo (Lyman, 1974). De acordo com o tipo de proteína adsorvida, a natureza da proteína irá afetar o comportamento da superfície de contato com o sangue. O acúmulo de plaquetas sobre a superfície é intensificado pela adsorção de uma camada de fibrinogênio ou gamaglobulina e é inibido pela adsorção de uma camada de albumina (Adams, 1981). Uma forma para se obter uma verdadeira superfície antitrombogênica seria com a deposição de uma camada benigna que não iniciasse um processo de coagulação sanguínea nem destruísse elementos do sangue (Kambic, 1978).

$\mathrm{Na}$ decorrência de trombo, a trombina que está sendo formada aumenta a agregação plaquetária, e propicia a formação de fibrina que estabiliza o trombo. As forças hemodinâmicas que geram as interações da plaqueta com a superfície do material, tendem a provocar a fragmentação do trombo, causando embolia.

Monócitos e polimorfonucleares que aderem à superfície secretam enzimas que podem remover plaquetas e proteínas aderidas à superfície. Com o intenso contato do sangue com a superfície do material, uma neo-íntima pode ser formada, propiciando tromboresistência ao biomaterial (Vašku e Urbánek, 1995).

\section{I.5 Biolização}

O termo "biolização" foi concebido em 1971 pela "Cleveland Clinic Foundation". Desde então o termo tem sido utilizado para referir-se a tecidos naturais ou proteínas (derivadas de tecidos naturais) tratados quimicamente ou termicamente e usados como cobertura ou blenda em polímeros.

A simples adição de materiais derivados de proteínas ou tecidos naturais sobre a superfície de contato não irá melhorar a compatibilidade de um material com o sangue, mas somente após tratamento com aldeídos (Nosé, 1971-b).

A hipótese estabelece que o processo aumentaria a compatibilidade com o sangue de praticamente qualquer material através da ativação biológica por agentes biológicos como proteínas e polissacarídeos. A tromboresistência ocorre devido à 
inativação biológica por aldeídos. Esse tratamento torna o material biológico não específico e insolúvel devido a denaturação ou reação química envolvida na ligação cruzada (Kambic, 1976 e 1978).

A biolização de um material pode ser obtida de três maneiras, sendo pela utilização de tecido natural, através de blenda a partir da mistura de proteína com polímero, ou pela aplicação de uma cobertura protéica sobre um polímero.

A biolização é feita por um processo de "dipping", onde a bomba de sangue é totalmente submersa em uma solução de gelatina a $5 \%$, usando vácuo para preencher completamente os poros da superfície texturizada, e tratada com uma solução de glutaraldeído a $0,45 \%$ para fazer a ligação cruzada das proteínas da gelatina. Essa cobertura de gelatina não deve apresentar descontinuidades. A superfície biolizada combinada com a utilização de próteses valvares de tecido natural elimina a necessidade do uso de drogas anticoagulantes para esse tipo de bomba de sangue (Andrade, 1998).

É utilizado acionamento mecânico do tipo pusher plate, onde o movimento realizado pelo diafragma pode ser controlado, evitando assim a super distensão do diafragma, causando o rompimento da cobertura protéica.

\section{I.5.1 Gelatina}

O componente protéico gelatina não existe na natureza, mas é derivado da proteína colágeno. A transição de colágeno para gelatina é um processo em que o colágeno, bem organizado e insolúvel em água, é transformado de uma rede assimétrica de fibras tropocolágenas para um sistema de moléculas independentes solúveis em água (Figura I.5.1-1).

A gelatina pode ser classificada como um tipo de hidrogel natural. O gel formado apresenta uma resistência à deformação, que serve como base de sua caracterização. A força do gel é classificada como Bloom, que é uma medida da força de geleificação determinada através de uma metodologia padronizada internacionalmente. $\mathrm{O}$ teste de resistência é realizado com uma sonda padrão penetrando $4 \mathrm{~mm}$ em um gel de concentração 6,66\%. A massa necessária para causar esta penetração é que determina sua rigidez, e é expressa em Bloom. A gelatina utilizada para o revestimento do polímero tem Bloom 240 (Rebière Gelatinas, São Paulo), o que significa que foram necessários $240 \mathrm{~g}$ para causar a deformação de $4 \mathrm{~mm}$. 


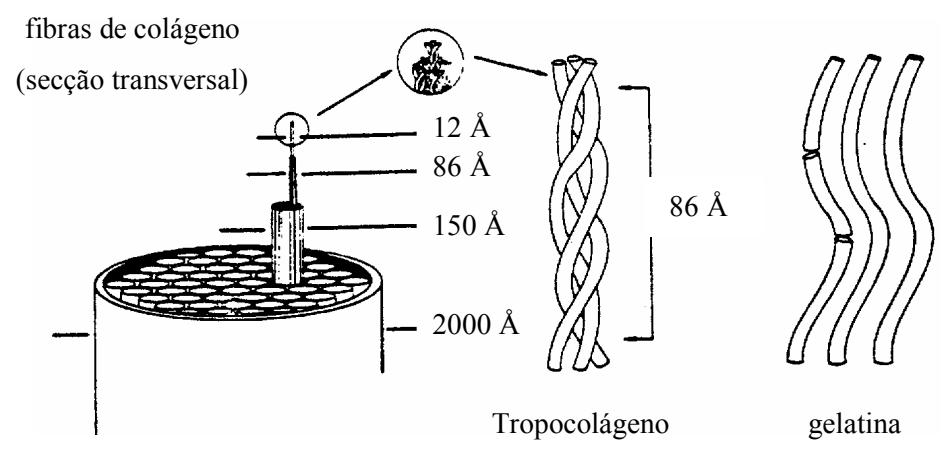

Figura I.5.1-1 Representação esquemática da orientação das fibras de tropocolágeno no colágeno e após separação e quebra as cadeias em segmentos, produzindo moléculas de gelatina.

\section{I.5.2 Processo de Biolização}

Para a utilização do dispositivo de assistência em experimentos In Vivo de até quinze dias, o diafragma texturizado passa por um processo no qual sua superfície recebe uma cobertura protéica. Nesse processo uma fina camada de gelatina composta de colágeno (tipo I) de pele bovina é tratada com glutaraldeído e aplicada na superfície do diafragma de material polimérico com intuito de melhorar a compatibilidade com o sangue em longo prazo. Um tratamento com glutaraldeído torna as proteínas da gelatina estabilizada por ligação cruzada. O glutaraldeído é um dos mais eficientes agentes de ligação cruzada devido a sua interação com um grupo reativo de proteínas, particularmente o grupo $\varepsilon$-amino de lisina. Este tratamento eleva a resistência mecânica da camada de gelatina e a torna insolúvel. A gelatina tem como função criar uma neointerface entre a poliuretana (material não orgânico) e o sangue. Ela é ancorada à superfície texturizada do diafragma por impregnação a vácuo, preenchendo totalmente os poros da superfície (Kambic, 1978).

O processo de biolização aplicado atualmente utiliza uma solução de gelatina a $5 \%$ que é preparada pela dissolução de gelatina em água destilada a $60^{\circ} \mathrm{C}$ por 60 minutos, sendo filtrada para remover quaisquer materiais insolúveis, e desgaseificada numa câmara de vácuo. A bomba de sangue montada, com um tubo temporariamente conectado para ventilação da câmara do motor, é imersa numa solução de gelatina e colocada numa estufa a $60^{\circ} \mathrm{C}$ por $30 \mathrm{~min}$. A extremidade do tubo de ventilação 
temporária não é submersa para prevenir entrada de gelatina na câmara do motor, ou seja, no alojamento do conversor de energia. Este tubo cria uma linha aberta ao vácuo de forma que não ocorra diferença de pressão entre os lados do diafragma. Após retornar à pressão atmosférica por 5 min, o vácuo é novamente aplicado por mais 5 min. Para garantir a impregnação de gelatina nos poros da superfície texturizada. A bomba é então tirada da solução de gelatina e colocada numa câmara refrigeradora a $4^{\circ} \mathrm{C}$ por 15 min. Sob essas condições, ocorre o resfriamento da cobertura sem secagem da fina camada de gelatina. Neste ponto, todos os poros da superfície texturizada estão preenchidos com gelatina. Entretanto, a camada de gelatina não é grossa o suficiente para proporcionar uma superfície com acabamento liso. Desta forma, a bomba é novamente mergulhada numa solução $(5 \%)$ de gelatina a $30^{\circ} \mathrm{C}$ por alguns segundos, e colocada numa câmara refrigeradora a $4^{\circ} \mathrm{C}$ para resfriamento da gelatina adicional. Esse procedimento complementar de imersão é repetido por diversas vezes, até que seja obtida uma superfície lisa com uma camada contínua de gelatina em toda a superfície da bomba que entrará em contato com sangue. A bomba é então imersa numa solução de glutaraldeído de $0,45 \%\left(\mathrm{pH} \mathrm{7,4)} \mathrm{a} 4^{\circ} \mathrm{C}\right.$ por pelo menos 24 h. para fixação da gelatina, seguida de limpeza da gelatina das superfícies externas. Após o término do processo de biolização, o dispositivo é mantido por no mínimo três dias em solução de formoldeído a $4 \%, \mathrm{pH} \mathrm{7,4} \mathrm{e} \mathrm{temperatura} \mathrm{ambiente.} \mathrm{O} \mathrm{uso} \mathrm{de} \mathrm{formoldeído} \mathrm{é} \mathrm{recomendado} \mathrm{para}$ esterilização do dispositivo depois de realizado o processo preliminar de polimerização das proteínas pelo glutaraldeído. Com duas horas de antecedência ao implante, o dispositivo deve ser imerso em solução salina para a total remoção do aldeído (Andrade, 1998).

\section{I.6 Endotelização}

Uma superfície de células endoteliais naturais tem como característica excelente tromboresistência, sendo sua utilização desejável em bombas de sangue. A presença de um tecido fibroso saudável bem aderido à superfície é um pré-requisito para o crescimento de células endoteliais. A qualidade do tecido fibroso está diretamente relacionada à porosidade do material, uma vez que o tecido fibroso geralmente se origina a partir do tecido conectivo que circunda a prótese. A melhor cicatrização de próteses vasculares ocorre quando são implantadas na aorta, devido ao maior tamanho 
do enxerto, fluxo de sangue mais intenso, e laminar. No entanto, em próteses cardíacas, é inevitável a ocorrência de estagnação e vórtice durante o ciclo de bombeamento. Devido a este distúrbio no fluxo de sangue, supõe-se que o processo de cicatrização em próteses cardíacas seja diferente do processo que ocorre em próteses arteriais.

Em uma superfície lisa é pressuposto que nenhum corpúsculo do sangue seja aderido ao material. No entanto, quando observada sob uma maior magnificência, a superfície do material sintético pode não ser perfeitamente lisa e essa irregularidade da superfície do material causa formação de trombo. Uma superfície rugosa tem como característica específica ancorar deposições à superfície do material, diminuindo as chances de seu desprendimento o que causaria embolia. Os problemas relacionados a este tipo de superfície são a dificuldade de controlar a espessura da neo-íntima e também da formação de trombos secundários da neo-íntima.

A quantidade e as características da neo-íntima formada sobre a superfície de contato de dispositivos cardíacos são determinadas pelas características da superfície do material, hemodinâmica do sangue que passa através do dispositivo, a disposição do dispositivo em relação ao órgão natural, e das condições físico-patológicas (tais como coagulação sanguínea e presença de infecção sistêmica) (Harasaki, 1978). 


\section{Capítulo II}

\section{II.1 Teste In Vitro}

A realização de testes In Vitro nos permite avaliar uma série de variáveis, sem que seja necessário o implante do dispositivo (Orime, 1994). Segundo Graham e colaboradores (1990), a utilização de um biomaterial como componente flexível em um dispositivo de assistência de uso prolongado, requer do mesmo uma performance de aproximadamente quarenta milhões de ciclos por ano.

Com o intuito de avaliar o diafragma, foi elaborado um circuito do tipo mock loop que pudesse reproduzir com certo grau de precisão e repetibilidade certas características fisiológicas da circulação humana tanto para condições normais quantos extremas.

Foi concebido um dispositivo mecânico que respeitasse as características funcionais do DAV e que pudesse ser usado exclusivamente para a realização de testes In Vitro. Nessa montagem são analisadas e identificadas as características mecânicas do diafragma e as possíveis falhas. A (Figura II.1.1-1) mostra esquematicamente o circuito de teste para a simulação do sistema circulatório humano.

$\mathrm{O}$ teste In Vitro com o dispositivo do tipo mock loop foi realizado com o objetivo de confirmar se os critérios estabelecidos para o projeto do diafragma foram atingidos, verificar o seu desempenho sob uma variedade de condições fisiológicas e não fisiológicas que ocorrem tanto de forma prolongada quanto de forma transitória, e obter dados sobre a sua vida útil, determinando o número de ciclos até o seu rompimento.

\section{II.1.1 Descrição do Sistema Mecânico}


O dispositivo de simulação (Figura II.1.1-2) consiste em um motor de corrente contínua com imã permanente (Supergauss - São Paulo, Brasil) fixado a uma base de alumínio, tendo seu eixo acoplado a um excêntrico. O excêntrico é conectado a um braço articulado, que por sua vez está conectado a um pino. Este pino que tem movimento linear irá empurrar o diafragma de forma a ejetar todo o líquido que se encontra no interior da câmara de bombeamento.

$\mathrm{Na}$ extremidade do eixo do motor oposta ao excêntrico, é acoplado um tacômetro (que consiste de um disco dentado e de um sensor óptico). Um osciloscópio (modelo 7613 Tektronix - Beaverton, Oregon, EUA) é utilizado para efetuar a leitura dos pulsos.

\section{Sistema Mock Loop}

No protocolo de teste foram estabelecidos parâmetros de 200 batimentos por minuto em taxa fixa, pré-carga de $50 \mathrm{~mm} \mathrm{Hg}$, pós-carga média de $110 \mathrm{~mm} \mathrm{Hg}$ (sendo a máxima de $150 \mathrm{~mm} \mathrm{Hg}$ e a mínima de $80 \mathrm{~mm} \mathrm{Hg}$ ) e o débito cardíaco de 5 litros por minuto.

A frequiência de batimento é ajustada pela leitura de pulsos através de osciloscópio. Assim, como o disco dentado possui 20 dentes, para uma volta completa devem ser lidos vinte pulsos. Como a frequiência desejada é de 200 bpm, que é igual a 3,3 bps ou rps. Multiplicando 3,3 voltas por segundo por $20\left(\mathrm{n}^{\circ}\right.$ de pulsos para uma volta completa) são obtidos $66 \mathrm{~Hz}$. Assim calculando o período, temos 1 dividido por 66 que é igual a 15 ms. Então, a velocidade do motor deve ser ajustada de forma a se obter 1 pulso em $15 \mathrm{~ms}$, mantendo uma média de 20 pulsos em $300 \mathrm{~ms}$, isso pelo fato de não podermos considerar este evento como linear. Essa não linearidade ocorre devido à diferença de carga aplicada durante o ciclo completo.

A frequiência de batimento foi acelerada de forma a diminuir a duração do experimento (Orime, 1994), chegando a quase três vezes a freqüência de batimento normal de um ser humano. Assim, a realização do teste por um período de setenta dias equivale a aproximadamente seis meses de teste em condições normais.

Embora tenha sido utilizada água como fluido de teste ao invés de uma solução de $37 \%$ de glicerina em água, a qual tem as mesmas condições de viscosidade do sangue (Ohashi, 1999), o sistema proporcionou pressões e fluxo suficientes. A pressão de précarga foi ajustada para $50 \mathrm{~mm} \mathrm{Hg}$, de forma a aumentar as exigências mecânicas 
relacionadas ao diafragma e o fluxo foi limitado a cinco litros por minuto. No entanto, a pressão de pós-carga ficou restrita a $110 \mathrm{~mm} \mathrm{Hg}$, que é uma condição normal do ser humano.

Duas mangueiras de borracha natural com comprimento de $70 \mathrm{~cm}$ cada foram utilizadas com a finalidade de simular a complacência venosa e aórtica. A altura de um reservatório de cardiotomia com volume de dois litros (Macchi - São Paulo, São Paulo, Brasil) e um torniquete permitem a regulagem das pressões de pré-carga e pós-carga. As valvas de disco de $23 \mathrm{~mm}$ de um folheto, modelo Jatene (Fundação Adib Jatene - São Paulo, Brasil), permitem o direcionamento do fluxo em sentido único, evitando que ocorra refluxo. O rotâmetro (modelo D74653, Gemü Gebr Muller - Ingelfingen, Criesbach, Alemanha) possibilita a quantificação desse fluxo. A monitoração da pressão é feita através de um manômetro diferencial (Fundação Adib Jatene - São Paulo, Brasil).

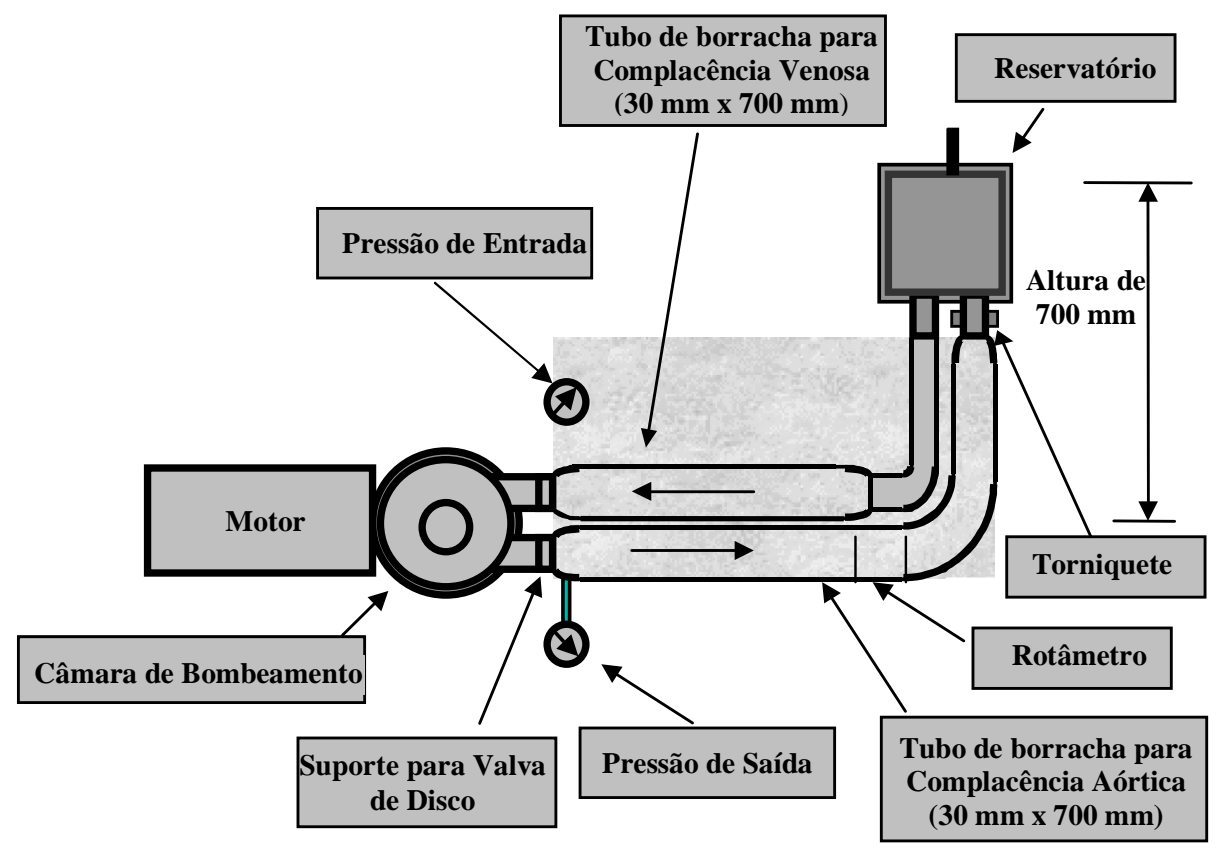

Figura II.1.1-1 Desenho esquemático do circuito de teste. 


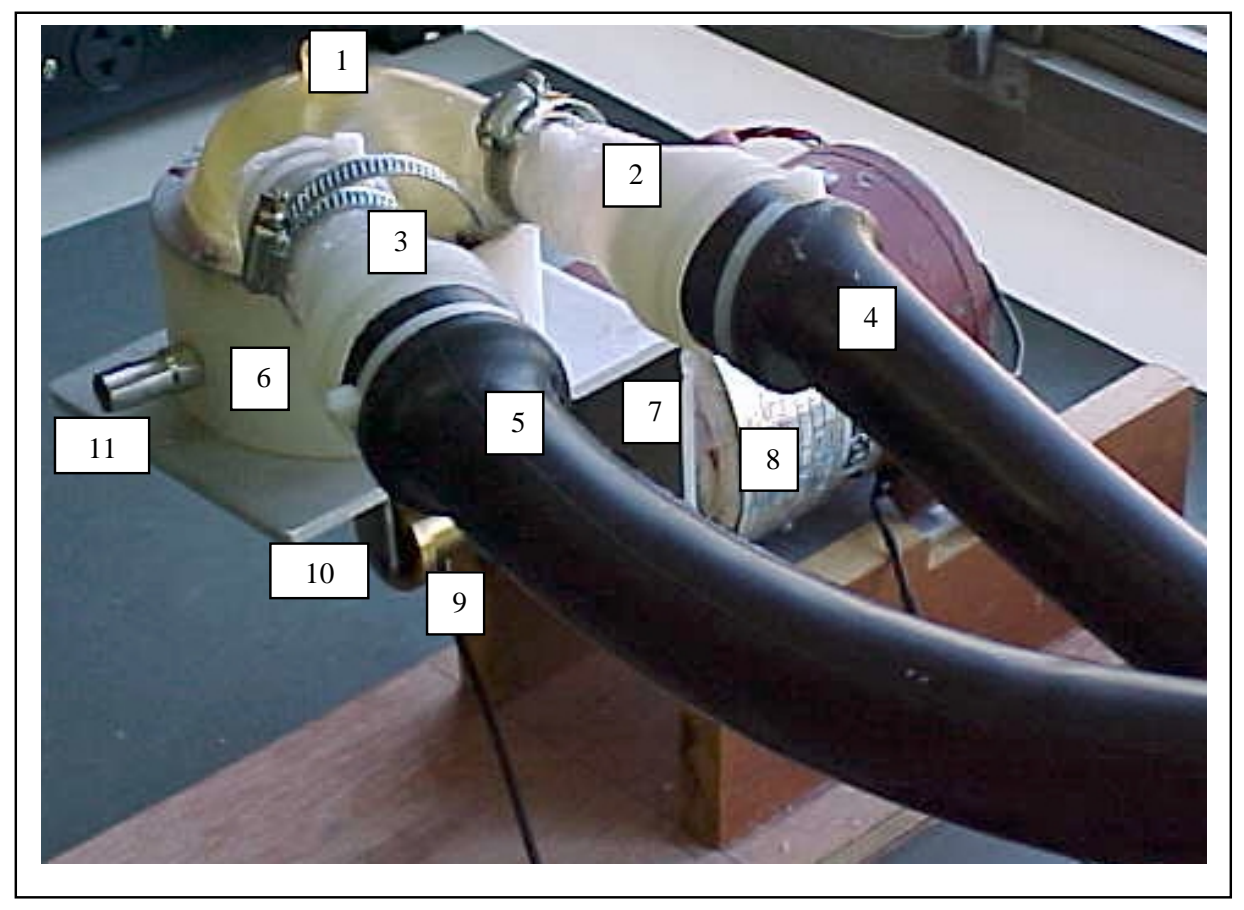

Figura II.1.1-2 Mock Loop System utilizado no teste de resistência do diafragma texturizado mostrando: (1) - Câmara de bombeamento; (2) - Suporte para valva aórtica; (3) - Suporte para valva venosa; (4) - Tubo de complacência aórtica; (5) - Tubo de complacência venosa; (6) - Base; (7) - Suporte de fixação do motor; (8) - Motor DC; (9) - Excêntrico; (10) - Braço articulado; (11) - Conector da antecâmara.

\section{II.2 Testes In Vivo}

\section{II.2.1 Implante de Patch}

O objetivo de teste In Vivo com implante de patch (Figura II.2.1-1) é de isolar as variáveis, que normalmente estão presentes no implante de um dispositivo de assistência e que possam interferir na biocompatibilidade do material estudado. Segundo Nosé e colaboradores (1967-b), uma maneira de avaliar um material quanto a sua propriedade antitrombogênica é implantar esse material permitindo o seu contato direto com o fluxo sanguíneo. Diante dessa necessidade, ficou definido que a extração de parte da parede da aorta e sutura do material nessa região permitiria o contato com sangue. A parede da artéria abdominal é constituída pelas camadas da íntima, lâmina elástica interna, média, lâmina elástica externa e adventícia (Figura II.2.1-2). Os vasa vasorum são os vasos dos vasos, que tem a função de nutrir as camadas adventícia e parte da média, onde os 
metabólitos não chegariam por difusão a partir da luz do vaso. No estudo In Vivo com implante de patch o enfoque está totalmente voltado para as reações que o material implantado possa causar devido ao contato com sangue.

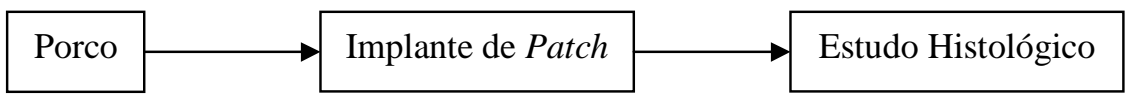

Figura II.2.1-1 Fluxograma do processo de experimento em animal com implante de patch.

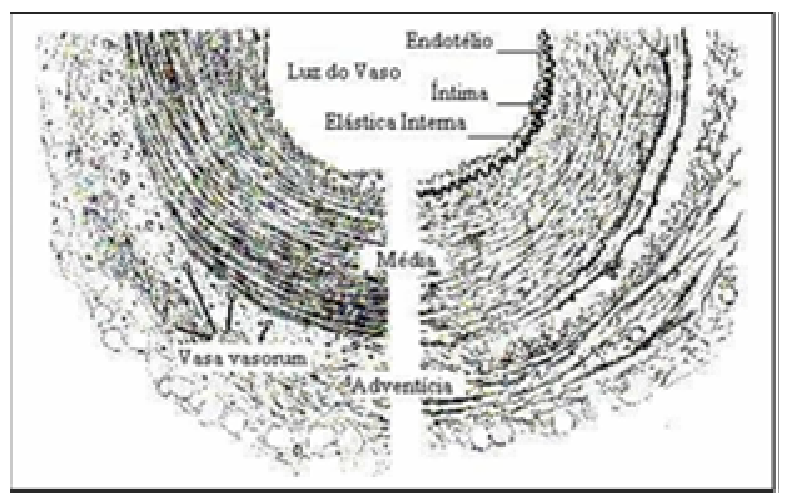

Figura II.2.1-2 Secção da parede arterial.

Protocolo de Teste In Vivo

O protocolo de teste In Vivo utilizado no procedimento em animal para implante de patch foi revisado e aprovado pelo comitê de ética em pesquisa experimental (CEPE) do Instituto "Dante Pazzanese" de Cardiologia (ver apêndice A).

$\mathrm{O}$ comitê de ética em pesquisa experimental considera que um grupo de sete animais é suficiente para a caracterização do material no que se refere a sua biocompatibilidade e que a utilização de mais animais dependerá dos resultados obtidos.

Seleção do Animal

A escolha desse modelo animal foi estabelecida devido à experiência dos integrantes da equipe envolvida no estudo com esse tipo de animal. Também foi levado em consideração disponibilidade e custo.

O animal candidato para a realização do implante deve ser selecionado previamente com uma semana de antecedência a cirurgia após consulta com o 
veterinário responsável. Esta seleção preliminar é baseada no histórico de doenças infecciosas, resultados de exames físicos e peso corporal.

Descrição dos Animais:

Suínos;

Macho ou fêmea de raça mestiça;

Peso de aproximadamente $25 \mathrm{~kg}$;

Até 3 meses de idade.

Os critérios de seleção do animal incluem as seguintes características e necessidades:

Ausculta respiratória e cardíaca normal;

Sem diarréia, rinorréia ou tosse;

Sem lesões de pele infectadas em áreas cirúrgicas;

Temperatura retal abaixo de $39,3^{\circ} \mathrm{C}$.

Cuidados com o Animal

Confinamento

O animal selecionado fica confinado no biotério, separado dos outros animais, até início do experimento. No dia antecedente a cirurgia, o animal é lavado com xampu neutro e mantido em confinamento até o momento da cirurgia.

Dieta

O animal deve seguir uma dieta alimentar, evitando complicações durante o ato cirúrgico. A quantidade de ração na dieta normal é estipulada pelo fabricante na embalagem do produto.

Pré-Operatório:

Jejum Total (a partir de 24 horas antes da cirurgia).

Pós-Operatório:

Ração Normal e Dieta Hídrica Normal.

Medicamentos

Enrofloxacina (Flotril 10\%) (5 mg/kg) no pré-operatório e no pós-operatório. 
Anestesia

Pré-Anestesia:

Acepromazina $(0,2 \mathrm{mg} / \mathrm{kg})$ e Midazolan $(0,3 \mathrm{mg} / \mathrm{kg})$

Indução:

Tiopental Sódico $(10 \mathrm{mg} / \mathrm{kg})$

Intubação orotraqueal e ventilação mecânica (modelo Takaoka)

Manutenção:

Halotano (+/- 2\%)

Pancuron $(0,2 \mathrm{mg} / \mathrm{kg})$

\section{Procedimento Cirúrgico}

A anti-sepsia é feita com álcool iodado (2\%). São utilizados campos cirúrgicos estéreis para isolamento da área. $\mathrm{O}$ animal é posicionado na mesa cirúrgica em decúbito dorsal. São posicionados os eletrodos para a monitoração com eletrocardiograma (modelo Hellige SMU-612).

A artéria femoral direita é dissecada, amarrada com fita cardíaca e puncionada com gelco $\mathrm{n}^{\circ} 18$ e após esse procedimento é introduzida uma linha de pressão arterial. Essa linha é preenchida com soro fisiológico heparinizado (na proporção de $2 \mathrm{ml} \mathrm{de}$ heparina para $500 \mathrm{ml}$ de soro fisiológico), evitando o entupimento da mesma pela coagulação de sangue.

É feita laparotomia mediana e utilizado afastador para permitir o acesso à aorta abdominal (Figura II.2.1-3). A aorta abdominal é dissecada e clampeada parcialmente e é então removida parte da parede da artéria (Figura II.2.1-4), onde são suturados os patches (Figura II.2.1-5). É feita uma avaliação para verificar qualquer tipo de vazamento através da sutura do implante e a seguir são fechadas todas as incisões. 


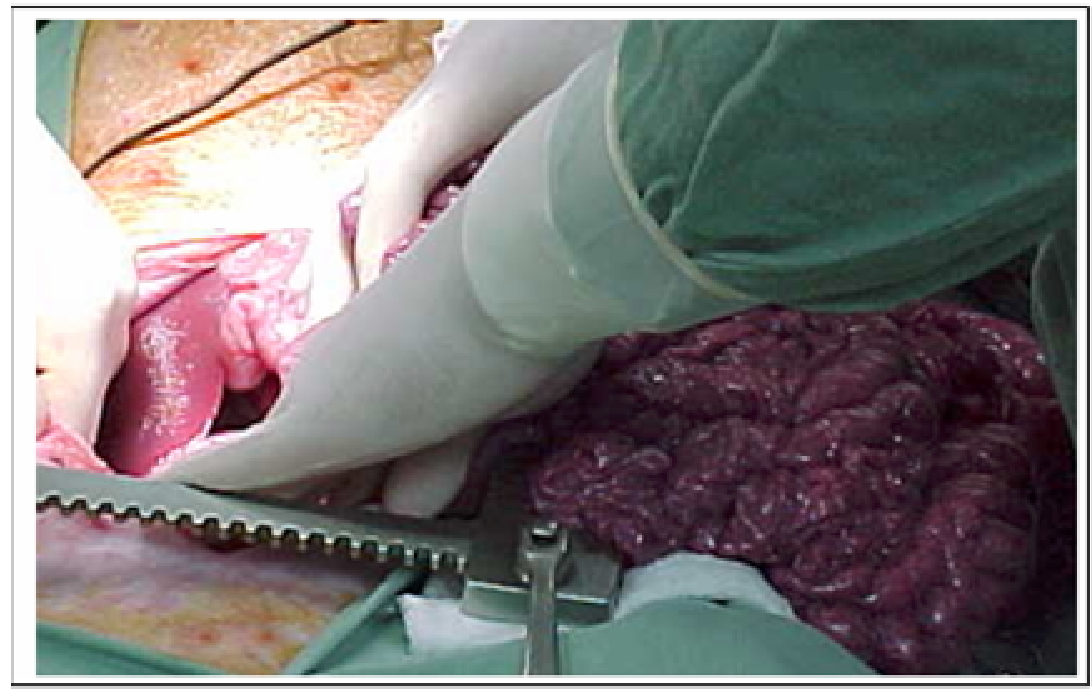

Figura II.2.1-3 Laparotomia mediana permitindo o acesso à aorta abdominal.

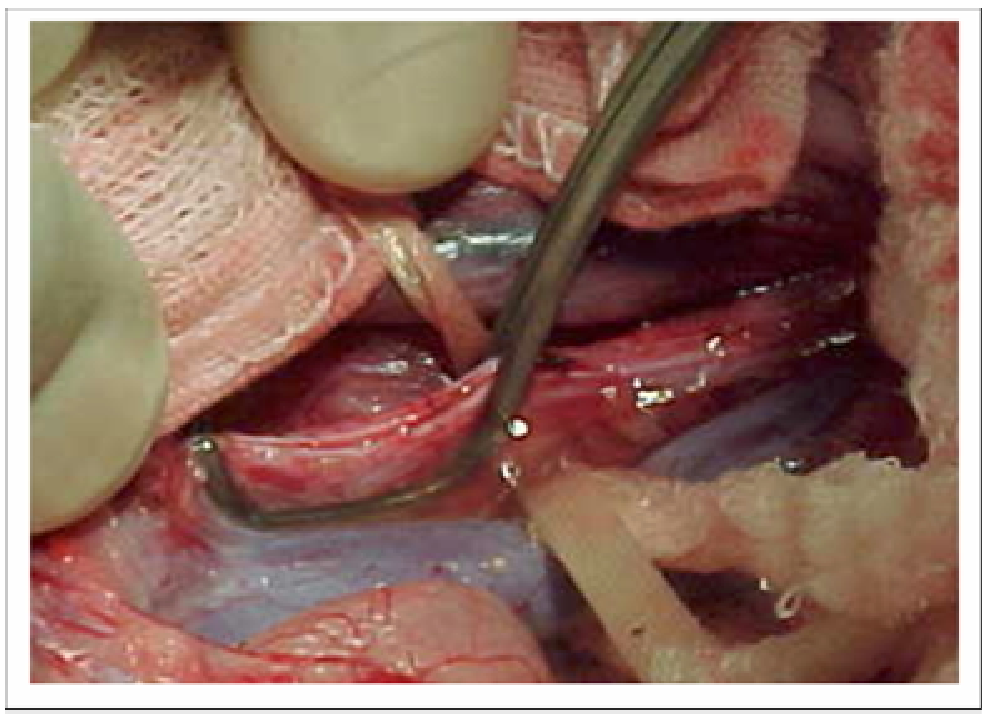

Figura II.2.1-4 Clampeamento parcial e remoção de parte da parede da artéria. 


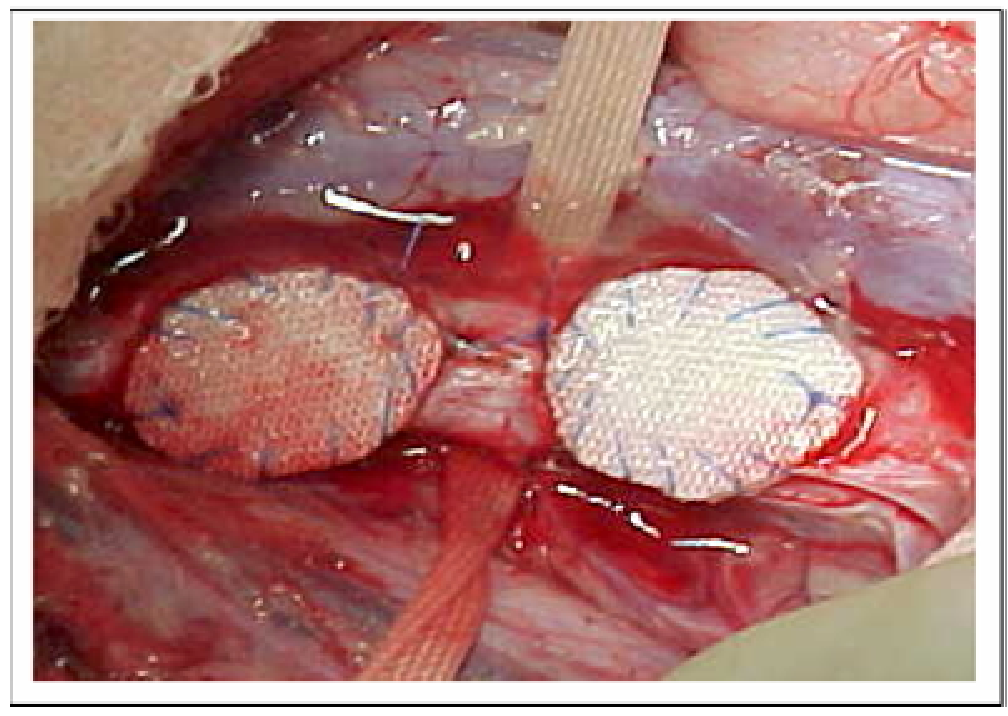

Figura II.2.1-5 Sutura dos patches na parede da aorta e verificação de qualquer tipo de vazamento.

Procedimentos no Pós-Operatório:

Terminado o procedimento cirúrgico o animal é mantido na mesa de cirurgia por um período de aproximadamente 3 horas, após o qual ele é desentubado e transferido para o biotério, onde ele é mantido em observação durante todo o período do experimento.

Eutanásia:

É realizada ao final do procedimento, com a anestesia do animal e injeção de 10 $\mathrm{ml}$ de cloreto de potássio pela veia jugular externa. A duração dos experimentos é definida de forma a mostrar um quadro evolutivo da proliferação celular sobre o material implantado. Sendo assim, fica estipulado um mínimo de 4 dias e um máximo de 48 dias, dentro do qual é possível realizar essa avaliação evolutiva.

\section{Estudo Morfológico e Histológico:}

A avaliação do implante é feita através de microscopia eletrônica de varredura (MEV) dos materiais a serem implantados, fotografia e microscopia óptica do patch imediatamente após explante. A MEV permite uma avaliação topográfica da superfície que entrará em contato com sangue, inclusive para constatar se o processo de biolização está adequado, ou seja, se o filme de gelatina está isolando completamente a 
poliuretana. O estudo histológico é realizado ao final de cada experimento para avaliação da superfície dos patches verificando suas interações com o sangue. Deve ser dada ênfase na qualificação e quantificação da formação de neo-íntima na superfície de contato com o sangue, calcificação, e deposição de elementos figurados do sangue.

\section{II.2.2 Implante do Dispositivo}

O objetivo de um teste In Vivo (Figura II.2.2-1) é de comprovar dentro de ambiente biológico e fisiológico fatores como biocompatibilidade, performance hemodinâmica, durabilidade em longo prazo, confiabilidade de controle, segurança e compatibilidade anatômica. O enfoque desta pesquisa é sobre todos os fatores que diretamente ou indiretamente possam vir a interferir na hemocompatibilidade do dispositivo.

Ainda que o dispositivo seja totalmente confeccionado com materiais nãotrombogênicos, fatores hemodinâmicos devem ser vastamente analisados de forma a evitar a formação de coágulos. A performance hemodinâmica irá interferir diretamente no sucesso do experimento através da formação de coágulos devido a pontos de estagnação dentro da câmara de bombeamento. Nosé et al. (1967-b) concluiu em experimentos que a coagulação sempre é iniciada a partir de pontos de estagnação dentro do dispositivo, sendo confirmada assim a necessidade de construção de um dispositivo onde seja evitada qualquer área onde ocorra estagnação de sangue.

Um fluxo inadequado de sangue também irá intervir no êxito do projeto. $\mathrm{O}$ sangue geralmente coagula quando flui muito lentamente porque pequenas quantidades de trombina e outros procoagulantes estão sempre sendo formados. Conseqüentemente, um fluxo inadequado irá aumentar as concentrações dos procoagulantes o suficiente para iniciar a coagulação (Guiton, 1977). Nosé (1967-a) concluiu em estudos experimentais que quanto maior for o fluxo, menor será a coagulação.

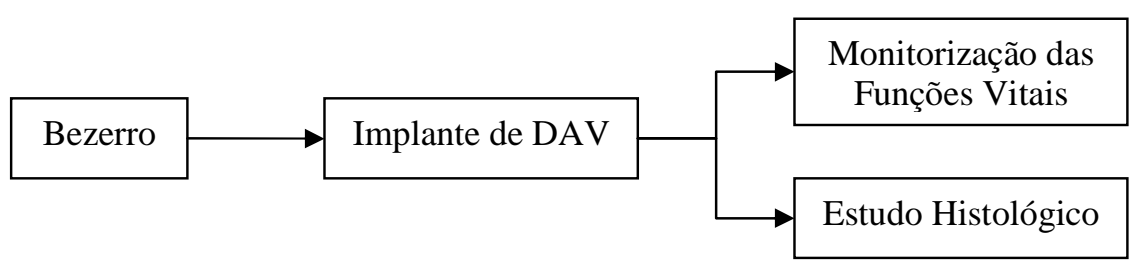


Figura II.2.2-1 Fluxograma do processo de experimento em animal com implante de DAV.

Protocolo de Teste In Vivo

O protocolo de teste In Vivo utilizado no procedimento em animal para implante do dispositivo de assistência foi revisado e aprovado pelo comitê de ética em pesquisa experimental do Instituto "Dante Pazzanese” de Cardiologia (ver apêndice A).

\section{Seleção do Animal}

Nosé (1967-a) utilizou bezerros como animais experimentais devido a menor tendência do sangue desse tipo de animal em coagular. De acordo com Mann e colaboradores (1996), bezerros desenvolvem uma tolerância a heparina, necessitando um aumento na dosagem conforme o tempo.

A escolha desse modelo animal foi baseada em experiências de estudos relatados em literatura, e também devido a sua anatomia, disponibilidade e custo. A faixa etária determinada do modelo animal foi estabelecida de maneira a manter uma equivalência com o porte de um ser humano. Assim, não sendo necessária nenhuma adaptação de instrumental, bem como de parâmetros de fluxo para o bombeamento (Mann, 1996).

O bezerro candidato para a realização do implante é selecionado uma semana antes da cirurgia após uma consulta com o veterinário. Esta seleção preliminar é baseada no histórico de doenças infecciosas, resultados de exames físicos e peso corporal. Uma seleção final é feita baseando-se em dados hematológicos adicionais, pela análise de amostras de sangue retiradas pela manhã, antes de alimentar os animais. O animal é retirado de seu habitat natural e levado ao biotério somente no dia antecedente ao início da dieta. Dessa forma evita-se que ele entre em um possível quadro de estresse, podendo dessa forma interferir nos dados a serem coletados.

Os critérios de seleção do animal incluem as seguintes características e necessidades:

Macho com peso entre 80 e $100 \mathrm{~kg}$;

Ausculta respiratória e cardíaca normal;

Sem diarréia, rinorréia ou tosse;

Sem lesões dérmicas infecciosas em áreas cirúrgicas;

Temperatura retal abaixo de $39,3^{\circ} \mathrm{C}$; 
Hematócrito acima de $28 \%$;

Bioquímica do fígado e função renal normais.

Coleta de Sangue para Reposição

São reservadas para transfusão dez bolsas com $450 \mathrm{ml}$ de sangue. O sangue utilizado é adquirido de um animal com parentesco direto ao bezerro separado para o experimento (preferencialmente de sua mãe) e é coletado no dia que antecede o experimento. $\mathrm{O}$ sangue é preservado a uma temperatura de aproximadamente $4^{\circ} \mathrm{C}$.

\section{Cuidados com o Animal}

\section{Confinamento}

O animal selecionado fica confinado no biotério, separado dos outros animais, até início do experimento. No dia antecedente a cirurgia, é feita tricotomia da região jugular, torácica e abdominal do animal. Após esse procedimento o animal é então lavado com xampu neutro e mantido em confinamento até o momento da cirurgia.

\section{Dieta}

$\mathrm{O}$ animal ruminante deve seguir uma dieta alimentar, evitando complicações durante $\mathrm{o}$ ato cirúrgico. A quantidade de ração na dieta normal é estipulada pelo fabricante na embalagem do produto.

\section{Pré-Operatório:}

1⁄2 Ração com Dieta Hídrica Normal (a partir de 48 horas antes da cirurgia);

Jejum Total (a partir de 24 horas antes da cirurgia).

Pós-Operatório:

Ração Normal e Dieta Hídrica Normal.

Medicamentos

Enrofloxacina (Flotril 10\%) (5 mg/kg) a cada 24 horas no pré-operatório e no pós-operatório.

Anticoagulante

Intra-Operatório:

Heparina (3 a $5 \mathrm{mg} / \mathrm{kg}$ ) mantendo TCA entre 500 e $600 \mathrm{~s}$; 
Pós-Operatório:

Nas primeiras 8 horas do pós-operatório não infundir heparina e realizar controle da drenagem torácica. Nas primeiras horas do pós-operatório administrar protamina (proporção 0,8 de protamina para cada um de heparina infundida durante a perfusão).

Após as primeiras 8 horas e até completar 24 horas de pós-operatório, infundir continuamente heparina mantendo TCA entre 200 e 250 s, dependendo da evolução hemostática do laboratório de hemostasia.

Após 24 horas de pós-operatório, infundir continuamente heparina mantendo TCA entre 250 e $300 \mathrm{~s}$.

Anestesia

Pré-Anestesia:

Acepromazina $(0,2 \mathrm{mg} / \mathrm{kg})$ e Midazolan $(0,3 \mathrm{mg} / \mathrm{kg})$

Indução:

Tiopental Sódico $(10 \mathrm{mg} / \mathrm{kg})$

Intubação orotraqueal e ventilação mecânica (modelo Takaoka)

Manutenção:

Halotano (+/- 2\%)

Pancuron $(0,2 \mathrm{mg} / \mathrm{kg})$

Procedimento Cirúrgico

$\mathrm{O}$ animal é colocado na mesa cirúrgica em decúbito lateral esquerdo. A antisepsia é feita com álcool iodado (2\%). São utilizados campos cirúrgicos estéreis para isolamento da área. São posicionados os eletrodos para a monitoração com eletrocardiograma (modelo Hellige SMU-612).

A artéria femoral direita é dissecada, amarrada com fita cardíaca e puncionada com gelco $\mathrm{n}^{\circ} 18$ e após esse procedimento é introduzida uma linha de pressão arterial. Essa linha é preenchida com soro fisiológico heparinizado (na proporção de $2 \mathrm{ml}$ de heparina para $500 \mathrm{ml}$ de soro fisiológico), evitando o entupimento da mesma pela coagulação de sangue. Essa linha também é utilizada para coleta de sangue para exames laboratoriais.

É puncionada a veia jugular externa com intracath para monitoração de pressão venosa central (PVC) e infusão de drogas. 
É feita incisão lateral ao logo do quarto espaço intercostal, onde é realizada uma toracotomia lateral direita (Figura II.2.2-2). As incisões são feitas com bisturi elétrico, sendo a hemostasia revisada com o mesmo. A quarta e a quinta costela são cortadas próximas de suas origens no esterno, sendo a quinta costela totalmente removida. É feita incisão em forma de "T" no pericárdio entre a aorta e a veia cava inferior.

Os dois tubos de silicone, que acomodam os fios dos sensores e de alimentação e que permitem a passagem livre de ar para a antecâmara do dispositivo, são ligados ao exterior do animal através de uma incisão na pele, na altura da $12^{\mathrm{a}}$ ou $13^{\mathrm{a}}$ costela na posição dorsal (Figura II.2.2-3).

É realizado procedimento para circulação extracorpórea para que o dispositivo seja implantado.

Os comprimentos dos enxertos de entrada e de saída são ajustados de forma a alcançarem respectivamente o ápice do ventrículo esquerdo e a aorta ascendente (Figura II.2.2-4). A bomba é posicionada em lugar apropriado no interior do tórax evitando a compressão ou dobra dos enxertos. Com o dispositivo vazador de ventrículo (Figura II.2.2-5) é produzido um orifício no ápice do ventrículo esquerdo, onde é suturado o bordelete (Figura II.2.2-6) que está ligado ao enxerto de entrada do dispositivo. O enxerto de saída do dispositivo é anastomosado na aorta ascendente. São utilizadas próteses valvares cardíacas de pericárdio bovino na entrada (com diâmetro de $25 \mathrm{~mm}$ ) e na saída (com diâmetro de $23 \mathrm{~mm}$ ) da câmara de bombeamento. Todo o circuito é preenchido com solução fisiológica evitando a inserção de bolhas no sistema circulatório do animal e também para verificação de vazamento nas suturas.

Nesse momento o animal sai de perfusão e o dispositivo é iniciado com taxa fixa de bombeamento. O esterno e o abdômen são comprimidos por fora do corpo para se avaliar o posicionamento da bomba de sangue. A incisão é fechada após confirmação da estabilidade da hemodinâmica, da gasometria do sangue arterial e do tempo de coagulação ativada. São fixados dois drenos intratorácicos. 


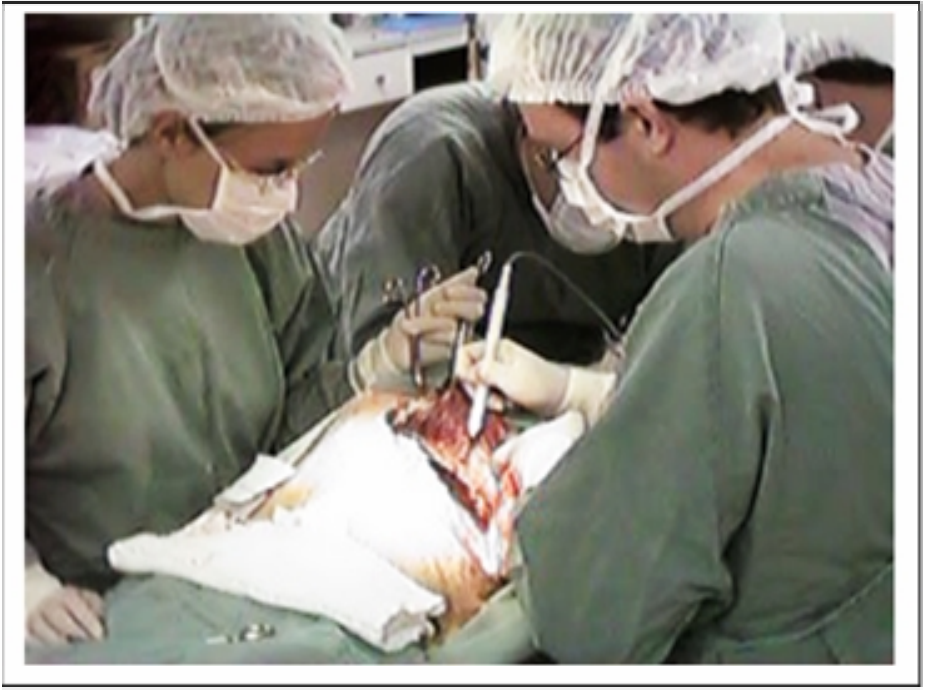

Figura II.2.2-2 Toracotomia lateral direita.

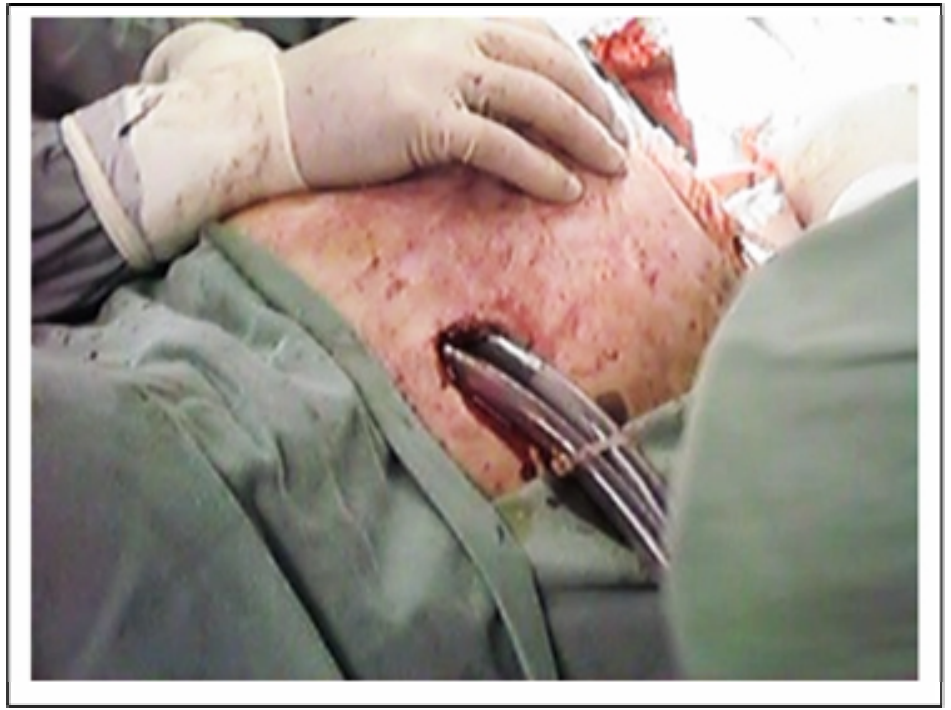

Figura II.2.2-3 Incisão na altura da $12^{\mathrm{a}}$ ou $13^{\mathrm{a}}$ costela para acomodação dos cabos de alimentação/sensores e de comunicação de ar com a antecâmara. 


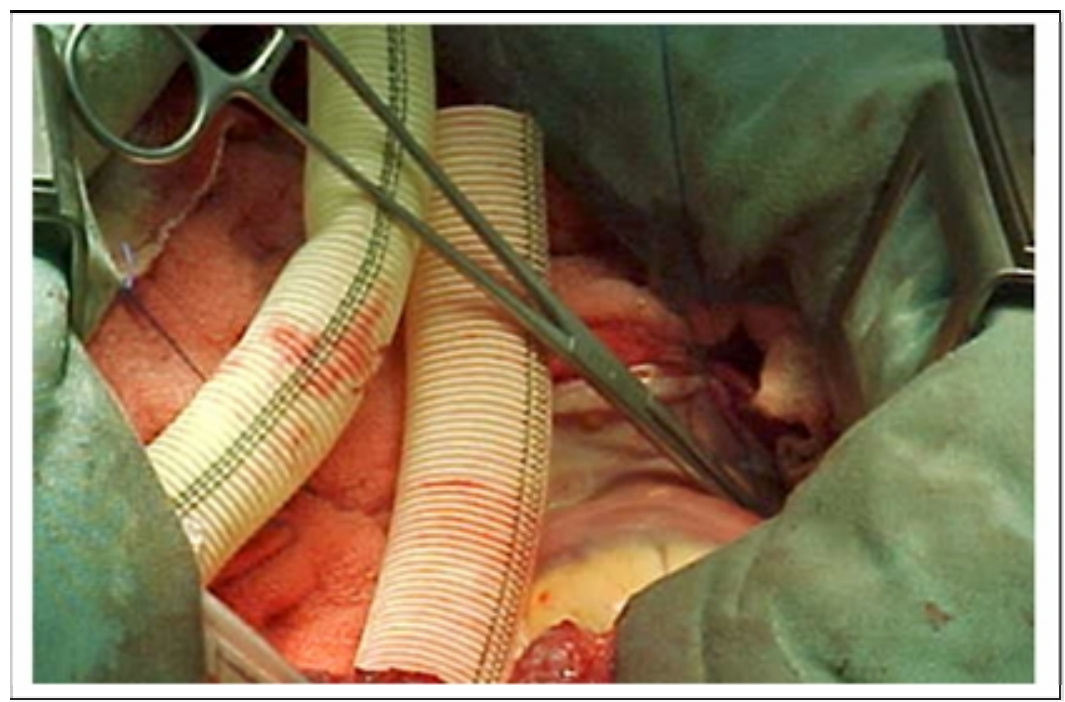

Figura II.2.2-4 Os enxertos de entrada e saída do DAV são suturados ao ápice do ventrículo esquerdo e à aorta ascendente. Também são feitos ajustes em relação ao comprimento dos enxertos.

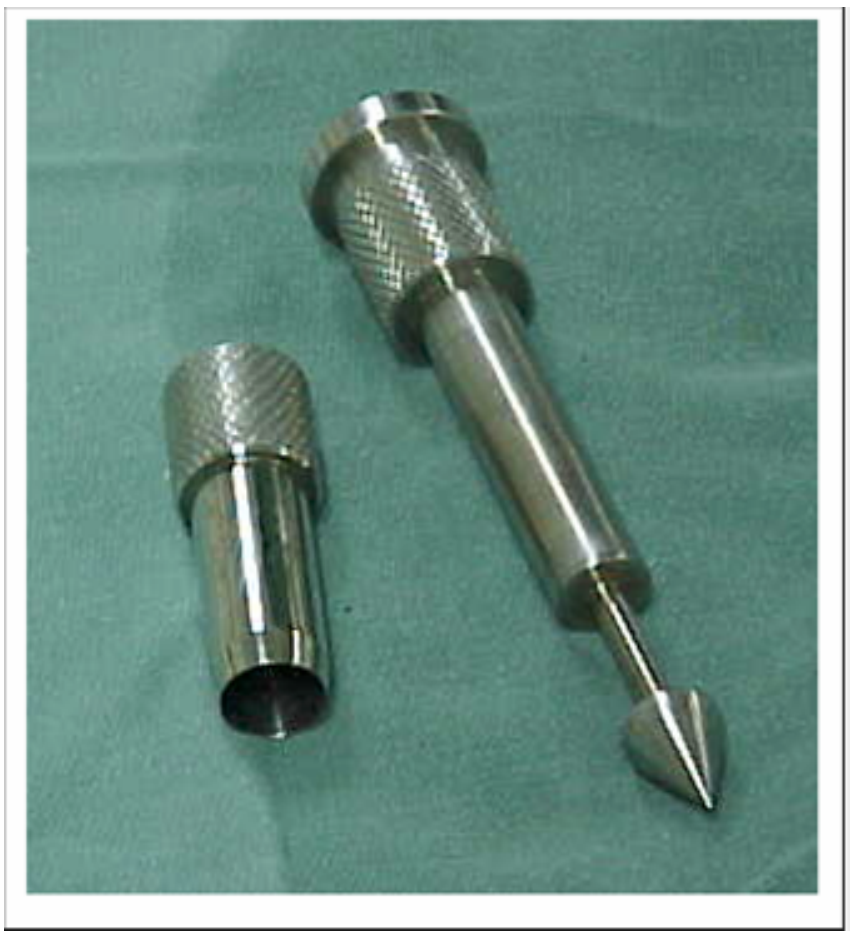

Figura II.2.2-5 O dispositivo vazador de ventrículo é utilizado para produzir um orifício no ápice do ventrículo esquerdo. 


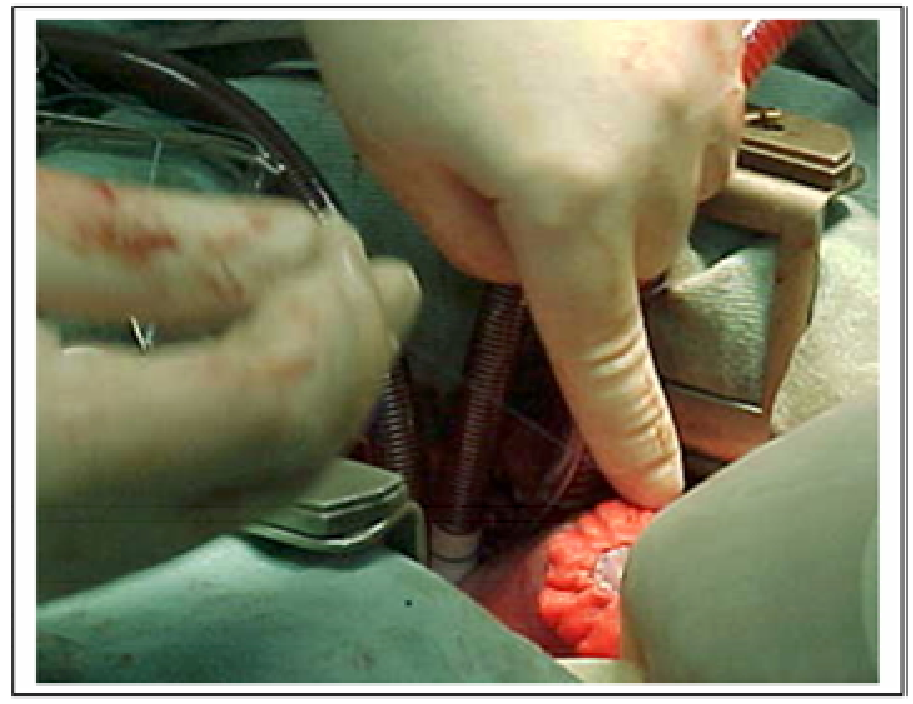

Figura II.2.2-6 Sutura do bordelete que é ligado ao enxerto de entrada do DAV.

Procedimentos no Pós-Operatório:

Após o ato cirúrgico o animal é mantido na mesa de cirurgia por 24 horas (Figura II.2.27), sendo depois transferido para uma gaiola e colocado sob constante observação na unidade de terapia intensiva (UTI) por uma equipe especializada.

Nas primeiras 48 horas o animal deverá receber de 4 a 8 bolsas de sangue, colhido de um animal com parentesco direto, conforme a necessidade.

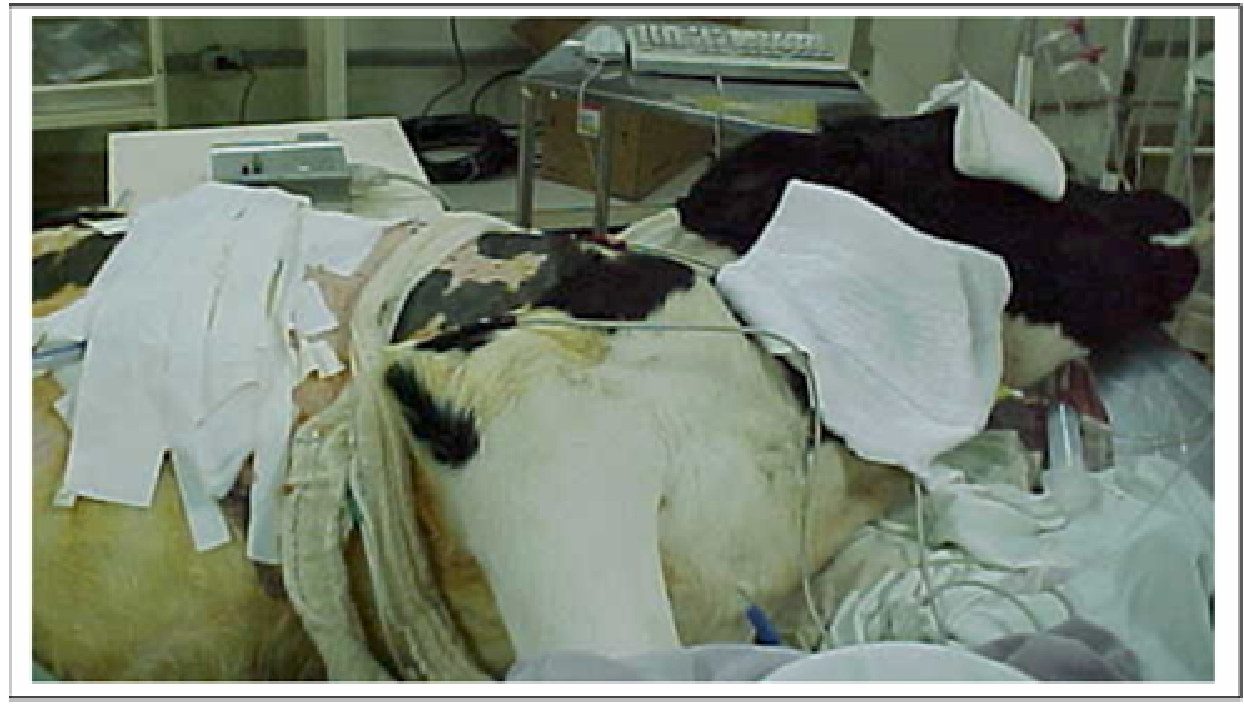

Figura II.2.2-7 Nas primeiras 24 horas do pós-cirúrgico, o animal é mantido na mesa cirúrgica sob constante observação. 
Manutenção do Animal:

A terapia antibiótica profilática é iniciada no pré-operatório e continuada por seis dias. As drogas anticoagulantes profiláticas são administradas durante a cirurgia, no pós-operatório e ao término dos experimentos para prevenir coagulação de sangue pósmorte.

Dados Monitorados:

Pressão arterial (PA);

Eletrocardiograma (ECG);

Diurese;

Pressão venosa central (PVC);

Frequiência de batimento e posicionamento do diafragma do dispositivo;

Frequiência respiratória;

Temperatura corpórea (retal);

Volume de líquido ingerido e de urina;

Volume de sangue drenado do tórax (primeiros dias do pós-operatório).

\section{Dados Laboratoriais:}

Hemoglobina livre no sangue: no pré-operatório, de uma em uma hora no intraoperatório, de 12 em 12 horas no $1^{\circ}$ dia do pós-operatório e a cada $24 \mathrm{~h}$ nos demais dias.

Sangue oculto na urina: no pré-operatório, de uma em uma hora no intraoperatório, de 12 em 12 horas no $1^{\circ}$ dia do pós-operatório e a cada $24 \mathrm{~h}$ nos demais dias.

Fibrinogênio, número de plaquetas e leucócitos: no pré-operatório, na terceira hora após o início do procedimento, de 12 em 12 horas no pós-operatório e a cada $24 \mathrm{~h}$ nos demais dias.

Tempo de Coagulação Ativado (TCA) e TP: no pré-operatório, de uma em uma hora no intra-operatório, de 12 em 12 horas no $1^{\circ}$ dia do pós-operatório e a cada 24 h nos demais dias.

Gasometria e Bioquímica: no pré-operatório, de uma em uma hora no intraoperatório, de 12 em 12 horas no $1^{\circ}$ dia do pós-operatório e a cada 24 h nos demais dias.

Eutanásia: 
Realizada ao final de seis dias de procedimento, com o animal anestesiado e com injeção de $10 \mathrm{ml}$ de cloreto de potássio pela veia jugular externa, e interrupção do dispositivo de assistência ventricular (DAV).

Estudos Patológicos:

Mecanismos Trombogênicos:

A detecção de êmbolos é um dos objetivos principais do estudo patológico. Os grandes vasos e suas principais ramificações são abertos e qualquer êmbolo macroscópico é procurado. Os principais órgãos são laminados a intervalos de $1 \mathrm{~cm}$ e as extremidades dos vasos são cuidadosamente examinadas. $\mathrm{O}$ tamanho e localização do êmbolo e o tamanho e extensão do infarto são registrados. O êmbolo é processado para histoquímica, para pesquisar a origem desse êmbolo. Estudos prévios sobre tromboembolismo em implantes de coração artificial em bezerros indicaram que o rim é o principal alvo para a embolia, e a embolização na circulação do cérebro é extremamente rara (Orime, 1994). É prestada uma especial atenção à patologia dos rins.

Avaliação do Coração do Animal e da Bomba de Sangue:

Os objetivos das análises morfológica e histológica do coração do animal e das superfícies da bomba são avaliar as interações entre o sangue e os biomateriais utilizados. É dada ênfase na qualificação e quantificação das cápsulas de tecido ou formação de membranas nas interfaces entre material e o tecido natural, calcificação das valvas biológicas e do diafragma da bomba, neo-íntima formada nos condutos e deposição de elementos na superfície lisa da gelatina que reveste o diafragma e a câmara da bomba de sangue. 


\section{Capítulo III}

\section{III.1 Resultados}

\section{III.1.1 Teste In Vitro}

Após o término do teste In Vitro, o dispositivo foi totalmente desmontado de forma a possibilitar uma análise individual de cada componente. Ocorreu desgaste na base de alumínio e na base de suporte da câmara devido ao atrito gerado pelo contato com o pino central. Ocorreu falha mecânica da valva de disco posicionada na saída da câmara, sendo esta imediatamente substituída por outra com as mesmas características. Como o objetivo deste teste é de garantir resistência mecânica do diafragma em aplicações de experimentos In Vivo por até quinze dias, a duração do teste In Vitro foi de setenta dias, o que representa aproximadamente vinte milhões de ciclos. Uma análise da antecâmara, que permaneceu seca durante toda a duração do teste, e do diafragma (Figura III.1.1-1), foi utilizada para a comprovação de que não ocorreu nenhum tipo de falha. A membrana não apresentou nenhum tipo de distensão ou fissura.

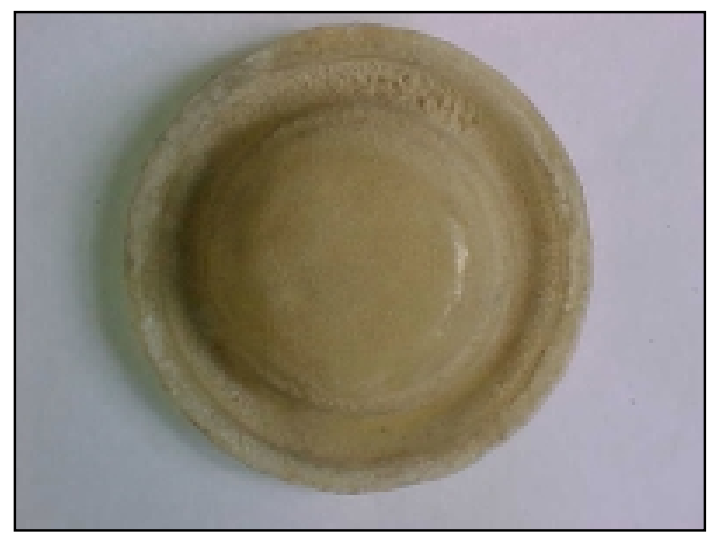

Figura III.1.1-1 Diafragma texturizado após término do experimento In Vitro. 


\section{III.1.2 Testes In Vivo}

\section{III.1.2.1 Implante de Patch}

Nos experimentos In Vivo para implante de patch foram utilizados sete animais, suínos de raça mestiça com peso entre 25 e $30 \mathrm{~kg}$, e sexo macho e fêmea (Tabela III.1.2.1-1). O material implantado utiliza como base o poliéster Dacron®, onde foram depositadas três camadas da poliuretana Biospan®. A última camada sofreu ou não texturização de acordo com a finalidade do patch.

Foram implantados patches com superfície totalmente lisa e sem cobertura de gelatina (Figura III.1.2.1-1- B), patches apenas com a superfície texturizada e sem cobertura de gelatina (Figura III.1.2.1-2 - B), e patches texturizados e com cobertura de gelatina (Figura III.1.2.1-3 - B). Através de microscopia eletrônica de varredura (MEV) (microscópio JEOL modelo JSM-5800, Japão) foram analisadas as superfícies e as estruturas dos materiais a serem implantados. Na elaboração das amostras para a MEV, os materiais foram desidratados com uma série de banhos com etanol, em concentrações diferentes $(10 \%, 25 \%, 50 \%, 75 \%, 90 \%, 95 \%$ e $100 \%$ por 10 minutos cada). Após esses banhos consecutivos, as amostras foram secas em estufas e acondicionadas em recipiente a vácuo. Elas foram recobertas com uma camada de ouro de $400 \AA$ de espessura em um metalizador Balsers modelo SDC 050 (Mitamura, 1990). Na (Figura III.1.2.1-1 - A) foi constatado que apesar de aparentemente lisa, quando vista sob uma maior magnitude (ampliação de 3000 vezes) a superfície do material se revelou rugosa. $\mathrm{Na}$ (Figura III.1.2.1-2 - A) é mostrada que a superfície de contato tem um aspecto extremamente poroso, que servirá como base para deposições de elementos constituintes do sangue. Na (Figura III.1.2.1-3 - A) a superfície da poliuretana está isolada por uma camada protéica, evitando o seu contato com o meio biológico. 


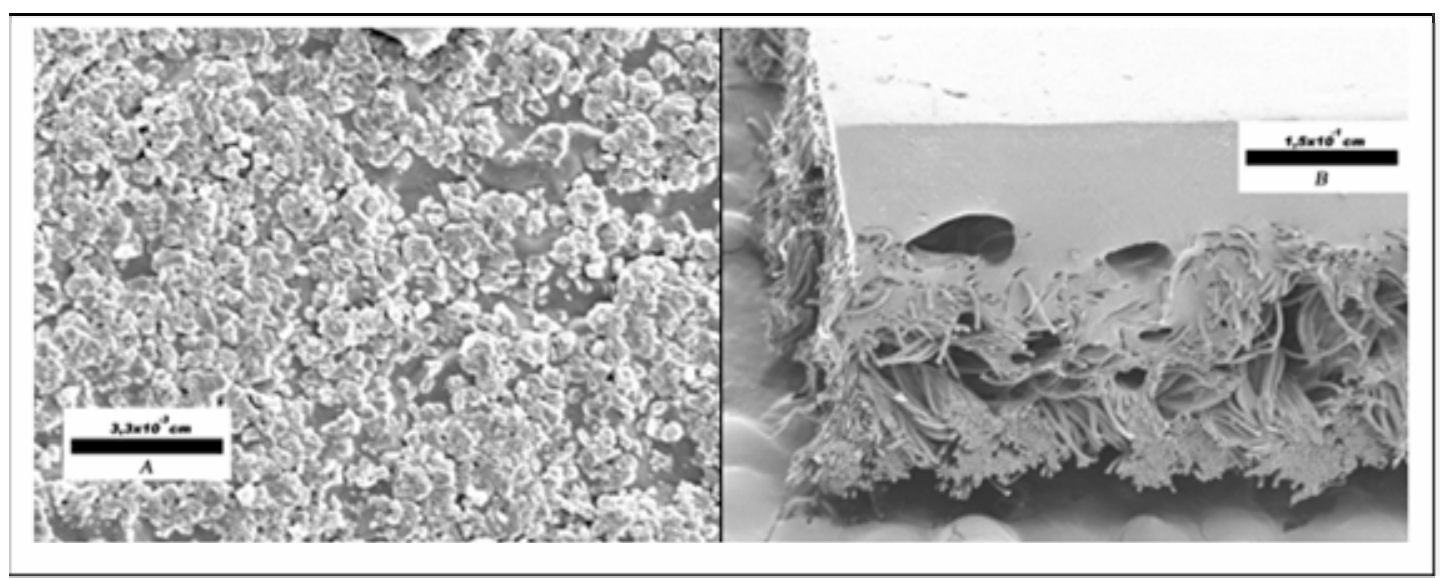

Figura III.1.2.1-1 MEV (A) Apesar de aparentemente lisa, a superfície do material se mostrou rugosa (aumento de 3.000x). (B) Base de poliéster com cobertura de poliuretana (superfície lisa sem gelatina) (aumento de 65x).

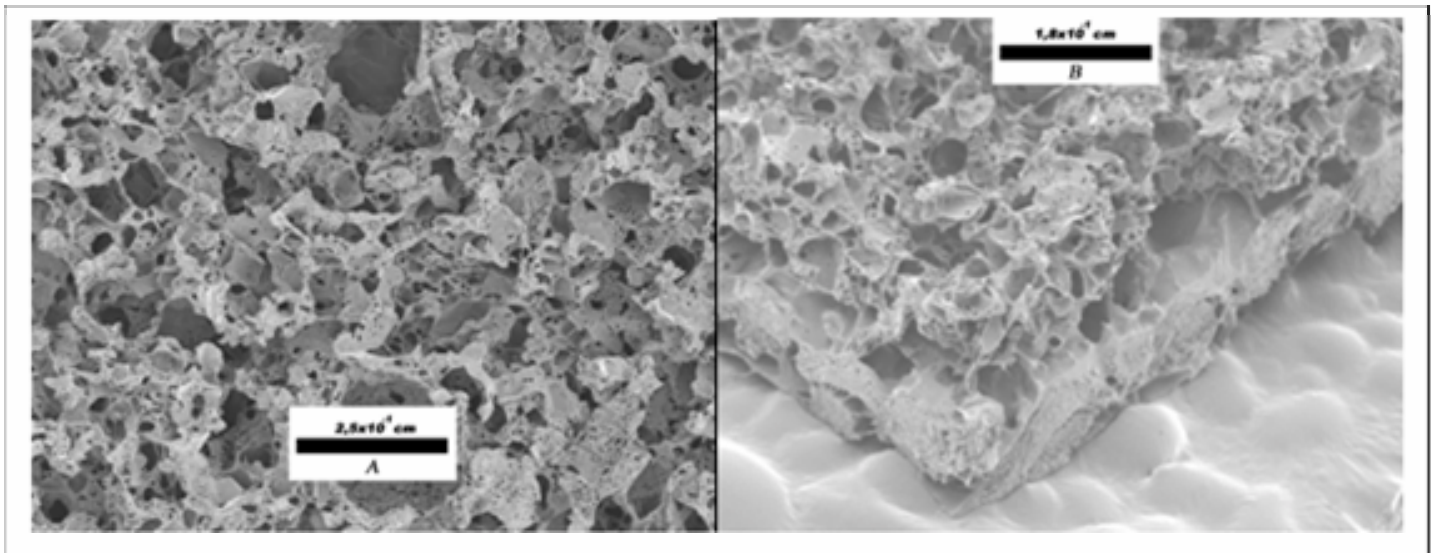

Figura III.1.2.1-2 MEV (A) A superfície de contato tem um aspecto extremamente poroso, servindo como base para deposições de elementos constituintes do sangue (aumento de 40x). (B) Base de poliéster com cobertura de poliuretana (superfície texturizada sem gelatina) (aumento de 55x). 


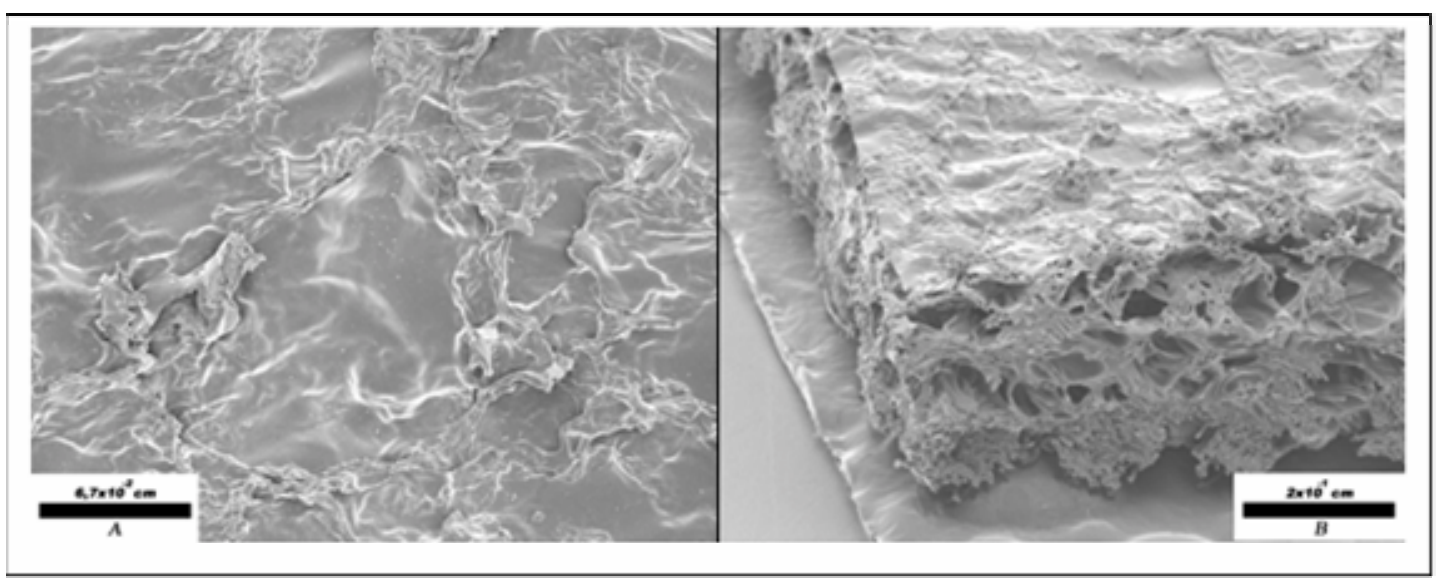

Figura III.1.2.1-3 MEV (A) A superfície do patch é constituída por uma camada protéica que isola totalmente a poliuretana, evitando o seu contato com o meio biológico (aumento de 150x). (B) Base de poliéster com cobertura de poliuretana biolizada (superfície texturizada e com cobertura de gelatina) (aumento de 50x). 
Tabela III.1.2.1-1 Dados referentes aos implantes de patch em animal.

\begin{tabular}{|c|c|c|c|c|c|c|c|c|c|c|c|c|c|c|}
\hline & & 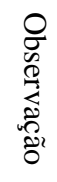 & & $\overline{7}$ & 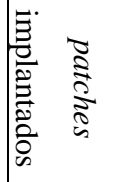 & $\begin{array}{l}Z_{0} \\
\text { \& }\end{array}$ & 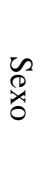 & 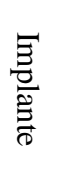 & 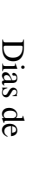 & 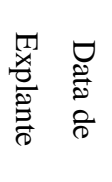 & 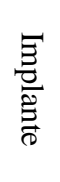 & 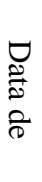 & 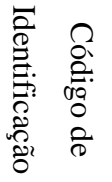 & $\begin{array}{l}\text { : } \\
\text { Oे }\end{array}$ \\
\hline \multirow[t]{6}{*}{ 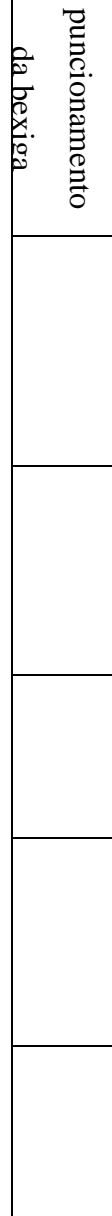 } & \multirow[t]{6}{*}{ 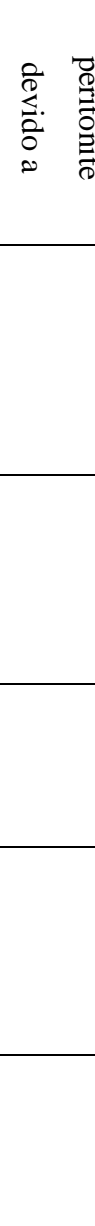 } & \multirow[t]{2}{*}{ 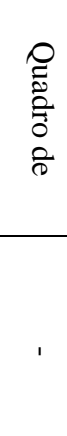 } & 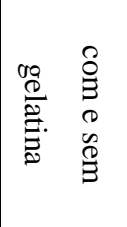 & 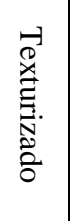 & & $N$ & 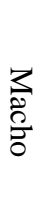 & \multicolumn{2}{|r|}{ 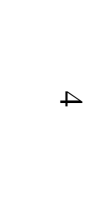 } & 商 & \multicolumn{2}{|c|}{ 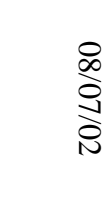 } & 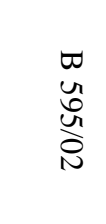 & - \\
\hline & & & 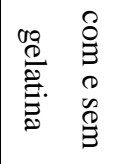 & 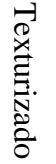 & & $N$ & 离 & & N & 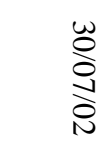 & & 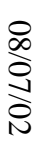 & 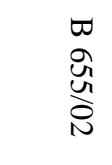 & $N$ \\
\hline & & ' & 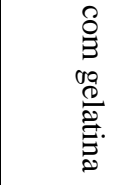 & 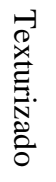 & & $N$ & 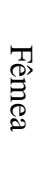 & & $\vec{\infty}$ & $\begin{array}{l}\text { On } \\
\text { ò } \\
\text { Oे }\end{array}$ & & 응 & $\begin{array}{l}\varpi \\
\infty \\
N \\
\stackrel{N}{O}\end{array}$ & $\omega$ \\
\hline & & ' & . & $\begin{array}{l}5.5 \\
\overline{0} \\
0 \\
\infty \\
0 \\
0\end{array}$ & & $N$ & 胥 & & N & $\begin{array}{l}\frac{N}{2} \\
\stackrel{D}{\infty} \\
\stackrel{N}{N}\end{array}$ & & 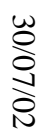 & 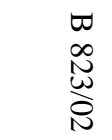 & $\perp$ \\
\hline & & ' & 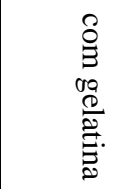 & 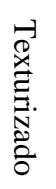 & & $N$ & 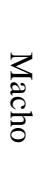 & & $\mathbb{\infty}$ & 옹 & & 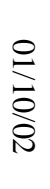 & 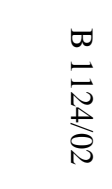 & $u$ \\
\hline & & ' & 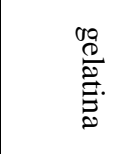 & $\begin{array}{l}5 . \\
0 . \\
0 \\
0 \\
\$ \\
8\end{array}$ & & $N$ & 常 & & \pm & $\frac{\stackrel{\infty}{N}}{\frac{N}{O}}$ & & 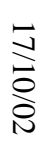 & $\begin{array}{l}\square \\
\Xi \\
\text { Ũ } \\
\text { ত্র }\end{array}$ & $a$ \\
\hline$\stackrel{\mathscr{E}}{\Xi}$ & 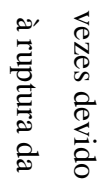 & $\begin{array}{l}\pi \\
0 \\
0 \\
0 \\
0 \\
00 \\
0 \\
0 \\
N\end{array}$ & 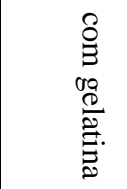 & 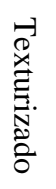 & & $N$ & 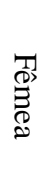 & & $\vec{\omega}$ & 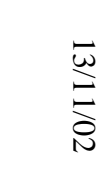 & & 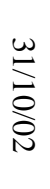 & $\begin{array}{l}\varpi \\
\bar{N} \\
\text { ڤ̊ } \\
\text { N }\end{array}$ & $\checkmark$ \\
\hline
\end{tabular}

$\mathrm{Na}$ autópsia, foram retirados os segmentos da artéria onde estavam suturados os patches, e imediatamente imersos em formalina (solução de formal a $10 \%$ ) (Shin, 1999). Esse material obtido foi cuidadosamente seccionado em diversos pontos, colocado em parafina e seccionado para a montagem das lâminas. As amostras foram coradas com tricrômico Masson, com a finalidade de corar tecido conjuntivo, e com 
hematoxilina e eosina (HE), com a finalidade de corar núcleos e citoplasma. Foram feitas lâminas para estudo histológico, através de microscopia óptica (microscópio Carl Zeiss, Alemanha), com o intuito de avaliar as interações entre o biomaterial implantado e o meio biológico. O foco principal deste estudo é verificar e caracterizar a ocorrência de uma íntima neo-formada sobre o material implantado.

\section{Caso 1 (B 595/02):}

Masson (aumento de 31,25x):

A figura (Figura III.1.2.1-4 - A) tem a intenção de mostrar que definitivamente foi rompida a parede do vaso para a colocação do implante, substituindo completamente a parede. Ainda são mostradas as porções de poliuretana (cor bege) e de gelatina (cor avermelhada) do material implantado. A fina faixa de cor vermelha com leves tons de azul ainda não é a íntima neo-formada, mas prenuncia o que ocorrerá devido à existência de elementos figurados do sangue, macrófagos e fibrina. Em azul mais forte é mostrado limiar da média e logo acima o da íntima, exatamente onde foi feito o corte. Nota-se a neo-íntima em formação pela proliferação a partir da íntima do vaso, pois se percebe uma ligação entre elas.

Masson (aumento de 200x):

A figura (Figura III.1.2.1-4 - B) mostra com maior aumento a íntima em formação, que tem como característica uma grande quantidade de pontos que são células inflamatórias. A íntima em formação constituí-se de fibrina, tendo de permeio células inflamatórias, tais como linfócitos, neutrófilos e macrófagos e que aguardam a migração de células musculares lisas a partir da área não lesada da íntima.

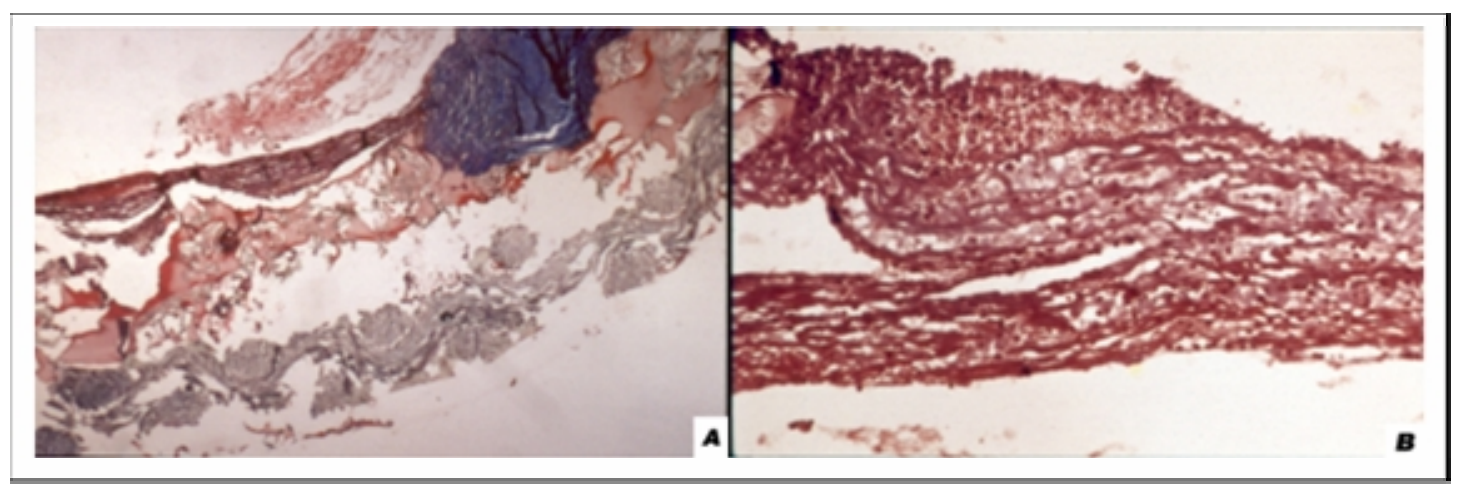


Figura III.1.2.1-4 (A) Definitivamente foi rompida a parede do vaso para a colocação do implante. (B) Íntima em formação, mas ainda com grande quantidade de células inflamatórias.

Caso 2 (B 655/02):

Masson (aumento de 31,25x):

A (Figura III.1.2.1-5 ) mostra a rotura da lâmina elástica interna, sendo nítida a rotura da média. Os tons de azul são predominantes, embora exista a presença de um tom avermelhado ao fundo, que indica a presença de células musculares lisas em migração para esta área. Há um limite nítido do que é a parede do vaso não lesado e do que é a íntima neo-formada. A íntima normal do vaso é caracterizada por células endoteliais e um pouco de células musculares lisas, no entanto ela não é muito espessa. Nota-se a existência da íntima neo-formada com um certo espessamento, provavelmente devido a dano celular, mas estando praticamente estabelecida. Está clara a presença do material implantado.

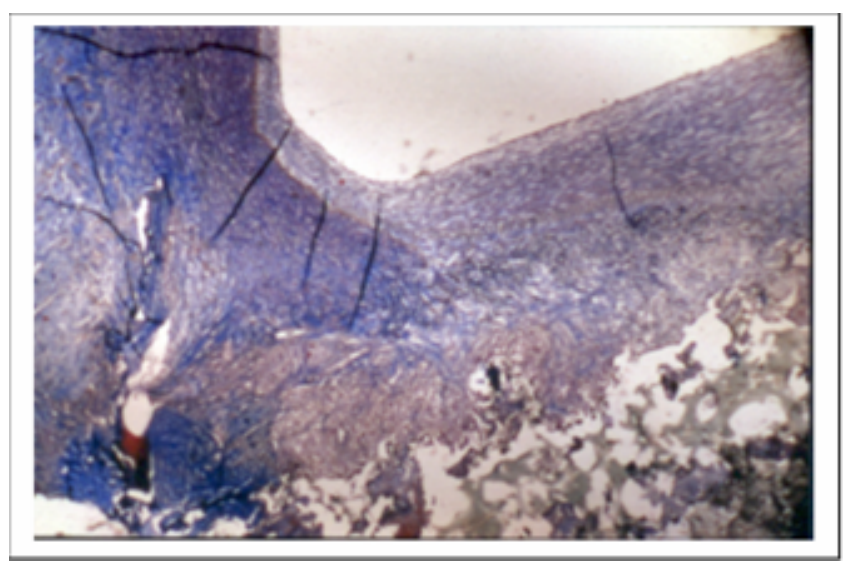

Figura III.1.2.1-5 Rotura da lâmina elástica interna e da média.

Caso 3 (B 822/02):

Masson (aumento de 28,75x):

Na (Figura III.1.2.1-6 - A) é mostrada a rotura da lâmina elástica interna e o limite da média. Percebe-se a presença de uma íntima neo-formada espessa, com células endoteliais e células musculares lisas bem evidentes (filetes avermelhados). Os edemas são interstícios normais da íntima vascular. 
Masson (aumento de 78,75x):

$\mathrm{Na}$ (Figura III.1.2.1-6 - B) nota-se a transição entre a área de rotura e a neoíntima, mostrando as células musculares lisas. É notada a presença do material implantado, e de uma densa fibrose (em azul). Tem-se uma íntima neo-formada cicatricial e espessa. Teoricamente com o decorrer do tempo as células lisas vão se proliferar, preenchendo de algum modo a área cicatrizada da média. Esse tempo é dependente do processo inflamatório. No bordo de interface, o processo inflamatório é mais evidente.

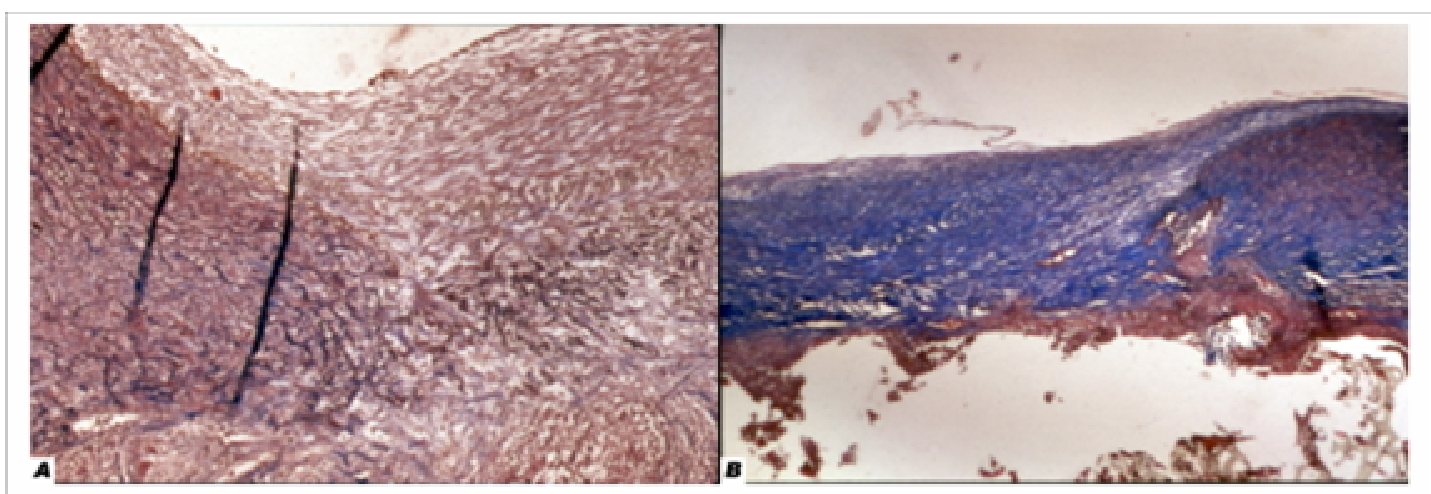

Figura III.1.2.1-6 (A) Íntima neo-formada, com células endoteliais e células musculares lisas bem evidentes. (B) Íntima neo-formada cicatricial e espessa.

Caso 4 (B 823/02):

As lâminas deste caso não foram utilizadas porque se mostraram impróprias para o estudo.

Caso 5 (B 1124/02):

Masson (aumento de 28,75x):

Na (Figura III.1.2.1-7 - A) é mostrada a área de secção e também a poliuretana (em bege), a gelatina (tom avermelhado), restos de fibrina que ainda não foi fagocitada (vermelho rutilante), e tecido conjuntivo (tom azulado). A neo-vascularização se dá a partir da parede não lesada.

Masson (aumento de 78,75x): 
Na (Figura III.1.2.1-7 - B) tem-se uma distinção clara da poliuretana, gelatina, uma neo-formação vascular (círculos) na área de rotura, células inflamatórias, há uma possível formação de calcificação distrófica (área pretejada), e também é mostrada a íntima neo-formada.

Masson (aumento de 78,75x):

$\mathrm{Na}$ (Figura III.1.2.1-7 - C) é mostrada a intensidade da neo-formação vascular em resposta ao trauma causado nessa área na tentativa de reconstruir o tecido cicatricial. Essa proliferação vascular concomitante ocorre no bordo da lesão pela necessidade de uma cicatrização.

Provavelmente esses vasos se formaram a partir da adventícia remanescente, pois ela apresenta os vasa vasorum até o seu terço médio de fora para dentro (vasos dos vasos que tem a função de nutrir a adventícia e a média).

Masson (aumento de 78,75x):

Na (Figura III.1.2.1-7 - D) é mostrado que apesar do tempo de implante, ainda se nota a presença de processo inflamatório.

HE (aumento de 200x):

Na (Figura III.1.2.1-7 - E) nota-se a presença de um tecido mais maduro, pois existe um número menor de núcleos, ou seja, menos celular, demonstrando uma fase mais cicatricial. Está evidente o que é a gelatina, a poliuretana, o tecido já mais maduro e a calcificação distrófica.

HE (aumento de 200x):

Na (Figura III.1.2.1-7 - F) é mostrada a abundância de células histiocitárias de corpo estranho. 


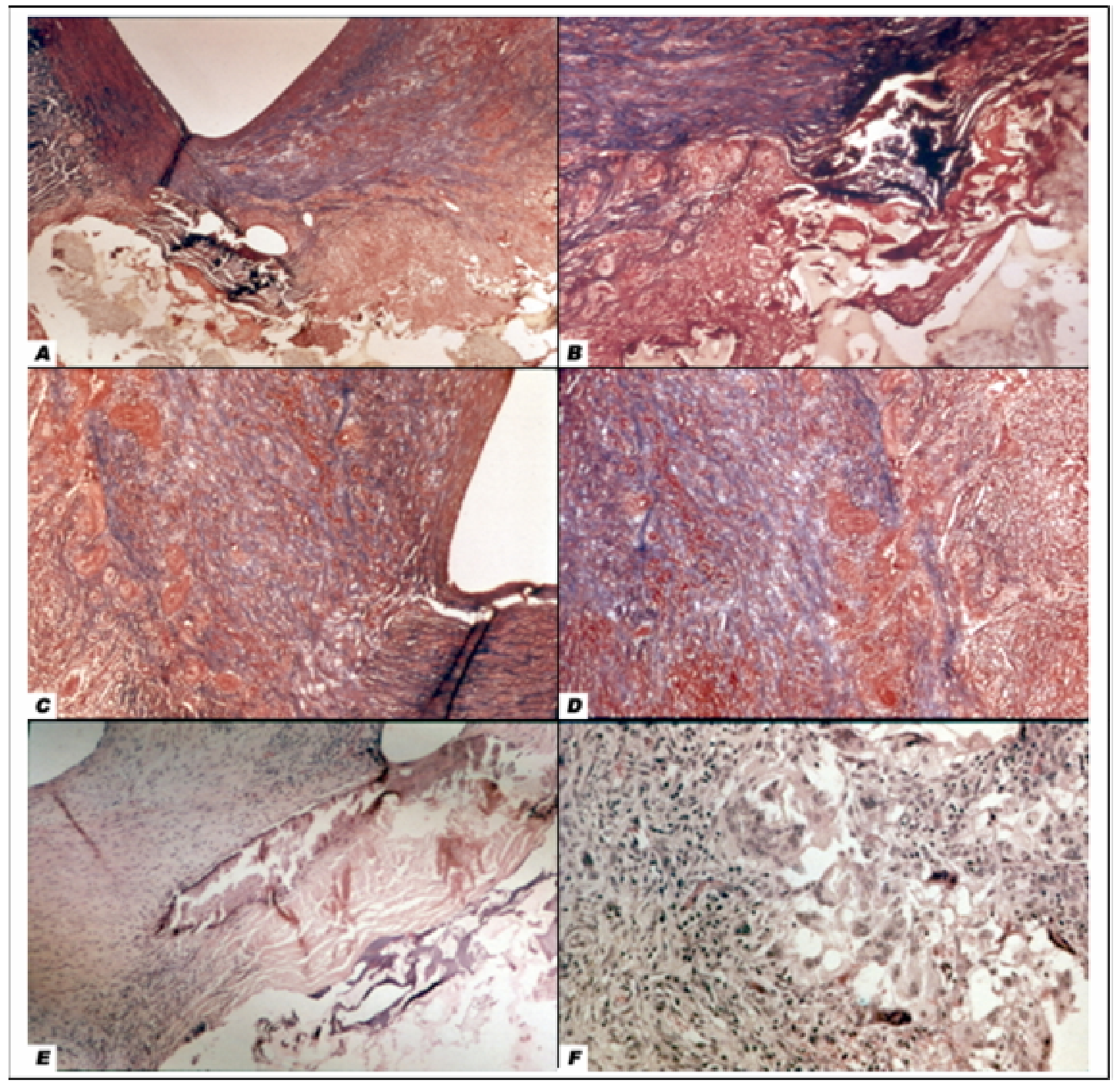

Figura III.1.2.1-7 (A) A neo-vascularização ocorre a partir da parede não lesada do vaso. (B) Ocorrência de uma possível calcificação distrófica. (C) Proliferação vascular concomitante no bordo da lesão devido à necessidade de uma cicatrização. (D) Presença de processo inflamatório. (E) Presença de um tecido mais maduro, pois existe um número menor de núcleos, o que demonstra uma fase mais cicatricial. (F) Grande quantidade de células histiocitárias de corpo estranho.

\section{Caso 6 (B 1125/02):}

Masson (aumento de 28,75x):

Nesse caso (Figura III.1.2.1-8), a íntima neo-formada aparenta estar um pouco mais delgada do que nos casos anteriores. Também é possível distinguir células musculares lisas (filetes vermelhos) e tecido conjuntivo. Existe a presença de células gigantes, multinucleadas, na tentativa de englobar material não próprio do corpo, 
ocorrendo uma resposta do tipo corpo estranho, ou seja, o hospedeiro responde ao material implantado.

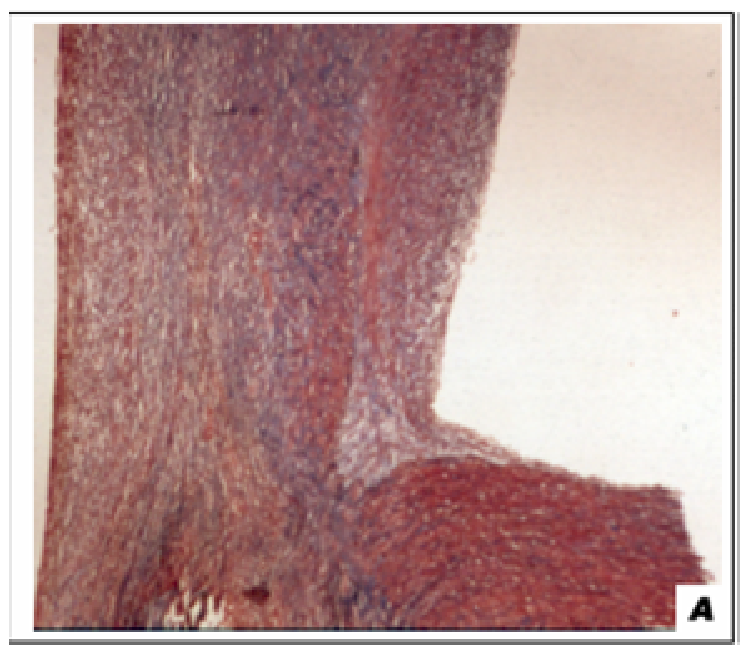

Figura III.1.2.1-8 Íntima neo-formada, células musculares lisas e tecido conjuntivo.

Caso 7 (B 1126/02):

Masson (aumento de 78,75x):

Na (Figura III.1.2.1-9 - A) verifica-se que há uma endotelização evidente da superfície interna do vaso na área lesada, mostrando a completa recuperação dessa parede lesada.

Masson (aumento de 28,75x):

A (Figura III.1.2.1-9 - B) mostra que a íntima neo-formada está bastante espessa, havendo presença de células musculares lisas (filetes avermelhados) que advém tanto da média quanto da íntima preservada e tecido conjuntivo (azul de fundo). Ainda há a presença de células inflamatórias concomitantes e macrófagos, que provavelmente fagocitaram a fibrina inicialmente formada, dispersos em meio a tecido conjuntivo jovem (tons de azul).

HE (aumento de 200x):

A (Figura III.1.2.1-9 - C) mostra a resposta do hospedeiro, e a resposta inflamatória ao material que é implantado. A resposta do hospedeiro mais evidente é aquela em que o material é visto como não pertencente ao meio, traduzido pela presença 
de células gigantes multinucleadas (do tipo corpo estranho). Nota-se a presença de um vacúolo que são restos de materiais cirúrgicos ou do próprio implante, sendo fagocitados. Tem-se uma neo-formação vascular, pela necessidade da presença de células inflamatórias para organizar a área lesada, (demonstrando um processo cicatricial normal). Estão presentes muitas células mononucleadas, histiócitos multinucleados e poucas células inflamatórias do tipo aguda porque esta já é uma fase subaguda, ou seja, de organização. Predominam células monocitárias que são linfócitos e macrófagos.

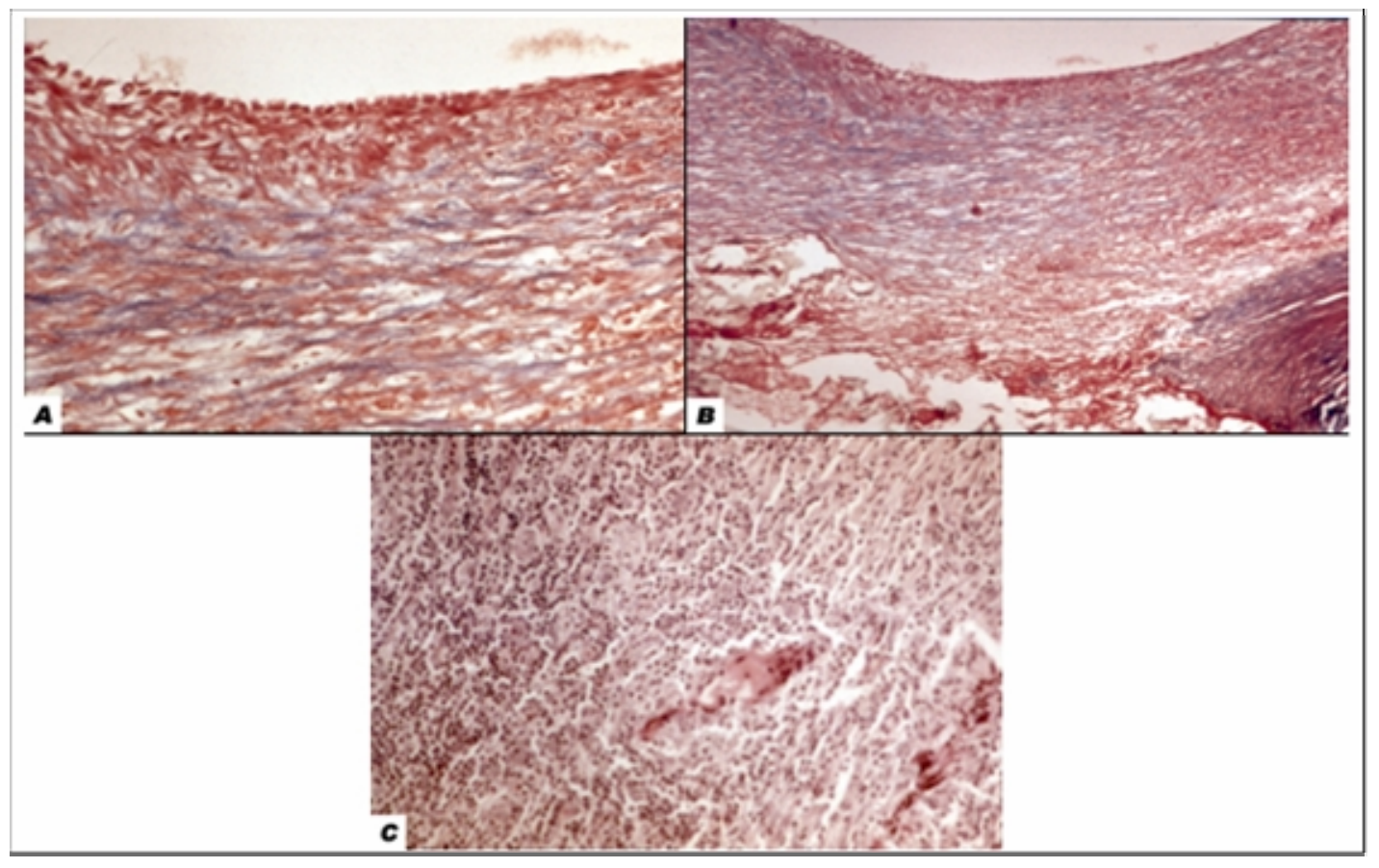

Figura III.1.2.1-9 (A) Células endoteliais mostrando a completa recuperação do tecido lesado. (B) Íntima neo-formada bastante espessa, com a presença de células musculares lisas e de tecido conjuntivo (C) Resposta do hospedeiro e resposta inflamatória ao material que é implantado.

\section{III.1.2.2 Implante do Dispositivo}

Foi realizado experimento In Vivo, onde foi implantado o dispositivo de assistência ventricular. Os procedimentos cirúrgicos foram realizados seguindo as condições e os parâmetros estipulados em protocolo. 
No experimento com bezerro, o animal teve um quadro de fibrilação ventricular que foi revertido após massagem cardíaca. Durante o procedimento cirúrgico, ocorreu à obstrução temporária do tronco braquio-cefálico por aproximadamente cinco minutos, fato que comprometeu a sua recuperação no pós-operatório. Como seqüela o animal ficou descerebrado, permanecendo inconsciente na mesa cirúrgica durante os seis dias de experimento. Durante esse período suas funções vitais foram monitoradas. Foram utilizadas bolsas de sangue com o intuito de manter o animal nutrido durante todo o período de experimento. Assim, na data prevista para o término do experimento o animal foi acometido por um quadro de bradicardia que comprometeu as suas funções vitais levando-o a óbito.

Os dados monitorados de suas funções vitais foram obtidos através de eletrocardiograma (ECG) e pressão arterial (PA). Na figura (Figura III.1.2.2-1 ), as duas curvas superiores registram o momento em que o DAV é desligado e ligado novamente. A primeira curva mostra que o ECG não sofre alteração devido à utilização do DAV. No momento em que o dispositivo é ligado e começa a atuar, um novo pulso é introduzido, diminuindo assim a amplitude da curva de pressão. A letra "A" representa a curva de pressão arterial no instante em que somente o coração natural está atuando. A letra "B" mostra a curva de pressão gerada pelo coração natural seguida da letra "C" que mostra a curva gerada pelo DAV. As duas curvas inferiores registram o momento em que o coração natural está em sincronismo com o DAV. Neste momento o dispositivo, representado pela letra "E", está ejetando mais do que o coração natural, representado pela letra " $\mathrm{D}$ ".

Na figura (Figura III.1.2.2-2) é observada a freqüência cardíaca de 78 bpm, as pressões arteriais máxima, média e mínima de respectivamente 151, 119 e $108 \mathrm{mmHg}$. No ECG foi utilizada derivação II com filtro e velocidade do papel de $25 \mathrm{~mm} / \mathrm{s}$. A letra “A” mostra o complexo QRS que ocorre devido à despolarização ventricular indicando que se iniciará uma nova sístole ventricular. Na letra "B" temos a curva gerada pelo coração natural e na letra "C" a curva gerada pelo DAV. O dispositivo foi colocado em modo de funcionamento com taxa variável de ejeção e velocidade do motor de $61 \mathrm{bpm}$. A curva "C" apresenta um platô que indica uma ejeção lenta do DAV devido à baixa velocidade do motor.

Na figura (Figura III.1.2.2-3) a freqüência cardíaca é de 56 bpm, e as pressões arteriais máxima, média e mínima de respectivamente 112, 86 e 69 mmHg. No ECG foi 
utilizada derivação I com filtro e velocidade do papel de $25 \mathrm{~mm} / \mathrm{s}$. A letra "A" mostra o complexo QRS, a letra "B" temos a curva gerada pelo coração natural que se adaptou ao dispositivo e na letra "C" a curva gerada pelo DAV. O dispositivo foi colocado em modo de funcionamento com taxa fixa de ejeção e velocidade do motor de 60 bpm.

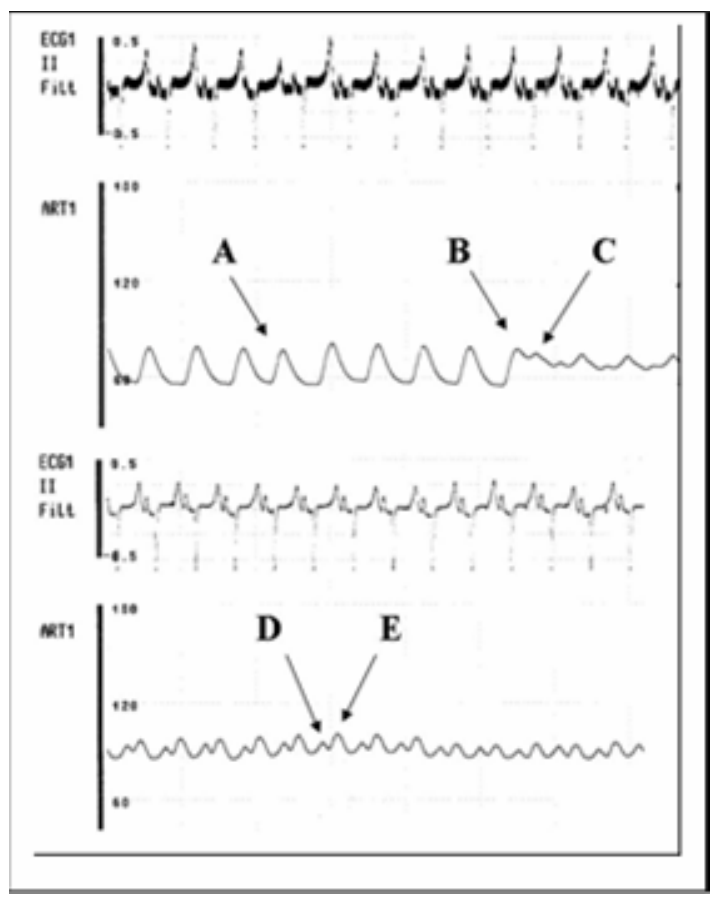

Figura III.1.2.2-1 As curvas superiores de eletrocardiograma e de pressão arterial registram o momento em que o dispositivo é desligado e ligado novamente. As curvas inferiores mostram o coração natural em sincronismo com o DAV. 


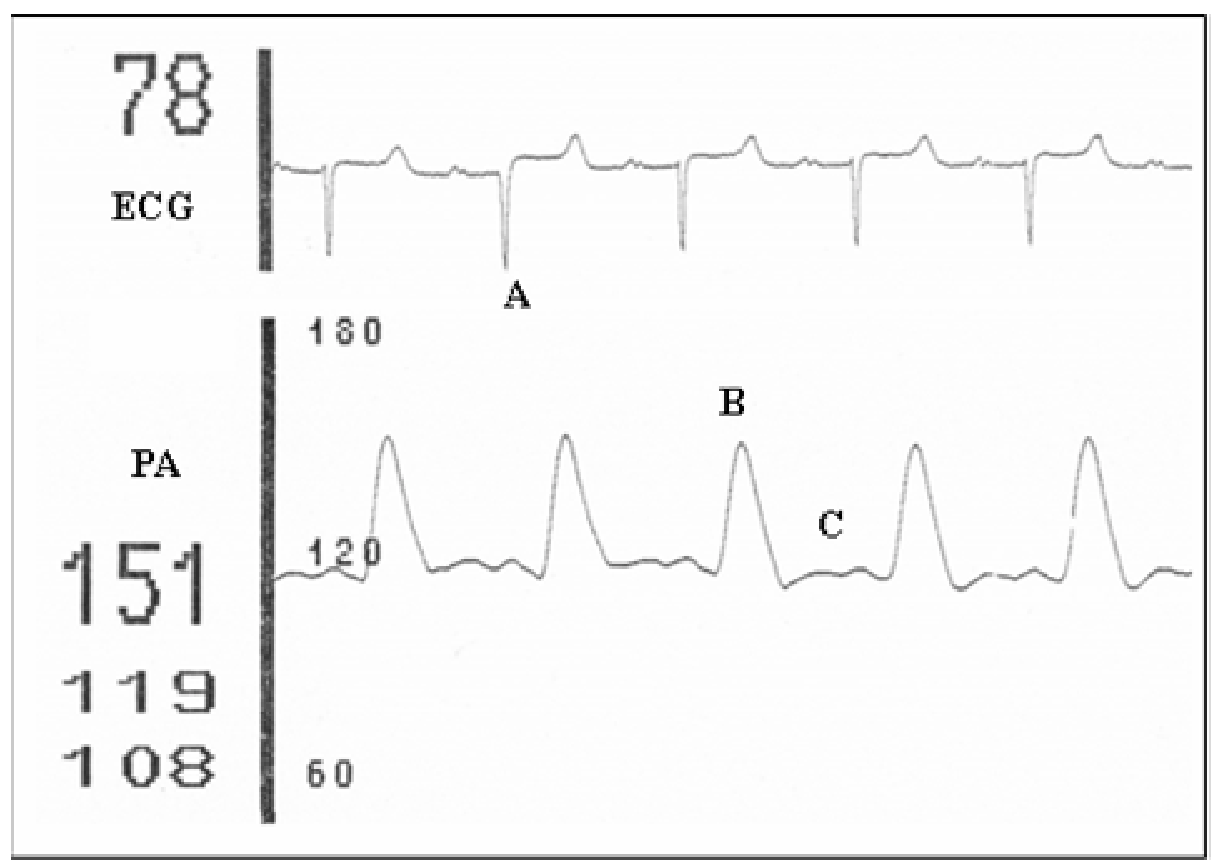

Figura III.1.2.2-2 As curvas indicam freqüência cardíaca de 78 bpm, pressões arteriais máxima, média e mínima de respectivamente 151,119 e $108 \mathrm{mmHg}$. O dispositivo foi colocado em modo de funcionamento com taxa variável de ejeção e velocidade do motor de $61 \mathrm{bpm}$.

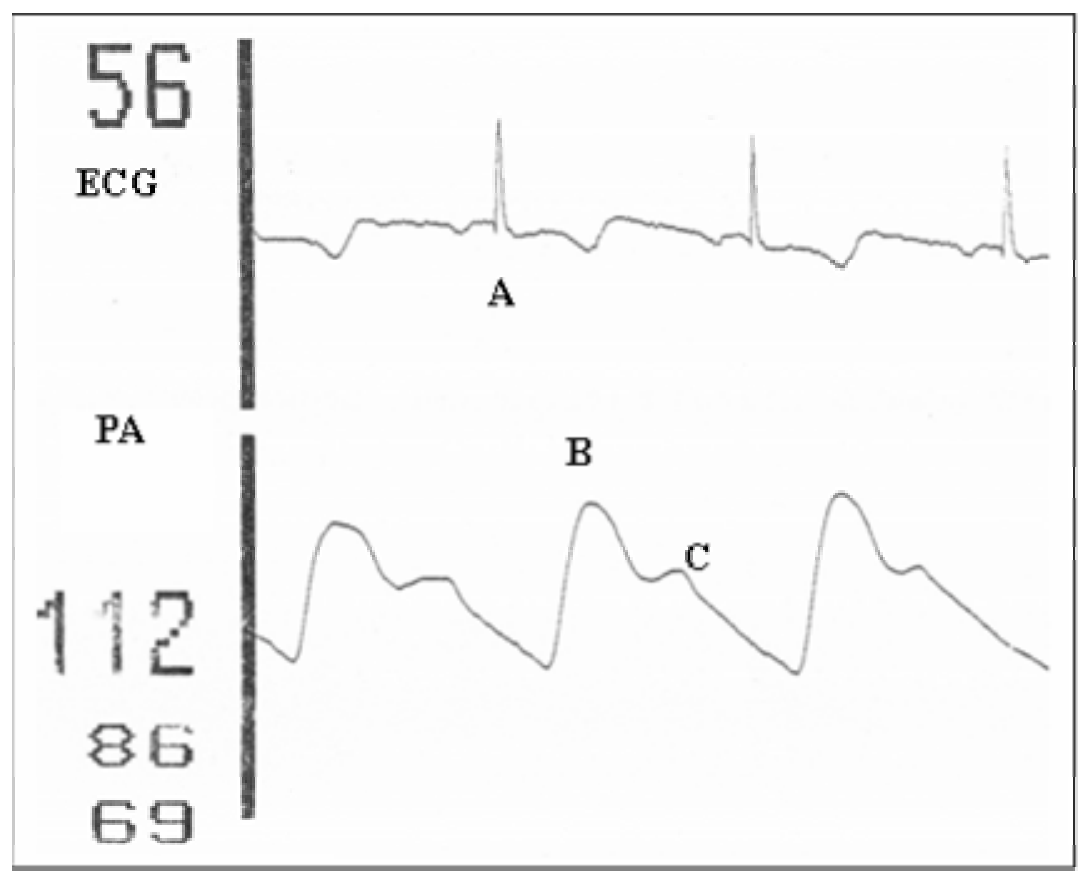

Figura III.1.2.2-3 A freqüência cardíaca é de 56 bpm, e as pressões arteriais máxima, média e mínima são de respectivamente 112, 86 e 69 mmHg. Foi utilizada derivação I 
com filtro e velocidade do papel de $25 \mathrm{~mm} / \mathrm{s}$. O dispositivo foi colocado em modo de funcionamento com taxa fixa de ejeção e velocidade do motor de $60 \mathrm{bpm}$.

Imediatamente após o término do experimento o dispositivo foi imerso em solução de formol a $10 \%$. Com isso foram coletadas amostras do material depositado sobre as superfícies do DAV que mantiveram contato direto com sangue. Foram preparadas lâminas para estudo histológico e coradas com hematoxilina e eosina (HE), de acordo com procedimento utilizado nos experimentos para implante de patch. As amostras foram analisadas e fotografadas através de microscópio óptico (microscópio Carl Zeiss, Alemanha), com a intenção de caracterizar o material coletado.

Na (Figura III.1.2.2-4 - A) é mostrada a superfície do diafragma do dispositivo de assistência parcialmente coberto por um trombo. Também é mostrada (Figura III.1.2.2-4 - B) a oclusão parcial do orifício de saída da câmara de bombeamento, devido à deposição deste trombo. Na (Figura III.1.2.2-4 - C) é mostrada uma lâmina HE com aumento de 78,75x. A imagem é de uma porção do trombo recente, intracavitário, e está constituída por uma rede de fibrina, hemácias e alguns elementos celulares. 


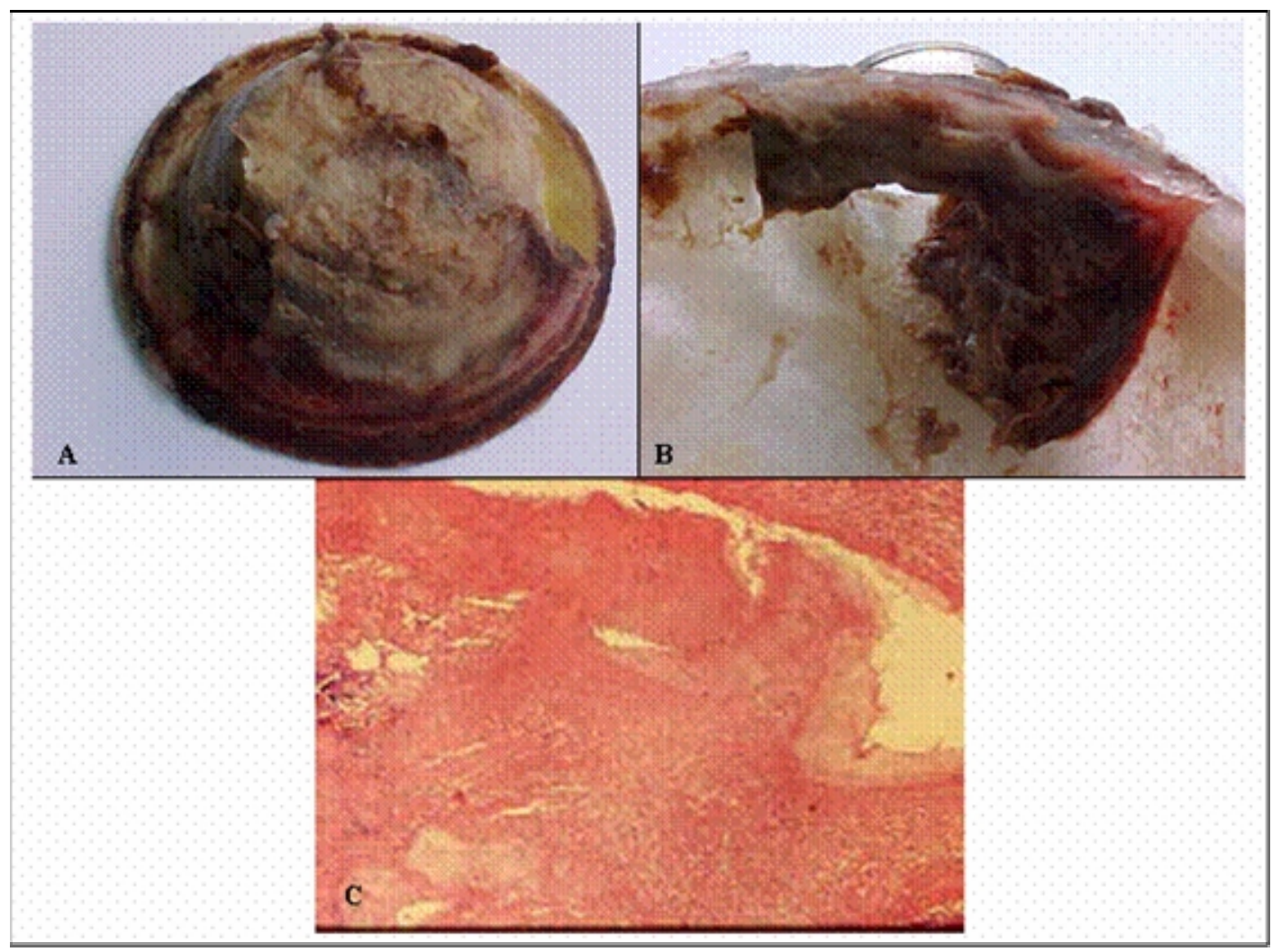

Figura III.1.2.2-4 (A) Diafragma do dispositivo de assistência após explante parcialmente coberto por trombo. (B) Câmara de bombeamento após explante com oclusão parcial do orifício de saída devido à formação de um trombo. (C) Porção do trombo recente, intracavitário, constituído por uma rede de fibrina, hemácias e alguns elementos celulares. 


\section{Capítulo IV}

IV.1 Discussão

\section{IV.1.1 Teste In Vitro}

A resistência da gelatina não pode ser avaliada através do sistema de simulação, pois devido à longa duração do teste, o material seria degradado por bactérias. Pelo mesmo motivo não é utilizada uma solução de água e glicerina para simular a viscosidade do sangue.

Novos testes visando avaliar a resistência máxima do diafragma devem ser preparados, no entanto utilizando o próprio dispositivo de assistência, permitindo assim avaliar a performance de todos os seus componentes. Dessa forma também é possível analisar falhas eletrônicas e do sistema de controle.

\section{IV.1.2 Implante de Patch}

No caso 1 (B 595/02) a íntima ainda não se formou, mas isso provavelmente ocorrerá devido à existência de elementos figurados do sangue, macrófagos e fibrina. Isso será o substrato para o desenvolvimento da proliferação celular que comporá a neoíntima no futuro. Células musculares lisas se proliferarão a partir da média residual. Existe ainda uma grande quantidade de células inflamatórias.

No caso 2 (B 655/02) é constatado que a neo-íntima apresenta características celulares próprias e que paulatinamente atingirá a sua maturidade.

No caso 3 (B 822/02) existe uma íntima neo-formada cicatricial e espessa, com células endoteliais e células musculares lisas. No bordo de interface, o processo inflamatório é mais evidente. 
No caso 4 (B 823/02) as lâminas se mostraram impróprias para o estudo devido às dificuldades de corte, portanto foram excluídas do estudo.

No caso 5 (B 1124/02) a resposta do hospedeiro ainda permanece, mas existe proliferação vascular e conjuntiva junto à área de implante. Dessa forma é mostrada a recuperação da íntima, se apresentando um pouco mais celular do que habitual e muito mais espessa, só que aliada à permanência do processo inflamatório, mas com certo grau de proliferação do tipo cicatricial. A neo-vascularização é necessária para que células inflamatórias alcancem o tecido lesado. Paralelamente a isso, existe a presença de alguns focos de calcificação distrófica que são comuns em alterações inflamatórias ou necróticas, não estando relacionada com níveis elevados de cálcio. A calcificação distrófica é caracterizada pela deposição de sais de cálcio em tecidos lesados, degenerados ou mortos (Nosé, 1981).

No caso 6 (B 1125/02) existe a formação da íntima, no entanto espessa, mas com estrutura bem organizada, ou seja, já com poucas células inflamatórias. O bordo de interface entre o material e o tecido se mostra mais liso do que nos demais casos, ou seja, sem ulcerações, proliferações inflamatórias, demonstrando que provavelmente a utilização de gelatina interfere na adesão do material.

No caso 7 (B 1126/02) o endotélio está formado e reveste completamente a íntima, que aparentemente apresenta conformidade semelhante àquela do tecido normal. Existe uma resposta do hospedeiro do tipo histiocitária de corpo estranho pela presença do material implantado, além da abundância de células inflamatórias.

\section{IV.1.3 Implante do DAV}

Através do implante do dispositivo pode ser realizada análise da resistência mecânica da gelatina, onde ao término do experimento é feito estudo histológico que identifica a presença ou não da camada protéica. Durante a autópsia são analisados os diversos órgãos do animal, o que possibilita a verificação de possíveis fragmentos da gelatina.

Ao ser acometido por um quadro de bradicardia, apesar da utilização de uma terapia com anticoagulante, ocorre um desequilíbrio da relação entre procoagulantes e anticoagulantes presentes no sangue devido à baixa velocidade do fluxo sanguíneo. Essa 
alteração na hemodinâmica permite que concentrações maiores de procoagulantes iniciem o processo de coagulação dentro do dispositivo.

\section{IV.2 Conclusões}

\section{IV.2.1 Teste Mecânico}

A duração do teste foi considerada suficiente, visto que vinte milhões de ciclos representa a utilização deste dispositivo em condições normais por seis meses.

O dispositivo de simulação foi considerado eficiente, pois proporcionou fluxo e pressão com certa precisão e repetibilidade. $\mathrm{O}$ desgaste ocorrido na base de suporte do motor e na base de suporte da câmara não provocou nenhum distúrbio significativo que comprometesse a realização do teste. A substituição da valva mecânica não afetou o sucesso do teste, uma vez que sua reposição tenha sido imediata.

O teste também comprovou que o ajuste estipulado para a distância máxima percorrida pelo diafragma durante a ejeção não provocou contato entre a membrana e a parede interna da câmara, o que em testes In Vivo teriam sérias conseqüências desde a ocorrência de hemólise até uma possível ruptura da membrana ou mesmo da câmara de bombeamento.

\section{IV.2.2 Estudo Morfológico e Histológico}

Dificuldades relacionadas ao artefato de corte na elaboração das lâminas para estudo histológico ocorreram devido à falta de navalhas específicas para corte de material não biológico, gerando cortes relativamente grossos.

Em todos os casos existem reações de resposta do hospedeiro, aliado a processo inflamatório. Essa resposta do meio fisiológico em relação à superfície de contato permite concluir que independente do material utilizado (gelatina ou BioSpan®), a reação do corpo é evidente. No entanto, em ambos os casos ocorreu processo cicatricial propiciando um ambiente adequado, uma vez que a íntima neo-formada apresenta células endoteliais. 
A utilização do processo de biolização como superfície de contato seria indicado para o revestimento das partes internas de um dispositivo de assistência, de forma a evitar o contato do sangue com materiais distintos, o que geraria diferença de potencial propiciando a formação de trombo. A utilização de gelatina também é apropriada para preencher todos os espaços formados dentro da prótese, devido à junção dos materiais (câmara de bombeamento, diafragma e valvas). A opção pela utilização da poliuretana lisa também se mostra viável, mas com certa ressalva, ou seja, ao invés da utilização de um diafragma, deveria ser modelada uma bolsa que acomodasse o sangue evitando assim seu contato com outros materiais.

É possível que o espessamento da íntima neo-formada tenha ocorrido devido à depressão criada pela extração de parte da parede do vaso para a fixação do patch. Esse crescimento excessivo seria uma tentativa do sistema de atenuar o desequilíbrio gerado no fluxo normal de sangue nessa região da artéria.

\section{IV.2.3 Implante do Dispositivo}

O dispositivo de assistência ventricular esquerda se adapta totalmente ao coração natural, sendo sua performance satisfatória, e capaz de proporcionar ao coração natural fluxo e pressão adequados.

O fato de o animal ter sido acometido por um quadro de bradicardia, provavelmente gerou grande impacto em sua hemodinâmica, iniciando assim um processo de formação de coágulo dentro da câmara de bombeamento. Possivelmente o coágulo que ocorreu próximo ao orifício de saída da câmara de bombeamento, surgiu devido ao longo tempo de espera para a ejeção do dispositivo. Já na região próxima ao orifício de entrada, não ocorreu formação de coágulo, uma vez que nesse local o fluxo de sangue é eficaz para a sua completa lavagem, evitando o acúmulo de procoagulantes.

Os exames laboratoriais realizados durante todo o tempo de experimento são mostrados no anexo. 


\section{Referências Bibliográficas:}

ADAMS G. A., FEUERSTEIN I. A. How much fibrinogen or fibronectin is enough for platelet adhesion? Trans. Am. Soc. Artif. Intern. Organs, v. 27, p. 219-224, 1981.

AKUTSU, T. e KOLFF, W. J. Permanent substitutes for valves and hearts. Trans. Am. Soc. Artif. Intern. Organs, v. 4, p. 230-232, 1958.

ALIANÇA BRASILEIRA PELA DOAÇÃO DE ÓRGÃOS E TECIDOS (2002). Educação e transplante. (Disponível em <http://www.adote.org.br〉), (acessado em 19 de Março).

ALLEN e LILLEHEI apud GALIOTO, F. M. JR. Cardiovascular Assist and Monitoring Devices. In: BRONZINO, J. D. Biomedical Engineering and Instrumentation: Basic Concepts and Applications. Boston, PWS Publishers. Cap. 3, p. 79-105, 1986. ISBN 0-534-06492-2.

ANDRADE, A. J. P. Projeto, Protótipo e Testes "In Vitro" e "In Vivo" de um Novo Modelo de Coração Artificial Total (TAH) por Princípio Eletro-Mecânico de Funcionamento, 1998. 230p, Tese (Doutorado) - Universidade Estadual de Campinas, Campinas.

CONWAY, F. New Heart, New Hope, Special Report. EUA, p. 41-49, June 25, 2001.

DEBAKEY, M. E. A simple continuous-flow blood transfusion instrument. New Orleans Med. Surg. J., v. 87, p. 386-389, 1934.

GRAHAM T. R. et al. Evaluation of textured biomaterial surfaces during clinical use of an implantable left ventricle assist device. Intern. Soc. for Artif. Organs, v. 14, p. $135-143,1990$.

GUYTON, A. C. Tratado de fisiologia médica. Rio de Janeiro, Interamericana. Cap. 9, p. 89-100, 1977.

HARASAKI H., KIRALY R., NOSÉ Y. Endothelization in blood pumps. Trans. Am. Soc. Artif. Intern. Organs, v. 24, p. 415-424, 1978. 
KAMBIC H. et al. Application of aldehyde treatments to cardiovascular devices. Trans Am Soc Artif Intern Organs, v. 22, p. 664-672, 1976.

KAMBIC H. et al. Glutaraldehyde-protein complexes as blood compatible coatings. Trans Am Soc Artif Intern Organs, v. 24, p. 426-437, 1978.

LELAH M. D., COOPER S. L. Polyurethanes in medicine. EUA, CRC Press, 1986.

LIOTA e DeVries apud ANDRADE, A. et al. Testes in vitro e in vivo com o coração artificial auxiliar (CAA): um novo modelo de coração artificial totalmente implantável e heterotópico. Revista Brasileira de Cirurgia Cardiovascular, v. 14, n. 2, p. 128-134, 1999.

LYMAN D. J. et al. The effect of chemical structure and surface properties of synthetic polymers on the coagulation of blood. III. In Vivo adsorption of proteins on polymer surfaces. Trans. Am. Soc. Artif. Intern. Organs, v. 20, p. 474-478, 1974.

MANN F. A. et al. A calf model for left ventricular centrifugal mechanical assist. Intern. Soc. for Artif. Organs, v. 20, p. 670-677, 1996.

MINISTÉRIO DA SAÚDE (2002). Doenças cardiovasculares Aspectos Epidemiológicos. (Disponível em <http://www.saude.gov.br/programas/cardio/

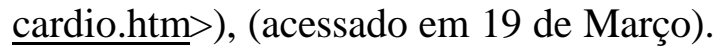

MITAMURA Y. et al. Scanning electron microscopic studies on ceramics/blood interface. Intern. Soc. for Artif. Organs, v. 14, p. 94-96, 1990.

MOULOPOULOS et al. apud SPOTNITZ, H. M. Circulatory Assists Devices. In: SKALAK, R. Handbook of Bioengineering. EUA, McGraw-Hill Book Company. Cap. 38, p. 38.2, 1987. ISBN 0-07-057783-8.

NOSÉ Y. Blood clotting problems in the artificial heart devices. J. Biomed. Mater. Res., v. 1, p. 151-169, 1967 (a).

NOSÉ Y. et al. Clot formation inside the artificial heart device. J. Thorac. Cardiov. Surg., v. 54, p. 697-706, 1967 (b). 
NOSÉ Y. et al. Cardiac prosthesis utilizing biological material. J. Thorac. Cardiov. Surg., v. 62, p. 714-724, 1971 (a).

NOSÉ Y. et al. Artificial heart constructed with biological material. Trans. Am. Soc. Artif. Intern. Organs, v. 17, p. 482-487, 1971 (b).

NOSÉ Y., HARASAKI H., MURRAY J. Mineralization of artificial surfaces that contact blood. Intern. Soc. for Artif. Organs, v. 27, p. 714-719, 1981.

OHASHI Y. et al. Augmented destruction test with an eletromechanical pulsatile total artificial heart. Intern. Soc. for Artif. Organs, v. 23, p. 884-887, 1999.

ORIME Y. et al. In Vitro and In Vivo validation tests for total artificial heart. Intern. Soc. for Artif. Organs, v. 18, p. 54-72, 1994.

OSHIRO, M. S. et al. Design, manufacturing, and testing of a paracorporeal pulsatile ventricular assist device: São Paulo Heart Institute VAD. Trans. Am. Soc. Artif. Intern. Organs, v. 19, p. 274-279, 1995.

SHIN C. K. et al. Histology and electron microscopy of explanted bifurcated endovascular aortic grafts: Evidence of early incorporation and healing. J. Endovasc. Surg., v. 6, p. 246-250, 1999.

VAŠKU J., URBÁNEK P. (1995). Electron microscopic study of driving diaphragms in long-term survival with a total artificial heart. Intern. Soc. for Artif. Organs, v. 19, p. 344-354, 1995. 


\section{APÊNDICE A - Protocolos de Cirurgia}




\section{SECRETARIA DE ESTADO DA SAÚDE}

Coordenadoria de Saúde da Região Metropolitana da Grande São Paulo INSTITUTO “DANTE PAZZANESE” DE CARDIOLOGIA

\section{Comitê de Ética em Pesquisa Experimental CEPE/IDPC}

\section{Protocolo de Pesquisa Experimental}

Número do Protocolo:

Título do Projeto: AVALIAÇÃO "IN VIVO” DO DISPOSITIVO ELETROMECÂNICO DE ASSISTÊNCIA VENTRICULAR ESQUERDA (DAV).

\section{Dados do Investigador Principal}

Nome: Aron J. P. Andrade / Jarbas J. Dinkhuysen

Formação: Engenharia / Medicina

Instituição: IDPC Setor: Centro Técnico de Experimentos

Cargo: Eng. IV

Tel: 50854011

Endereço:

Av. Dante Pazzanese, N. 500, Ibirapuera, Cep: 04012-180, SP-SP

\section{Equipe de Pesquisadores Envolvidos}

\begin{tabular}{ccc}
\hline Nome & Função na Pesquisa & Telefone \\
\hline Eng. Daniel Legendre & Eng. Mecatrônico & 50854010 \\
\hline Eng. Jeison Fonseca & Eng. Elétrico & 50854010 \\
\hline Dr. Paulo Paulista & Cirurgião & 50854153 \\
\hline Dr Josué de Castro Neto & Cirurgião & 50854153 \\
\hline Dr. Paulo Valente & Médico Veterinário & 50854037 \\
\hline Dra. Elizabete Catarina Leone & Médica Veterinário & 50854037 \\
\hline Dr. Ricardo Manrique & Hematologista & 50854095 \\
\hline Dra. Lilian Mary da Silva & Médica Patologista & 50854030 \\
\hline Dra. Mabel M. B. Zamorano & Médica Patologista & 50854030 \\
\hline
\end{tabular}




\section{Dados do Patrocinador do Projeto}

Nome: Fundação Adib Jatene

Endereço: Av. Dante Pazzanese, 500, CEP: 04012-180, Ibirapuera SP-SP Tel.:50854009

Tipo de Patrocínio: Próprio

\section{Descrição da Pesquisa}

\subsection{Introdução com Embasamento Teórico:}

O Brasil é considerado um país que acompanha o estado da arte da cardiologia mundial, em particular da cirurgia cardíaca. No Brasil, foram desenvolvidos nas últimas décadas, diversos equipamentos e dispositivos necessários a uma cirurgia cardíaca, fazendo com que hoje seja possível a realização de uma cirurgia cardíaca com tecnologia 100\% nacional e até mesmo exportar esta tecnologia. Consta na literatura mundial que várias técnicas cirúrgicas desenvolvidas no Brasil são hoje aplicadas em todo o mundo, comprovando a importância da contribuição brasileira na área. Com o avanço das técnicas cirúrgicas é possível a realização, também no Brasil, de transplantes cardíacos com grande sucesso. Porém, o número de doadores é insuficiente e muitos receptores vão a óbito nas filas de espera para estes transplantes. Os centros de pesquisas mais importantes do mundo têm se empenhado no desenvolvimento de equipamentos para suporte à vida destes pacientes, enquanto aguardam o transplante. Existem alguns dispositivos de assistência ventricular sendo comercializados nos EUA e em alguns países da Europa, porém no Brasil não estão disponíveis e nem seriam acessíveis à grande maioria dos pacientes brasileiros. Atualmente, são realizadas 42.000 cirurgias cardíacas com circulação extracorpórea por ano no Brasil, colocando-o em terceiro lugar no mundo em número de cirurgias. Estima-se que aproximadamente 2000 pacientes poderiam ser candidatos à utilização de dispositivos de assistência ventricular. Desta forma, torna-se importante a evolução de linhas de pesquisa na área de assistência ventricular e coração artificial para geração de tecnologia nacional e com custos acessíveis à gestão da saúde pública brasileira. Este Protocolo visa estudar o Dispositivo de Assistência Ventricular Esquerda (DAV) em desenvolvimento no IDPC/FAJ, aperfeiçoando os procedimentos e técnicas cirúrgicas em estudos "In Vivo" em bezerros. Serão testadas novas gerações de equipamentos e biomateriais para assistência ventricular esquerda no pré e pós-cirúrgico. 


\subsection{Objetivos da Pesquisa:}

- Avaliar as alterações causadas pelo dispositivo de assistência ventricular (DAV) ao organismo do animal.

- Analisar a eficácia do DAV.

- Avaliar as interações entre os biomateriais e os tecidos adjacentes.

\subsection{Hipóteses a serem testadas:}

Será realizada uma análise do dispositivo procurando manter os animais com assistência ventricular esquerda e pressão arterial média de $100 \mathrm{~mm} \mathrm{Hg}$, durante seis dias. Serão efetuados os seguintes estudos:

\section{Estudos Bioquímicos}

Exames hematológicos e bioquímicos completos do sangue serão feitos durante os experimentos do DAV "In Vivo". O objetivo desses extensivos testes laboratoriais é avaliar os efeitos dos biomateriais da bomba e do bombeamento na fisiologia do animal, isto é, nas principais funções dos órgãos e nos componentes do sangue, especialmente nos elementos figurados, tais como: eritrócitos e plaquetas.

\section{Testes de Desempenho do DAV}

Uma variedade de estados patológicos pode ser observada durante os primeiros dias pósoperatórios. Hipovolemia, hipotensão ou hipertensão, taquicardia ou bradicardia e taquipnéia, podem ocorrer durante a recuperação do trauma cirúrgico. Após este período (período de recuperação), deve ser observada uma condição hemodinâmica relativamente estável, isto é correlacionado estreitamente com as condições normais do animal e seu apetite.

\section{Exame Anatômico}

O objetivo deste extensivo protocolo de patologia é avaliar o formato do sistema DAV e seu desempenho "In Vivo" do ponto de vista morfológico. O exame patológico dos principais órgãos reflete a compatibilidade do tamanho e peso do sistema, o desempenho hemodinâmico e a compatibilidade sangüínea de todos os componentes do sistema em contato com sangue. A infecção ao redor do DAV juntamente com os efeitos da vibração e dissipação de calor de cada componente são examinados através de cuidadosa análise do tecido de encapsulamento e dos órgãos adjacentes, inclusive do tecido ósseo. Serão feitas culturas bacteriológicas nas superfícies do dispositivo. 


\section{Compatibilidades do Tamanho, Peso e Configuração}

A aceitação do tamanho, peso e configuração do sistema é avaliada através de observações cuidadosas do local do implante, verificando possíveis deslocamentos anatômicos dos átrios, veia cava, pulmões e diafragma.

\section{Os Efeitos do Desempenho Hemodinâmico}

A adequação do débito da bomba é melhor avaliado através do ganho de peso do animal, do crescimento dos principais órgãos e da perfusão dos tecidos revelada pela presença ou ausência de mudanças isquêmicas agudas ou crônicas. Um débito insuficiente da bomba induz um aumento no volume de sangue em circulação e relativa anemia, conforme pode ser visto em falhas cardíacas congestivas crônicas. Isto é refletido por anemia e edema nos principais órgãos e tecidos musculares. A sensibilidade do sistema à pressão de enchimento se reflete no peso e histologia dos pulmões. Uma pressão venosa central elevada é refletida no peso do fígado com alterações patológicas, inclusive necrose central. A presença de elevada pressão atrial esquerda é mostrada prontamente em mudanças na estrutura capilar alveolar (pulmões). Os níveis de pressão e a amplitude do pulso são refletidos na arquitetura da parede arterial tanto do sistema circulatório periférico quanto pulmonar. É um procedimento de rotina medir-se a espessura da parede arterial nos pulmões, rins e baço em experimentos com DAVs.

\subsection{Descrição dos animais a serem utilizados:}

Espécie: Bovinos

Raça:

Idade: até 6 meses Tamanho: Peso: $80 \mathrm{Kg} \mathrm{a} 100 \mathrm{Kg}$ Justificativas:

O bezerro candidato para a realização do implante é selecionado uma semana antes da cirurgia após uma consulta com o veterinário. Esta seleção preliminar é baseada no histórico de doenças infecciosas, resultados de exames físicos e peso corporal. Uma seleção final é feita baseando-se em dados hematológicos adicionais, pela análise de amostras de sangue retiradas pela manhã, antes de alimentar os animais.

Os critérios de seleção do animal incluem as seguintes características e necessidades:

- Macho com peso entre 80 e $100 \mathrm{~kg}$;

- Ausculta respiratória e cardíaca normal;

- Sem diarréia, rinorréia ou tosse;

- Sem lesões dérmicas infecciosas em áreas cirúrgicas; 
- Temperatura retal abaixo de $39,3^{\circ} \mathrm{C}$;

- Hematócrito acima de 28\%;

- Bioquímica do fígado e função renal normais.

\subsection{Tamanho da Amostra e Periodicidade dos Testes:}

Número de animais a serem utilizados: 5 animais

Justificativas e descrição da análise estatística dos dados:

Consideramos que um grupo de cinco animais é suficiente para uma comparação

estatisticamente significativa das variáveis e dados obtidos nos experimentos com os dispositivos.

Dias da semana e horário para realização dos experimentos: segunda ou quarta- feira das 8 às $16 \mathrm{hs}$

4.6 Descrição dos Procedimentos Cirúrgicos (incluir: Técnicas, períodos, equipamentos, instrumentos, administração de drogas, descartáveis, alimentação e cuidados especiais):

\subsubsection{Preparação do Animal:}

Punção de Veia Jugular Externa com intracath para medida de Pressão Venosa Central (PVC) e infusão de líquidos

Punção de Artéria Femural Direita para monitoração de Pressão Arterial (PA) com gelco n- 18

Punção de bexiga urinária com colocação de sonda de Foley N- 14 para aferição da diurese e coleta de urina para exames

Monitoração com eletrocardiograma Hellige SMU-612

\subsubsection{Anestesia:}

-MPA: Acepromazina $(0,5 \mathrm{mg} / \mathrm{Kg})+$ Midazolan $(0,5 \mathrm{mg} / \mathrm{Kg})$

-Intubação orotraqueal e ventilação mecânica

-Manutenção: Halotano +/- 2\%

\subsubsection{Medicamentos:}

- Acepromazina (0,2mg / kg) - (Pré Operatório)

- Enrofloxacina (Flotril 10\%) (5mg / kg - cada 24h) - (Pré e Pós Operatório)

- Selênio e Vitamina E (MU-SE - 1ml / 100 kg) - (Pré Operatório) 


\subsubsection{Anticoagulante:}

- Heparina (3 a 5mg / kg) mantendo TCA (500 a 600 s) - (Pré Operatório)

- Heparina (3 a 5mg / kg) mantendo TCA (500 a 600 s) - (Intra Operatório)

- Nas primeiras 8 horas do Pós Operatório não infundir heparina (realizar controle da drenagem torácica)

- No Pós Perfusão administrar Protamina (proporção 0,8 de Protamina para cada 1 de Heparina usada na Perfusão)

- Após as Primeiras 8h e até Completar 24h de Pós Operatório - Infusão Contínua de Heparina mantendo TCA (200 a 250 s) (dependendo da evolução hemostática e do laboratório de hemostasia - Após 24h de Pós Operatório - Infusão Contínua de Heparina na proporção de $4 \mathrm{ml}$ para $250 \mathrm{ml}$ de soro fisiológico com vazão de 3 a $10 \mathrm{ml} / \mathrm{h}$ mantendo TCA (250 a $300 \mathrm{~s}$ )

\subsubsection{Ato Cirúrgico:}

- Toracotomia Lateral direita;

- Ligadura de Artéria Descendente Anterior;

- Drenagem de veia pulmonar direita com cânula 22F diretamente para bomba em uso e retorno do sangue para o animal através da aorta ascendente com cânula do mesmo número;

- Implante do dispositivo drenando o ventrículo esquerdo e bombeando para a aorta descendente;

- Saída de circulação extracorpórea e fechamento das incisões;

- Colocação de drenos;

- Acompanhamento para o pós operatório.

\subsubsection{Dados Monitorados:}

Pressão Arterial

Eletrocardiograma

Diurese

Pressão Venosa Central

Freqüência de batimento e posicionamento do diafragma do dispositivo

Em adição serão monitorados:

- Freqüência respiratória;

- Temperatura corpórea (retal); 
- Volume de líquido ingerido e de urina;

- Volume de sangue drenado do tórax (primeiros dias pós-operatório);

- Posição do animal (em pé ou deitado).

\subsection{Dados Laboratoriais (tipos, frequência e horário dos exames):}

Hemoglobina livre no sangue: no pré operatório, de uma em uma hora no intra operatório, de 12 em 12 horas no $1^{\circ}$ dia do pós operatório e a cada $24 \mathrm{~h}$ nos demais dias.

Sangue oculto na urina: no pré operatório, de uma em uma hora no intra operatório, de 12 em 12 horas no $1^{\circ}$ dia do pós operatório e a cada $24 \mathrm{~h}$ nos demais dias.

Fibrinogênio, número de plaquetas e leucócitos: no pré operatório, na terceira hora após o início do procedimento, de $12 \mathrm{em} 12$ horas no pós operatório e a cada $24 \mathrm{~h}$ nos demais dias.

Tempo de Coagulação Ativado (TCA) e TP: no pré operatório, de uma em uma hora no intra operatório, de 12 em 12 horas no $1^{\text {o }}$ dia do pós operatório e a cada $24 \mathrm{~h}$ nos demais dias.

Desidrogenase Lática (DHL): no pré operatório, na terceira hora após o início do procedimento, de 12 em 12 horas no pós cirúrgico e a cada 24h nos demais dias.

Gasometria e Bioquímica: no pré operatório, de uma em uma hora no intra operatório, de 12 em 12 horas no $1^{\mathrm{o}}$ dia do pós operatório e a cada $24 \mathrm{~h}$ nos demais dias. (Na, K, Ca, glicemia, uréia, creatinina, TGA, TGP, bilirrubina, hemograma, e função plaquetária, urina tipo I e DHL.

De acordo com o responsável pelo setor :

Nome:

Data:

Assinatura: 


\subsection{Procedimentos no Pós operatório:}

Após o ato cirúrgico o animal é mantido na mesa de cirurgia por 24 horas, e depois é transferido para uma gaiola e colocado sob constante observação na UTI por uma equipe especializada.

Nas primeiras 48 horas o animal deverá receber de 4 a 8 bolsas de sangue, colhido de um animal com parentesco direto, conforme a necessidade

\subsection{Manutenção do animal:}

A pressão aórtica ou arterial é monitorada utilizando um cateter preenchido com soro fisiológico e heparina (na proporção de $2 \mathrm{ml}$ de heparina para $500 \mathrm{ml}$ de soro fisiológico) colocado na artéria femural direita, e a pressão venosa central utilizando um cateter colocado na veia cava. Esses cateteres são conectados aos transdutores de pressão. O eletrocardiograma (ECG) é monitorado com eletrodos colocados externamente ao tórax. A terapia antibiótica profilática é iniciada no préoperatório e continuada por seis dias. As drogas anti-coagulantes profiláticas são administradas durante a cirurgia, no pós operatório e ao término dos experimentos para prevenir coagulação de sangue pós morte. $\mathrm{O}$ animal é pesado. $\mathrm{O}$ balanço de volume de água é verificado todos os dias.

\subsection{Eutanásia:}

Será realizada ao final de seis dias de procedimento, com o animal anestesiado e com injeção de 10 $\mathrm{ml}$ de cloreto de potássio pela veia jugular externa, e interrupção do dispositivo de assistência ventricular (DAV).

\subsection{Estudos Patológicos (tipos e frequência dos exames)}

Serão realizados no final de cada experimento para verificação dos efeitos a seguir:

$\underline{O}$ efeito de vibração e dissipação de calor

As fontes de vibração incluem o acionador e a bomba de sangue. A vibração de um implante se reflete na espessura da cápsula de tecido e sua natureza histológica. A dissipação de calor do dispositivo nos tecidos adjacentes é refletida na cápsula de tecido, especialmente com relação à quantidade de formação capilar nesta cápsula. Na autópsia, a cápsula de tecido é aberta, e a natureza e quantidade de cada fluido na cápsula são documentados. A maturidade da cápsula, ou seja, o grau de colagenização, as reações inflamatórias e densidade dos vasos capilares são avaliados.

\section{Mecanismos Trombogênicos}

A detecção de êmbolos é um dos objetivos principais do estudo patológico. Os grandes vasos e suas principais ramificações são abertos e qualquer êmbolo macroscópico é procurado. Os principais 
órgãos são laminados a intervalos de $1 \mathrm{~cm}$ e as extremidades dos vasos são cuidadosamente examinadas. O tamanho e localização do êmbolo e o tamanho e extensão do infarto são registrados. O êmbolo é processado para histoquímica, para pesquisar a origem desse êmbolo. Estudos prévios sobre tromboembolismo em implantes de coração artificial em bezerros indicaram que o rim é o principal alvo para a embolia, a embolização na circulação do cérebro é extremamente rara. É prestada uma especial atenção à patologia dos rins. Em bezerros, é comum a nefrite intersticial crônica. Esta lesão causa descoloração esbranquiçada bem circunscrita que aparenta velhos infartos. O número, tamanho e natureza das descolorações são cuidadosamente documentados e fotografados. Avaliação do Coração do Animal e da Bomba de Sangue

Os objetivos das análises morfológicas do coração do animal e das superfícies da bomba são avaliar as interações entre o sangue e os biomateriais utilizados. É dada ênfase na qualificação e quantificação das cápsulas de tecido ou formação de membranas nas interfaces entre material e o tecido natural, calcificação das válvulas biológicas e do diafragma da bomba, pseudoneoíntima formada nos condutos e deposição de elementos na superfície lisa da gelatina que reveste a câmara da bomba de sangue.

De acordo com o responsável pelo setor:

Nome:

Data: Assinatura:

\section{Destino do Material e/ou Dados Coletados}

Este material servirá de subsídio para utilização do dispositivo de assistência ventrícular mecânica em pacientes com falência uni ou biventricular aguda pós-cardiotomia ou como ponte para transplante em pacientes com insuficiência cardíaca que apresentam descompensação clínica durante a espera de doação. 


\section{Setores de Apoio à Pesquisa}

\begin{tabular}{ccc}
\hline Nome do Setor & Nome do Responsável & Data \\
\hline Bioengenharia & Dr. Aron Andrade \\
\hline Transplantes & Dr. Jarbas J. Dinkhuysen \\
\hline Laboratório & Dr. Ricardo Manrique \\
\hline Cirurgia Experimental & Dr. Saul Goldenberg \\
\hline Patologia & Dra. Lilian Mary da Silva \\
\hline
\end{tabular}

\section{Certificação}

Certificamos que os dados e procedimentos relatados neste protocolo serão seguidos e as normas do Comitê de Ética em Pesquisa Experimental serão respeitadas :

Investigador Principal

Investigador Principal

De acordo :

Assinatura do Responsável pelo Setor de Cirurgia Experimental
Data

Data

Data

Após análise pelos membros do Comitê de Ética em Pesquisa Experimental do Instituto "Dante Pazzanese" de Cardiologia este protocolo foi considerado:

( ) Aprovado sem modificações

( ) Aprovado após pequenas alterações

( ) Efetuar grandes alterações e submetê-lo novamente 


\section{SECRETARIA DE ESTADO DA SAÚDE}

Coordenadoria de Saúde da Região Metropolitana da Grande São Paulo INSTITUTO “DANTE PAZZANESE” DE CARDIOLOGIA

\section{Comitê de Ética em Pesquisa Experimental CEPE/IDPC}

\section{Protocolo de Pesquisa Experimental}

Número do Protocolo:

Título do Projeto:

ANÁLISE QUALITATIVA E QUANTITATIVA DAS

INTERAÇÕES NA INTERFACE SANGUE - BIOMATERIAL

\section{Dados do Investigador Principal}

Nome: $\quad$ Daniel F. Legendre / Aron J. P. Andrade

Formação: Engenharia

Instituição: $\quad \underline{\mathrm{USP} / \mathrm{IDPC}}$

Setor: $\quad$ Centro Técnico de Experimentos

Cargo: $\quad$ Pesquisador / Eng. IV

Tel: $\quad \underline{50854010}$

Endereço: $\quad$ Av. Dante Pazzanese, $\mathrm{n}^{\circ}$ 500, Ibirapuera, cep 04012-180, SP-SP

2. Equipe de Apoio (Co-investigador, Cirurgiões, Anestesistas, Técnicos, etc)

\begin{tabular}{ccc}
\hline Nome & Função na Pesquisa & Telefone \\
\hline Dr. Paulo Valente & Médico Veterinário & 50854037 \\
\hline Dra. Elizabete Catarina Leone & Médica Veterinária & 50854037 \\
\hline Dr. Ricardo Manrinque & Hematologista & 50854095 \\
\hline Dra. Lilian Mary da Silva & Médica Patologista & 50854030 \\
\hline- & Residentes & - \\
\hline
\end{tabular}




\section{Dados do Patrocinador do Projeto}

Nome:

Fundação Adib Jatene

Endereço:

Av. Dante Pazzanese, 500, Ibirapuera - SP/SP

Tipo de Patrocínio: $\quad \underline{\text { Próprio }}$

\section{Descrição da Pesquisa}

\subsection{Introdução com Embasamento Teórico:}

O Brasil é considerado um país que acompanha o estado da ate da cardiologia mundial, em particular da cirurgia cardíaca. No Brasil, foram desenvolvidos nas últimas décadas, diversos equipamentos e dispositivos necessários a uma cirurgia cardíaca, fazendo com que hoje seja possível a realização de uma cirurgia cardíaca com tecnologia 100\% nacional e até mesmo exportar esta tecnologia. Consta na literatura mundial que várias técnicas cirúrgicas desenvolvidas no Brasil são hoje aplicadas em todo o mundo, comprovando a importância da contribuição brasileira na área. Com o avanço das técnicas cirúrgicas é possível a realização, também no Brasil, de transplantes cardíacos com grande sucesso. Porém o número de doadores é insuficiente e muitos receptores morrem nas filas de espera para estes transplantes em todo o mundo. Desta forma, os centros de pesquisas mais importantes do mundo têm se empenhado no desenvolvimento de equipamentos para suporte à vida destes pacientes, enquanto aguardam o transplante. Existem alguns dispositivos de assistência ventricular sendo comercializados nos EUA e em alguns países da Europa, porém em nosso meio não estão disponíveis e nem seriam acessíveis à grande maioria dos pacientes brasileiros. Atualmente, são realizadas 42.000 cirurgias cardíacas com circulação extracorpórea por ano no Brasil, colocando-o em terceiro lugar no mundo em número de cirurgias. Estima-se que aproximadamente 2000 pacientes poderiam ser candidatos à utilização de dispositivos de assistência ventricular. Desta forma, torna-se importante a evolução de linhas de pesquisa na área de assistência ventricular e coração artificial para geração de tecnologia nacional e com custo acessível à gestão da saúde pública brasileira. Este Protocolo tem como objetivo estudar o crescimento de uma pseudoneoíntima (PNI) sobre a camada biológica que é utilizada como cobertura das superfícies internas de um Dispositivo de Assistência Ventricular Esquerda (DAV) em desenvolvimento no IDPC/FAJ. Será realizado estudo "In Vivo" em porco, onde serão implantados "patches" com cobertura protéica, e sem cobertura protéica com superfície lisa e texturizada e avaliados quantitativamente e qualitativamente. 


\subsection{Objetivos da Pesquisa:}

Análise qualitativa e quantitativa das interações na interface sangue - biomaterial.

\subsection{Descrição dos Animais a Serem Utilizados:}

Espécie: $\quad \underline{\text { Suínos }} \quad$ Raça: $\underline{\text { Mestiça }}$ Sexo: $\underline{\text { Macho e }}$

Fêmea

Idade: $\quad$ até 03 meses $\quad$ Peso: $25(\mathrm{~kg})$

\subsection{Justificativas:}

O animal candidato para a realização do implante deve ser selecionado uma semana antes da cirurgia após consulta com o veterinário responsável. Esta seleção preliminar é baseada no histórico de doenças infecciosas, resultados de exames físicos e peso corporal. Uma seleção final é feita baseando-se em dados hematológicos adicionais, pela análise de amostras de sangue retiradas pela manhã, antes de alimentar os animais.

Os critérios de seleção do animal incluem as seguintes características e necessidades:

? Ausculta respiratória e cardíaca normal;

? Sem diarréia, rinorréia ou tosse;

? Sem lesões de pele infectadas em áreas cirúrgicas;

? Temperatura retal abaixo de $39,3^{\circ} \mathrm{C}$;

? Hematócrito acima de $28 \%$.

? Bioquímica do fígado e função renal normais.

\subsection{Tamanho da Amostra e Periodicidade dos Testes:}

Número de animais a serem utilizados: 07 animais (dependendo dos resultados obtidos)

Número de "patches" a serem implantados em cada animal: $\underline{02}$

Justificativas e descrição da análise estatística dos dados: Consideramos que um grupo de

$\underline{\text { sete animais é suficiente para uma comparação estatisticamente significativa das variáveis e }}$

dados obtidos nos implantes.

Dias da semana e horário para realização dos experimentos: $\underline{\text { Segunda. a sexta. feira das } 8 \text { às }}$ $\underline{16 h s}$

\subsection{Descrição dos Procedimentos Cirúrgicos:}

\subsubsection{Preparação do Animal:}


Punção de artéria femoral direita para aferição de pressão arterial média (PAM) com gelco n 18; Posicionamento dos eletrodos do eletrocardiograma.

\subsubsection{Anestesia:}

Acepromazina $(0,2 \mathrm{mg} / \mathrm{kg})$ e Midazolan $(0,3 \mathrm{mg} / \mathrm{kg})$;

Intubação orotraqueal e ventilação mecânica;

Manutenção: Halotano (2\%).

\subsubsection{Medicamentos:}

Enrofloxacina (Flotril 10\%) (5mg / kg - cada 24h) - (Pré e Pós Operatório).

\subsubsection{Ato Cirúrgico:}

Laparotomia mediana;

Clampear parcialmente a aorta abdominal;

Suturar os "patches" na aorta abdominal;

Fechar as incisões;

Acompanhamento para o pós-operatório.

\subsubsection{Dados Monitorados:}

Pressão arterial média;

Eletrocardiograma.

\subsection{Avaliação do Implante:}

Fotografar o "patch" imediatamente após a sua retirada;

Superfície livre de trombo (TFS);

Microscopia eletrônica de varredura (SEM);

Microscopia Óptica.

De acordo com o responsável pelo setor:

Nome:

Data:

Assinatura:

\subsection{Procedimentos no Pós-operatório (quando houver):}


Após a cirurgia, o animal é transferido para o biotério e mantido sob observação na UTI.

\subsection{Eutanásia:}

Será realizada ao final de quinze dias de procedimento, com a anestesia do animal e posteriormente injetando $10 \mathrm{ml}$ de cloreto de potássio na veia jugular externa.

\subsection{Estudo Morfológico}

Será realizado no final de cada experimento para verificação dos efeitos a seguir:

Avaliação da Superfície do Implante

O objetivo da análise morfológica da superfície dos "patches" é avaliar as interações entre sangue e biomaterial. Será dada ênfase na qualificação e quantificação da formação de pseudoneoíntima formada na superfície de contato com o sangue, calcificação, e deposição de elementos de sangue na superfície lisa da gelatina que reveste o implante.

De acordo com o responsável pelo setor:

Nome:

Data: Assinatura:

\section{Destino do Material e/ou Dados Coletados}

Este material servirá de subsídio para utilização desta técnica em dispositivos de assistência ventrícular mecânica em pacientes com falência uni ou biventricular aguda pós-cardiotomia ou como ponte para transplante em pacientes com insuficiência cardíaca que apresentam descompensação clínica durante a espera de doação.

\section{Setores de Apoio à Pesquisa}

\begin{tabular}{ccc}
\hline Nome do Setor & Nome do Responsável & Data \\
\hline Bioengenharia & Dr. Aron Andrade & \\
\hline Laboratório & Dr. Ricardo Manrique & \\
\hline Cirurgia Experimental & Dr. Saul Goldenberg & \\
\hline Patologia & Dra. Lilian Mary da Silva \\
\hline
\end{tabular}




\section{Certificação}

Certificamos que os dados e procedimentos relatados neste protocolo serão seguidos e as normas do Comitê de Ética em Pesquisa Experimental serão respeitadas:

Investigador Principal

Investigador Principal

De acordo:

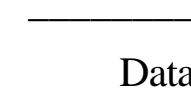

Data

Data

Assinatura do Responsável pelo Setor de

Data

Após análise pelos membros do Comitê de Ética em Pesquisa Experimental do Instituto "Dante Pazzanese" de Cardiologia este protocolo foi considerado:

( ) Aprovado sem modificações

( ) Aprovado após pequenas alterações

( ) Efetuar grandes alterações e submetê-lo novamente 


\section{APÊNDICE B - Desenhos Técnicos}




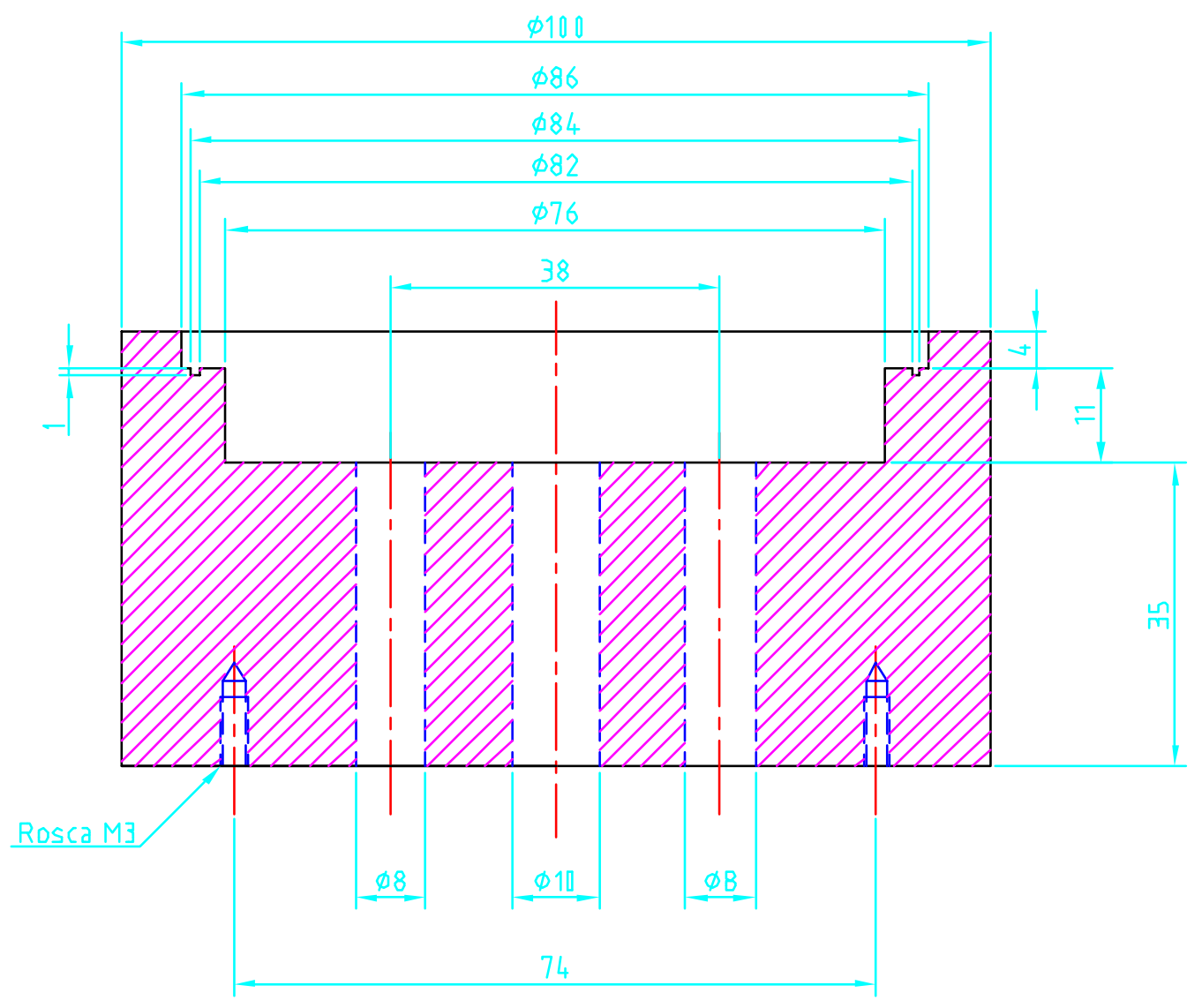

\begin{tabular}{|c|c|c|c|c|}
\hline MATERIAL & PESO B. & PESOL. & QUANT. & ESCALA \\
\hline$P \vee[$ & & & & 1:1 \\
\hline \multirow{2}{*}{\multicolumn{2}{|c|}{ DISCRIMINA[C̃̃O: Suporte }} & \multirow{2}{*}{\multicolumn{2}{|c|}{$\begin{array}{l}\text { TOL. NÃO ESP. } \\
\pm 1,2 \text { ÂNG. } 30^{\prime}\end{array}$}} & \\
\hline & & & & \\
\hline \multirow[t]{3}{*}{ OBSERVAÇÃ: Furação conforme anel de fixação da câmara } & DESENHADO & \multicolumn{2}{|l|}{ DATA } & \\
\hline & Eng. Legendre & \multicolumn{2}{|l|}{$14 / 03 / 2002$} & \\
\hline & APRUVAUU & \multicolumn{2}{|l|}{ DATA } & \\
\hline & Eng. Агоп & $14 / 03 / 2002$ & & \\
\hline MUUUIFILACAU: & \multicolumn{3}{|c|}{ ACABAMENTO ESPECIAL } & ${ }^{\circ}$ DESENHO \\
\hline & & & & 01 \\
\hline
\end{tabular}




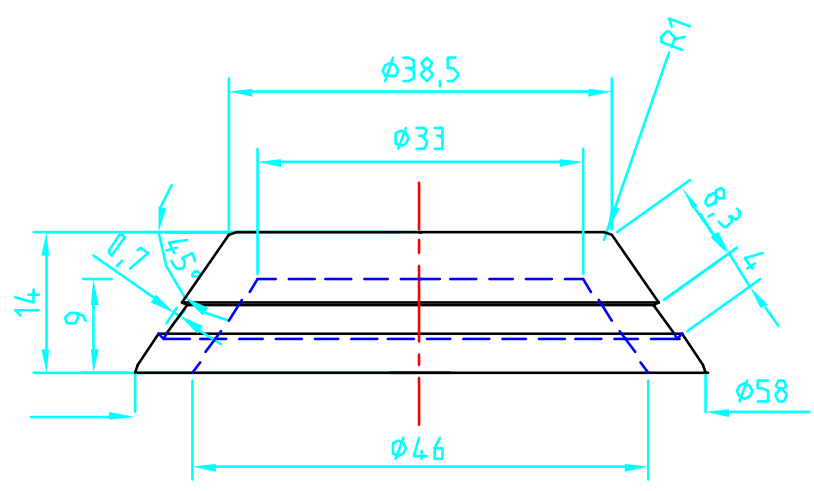

\begin{tabular}{|c|c|c|c|c|c|}
\hline MATERIAL & BITOLA & PESO B. & PESO L. & QUANT & ESCALA \\
\hline Alumínio & & & & & 1:1 \\
\hline \multirow{2}{*}{\multicolumn{3}{|c|}{ DISCRIMINAC̄ÃO: Pusher Plate }} & \multirow{2}{*}{\multicolumn{2}{|c|}{$\begin{array}{l}\text { TOL. NÃO ESP. } \\
\pm 1,2 \text { ÂNG. } 30^{\prime}\end{array}$}} & \\
\hline & & & & & \\
\hline \multirow[t]{3}{*}{ OBSERVAÇÃO: } & & DESENHADO & \multicolumn{2}{|l|}{ DATA } & \\
\hline & & Eng. Legendre & \multicolumn{2}{|l|}{$14 / 03 / 2002$} & \\
\hline & & APROVADO & \multicolumn{2}{|l|}{ DATA } & \\
\hline \multirow{2}{*}{\multicolumn{2}{|c|}{ MODIFICAC̄ĀO: }} & Eng. Агоп & \multicolumn{2}{|l|}{$14 / 03 / 2002$} & \\
\hline & & \multicolumn{3}{|c|}{ ACABAMENTO ESPECIAL } & $N^{\circ}$ DESENHO \\
\hline & & & & 02 \\
\hline
\end{tabular}




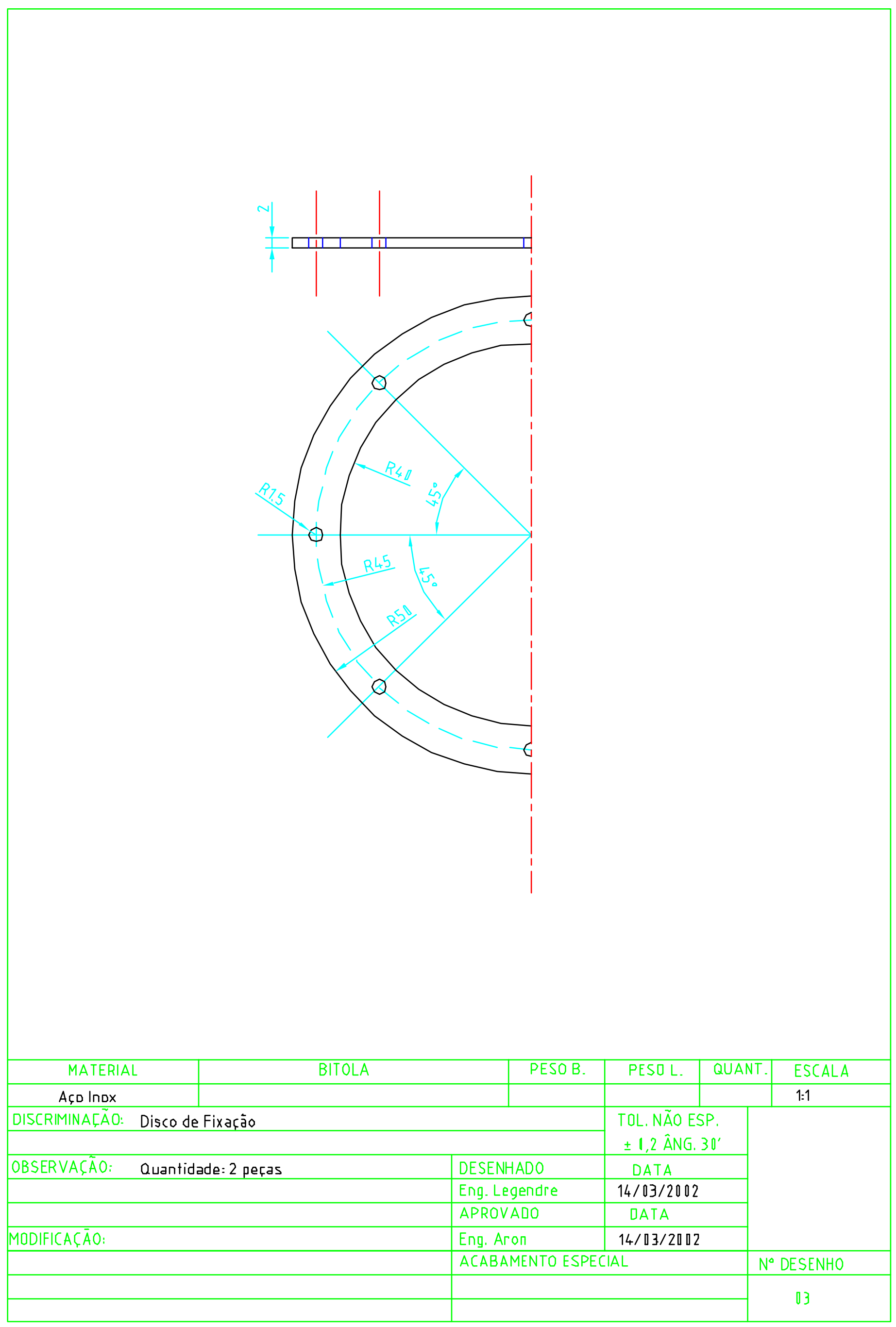




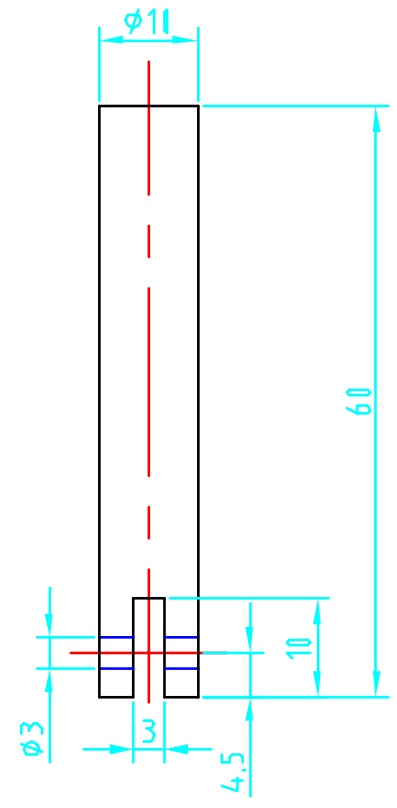

\begin{tabular}{|c|c|c|c|c|c|}
\hline MATERIAL & BITOLA & PESO B. & PESO L. & QUANT & ESCALA \\
\hline$A c ̧ D \ln D x$ & & & & & $1: 1$ \\
\hline DISCRIMINAČ̃̃O: & & & \multirow{2}{*}{\multicolumn{2}{|c|}{$\begin{array}{l}\text { TOL. NÃO ESP. } \\
\pm 1,2 \text { ÂNG. } 30^{\prime}\end{array}$}} & \\
\hline & & & & & \\
\hline \multirow[t]{3}{*}{ OBSERVAÇÃO: } & & DESENHADO & \multicolumn{2}{|l|}{ DATA } & \\
\hline & & Eng. Legendre & \multicolumn{2}{|l|}{$14 / 03 / 2002$} & \\
\hline & & APROVADO & \multicolumn{2}{|l|}{ DATA } & \\
\hline & Eng. Агоп & $14 / 03 / 2002$ & & \\
\hline \multicolumn{2}{|l|}{ MODIFICAÇAO: } & \multicolumn{3}{|c|}{ ACABAMENTO ESPECIAL } & $N^{\circ}$ DESENHO \\
\hline & & & & 04 \\
\hline
\end{tabular}




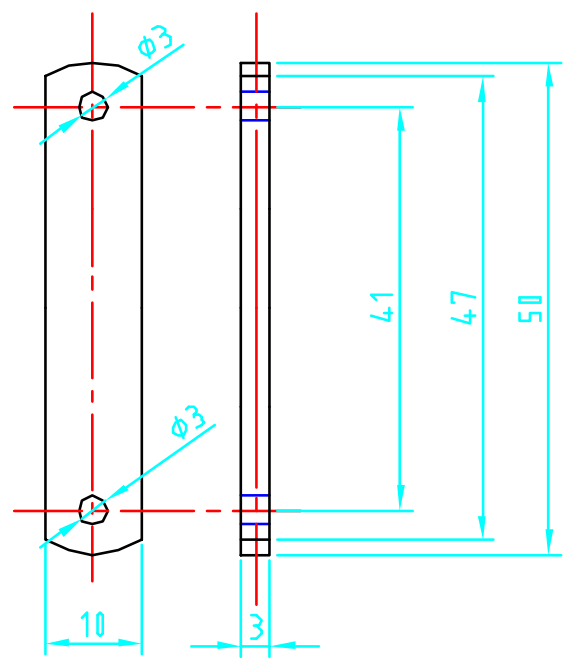

\begin{tabular}{|c|c|c|c|c|c|}
\hline MATERIAL & BITOLA & PESO B. & PESO L. & QUANT & ESCALA \\
\hline$A c ̧ D \ln D x$ & & & & & 1:1 \\
\hline \multirow{2}{*}{\multicolumn{3}{|c|}{ DISCRIMINAČ̃̃O: Braço Articulado }} & \multirow{2}{*}{\multicolumn{2}{|c|}{$\begin{array}{l}\text { TOL. NÃO ESP. } \\
\pm 1,2 \text { ÂNG. } 30^{\prime}\end{array}$}} & \\
\hline & & & & & \\
\hline \multirow{3}{*}{\multicolumn{2}{|c|}{ OBSERVAČ̃O: }} & DESENHADO & \multicolumn{2}{|l|}{ DATA } & \\
\hline & & Eng. Legendre & \multicolumn{2}{|l|}{$14 / 03 / 2002$} & \\
\hline & & APROVADO & \multicolumn{2}{|l|}{ DATA } & \\
\hline \multicolumn{2}{|l|}{ MODIFICAÇĀO: } & Eng. Агоп & \multicolumn{2}{|l|}{$14 / 03 / 2002$} & \multirow[b]{2}{*}{$\mathrm{N}^{\circ}$ DESENHO } \\
\hline & & \multicolumn{3}{|c|}{ ACABAMENTO ESPECIAL } & \\
\hline & & & & 05 \\
\hline
\end{tabular}




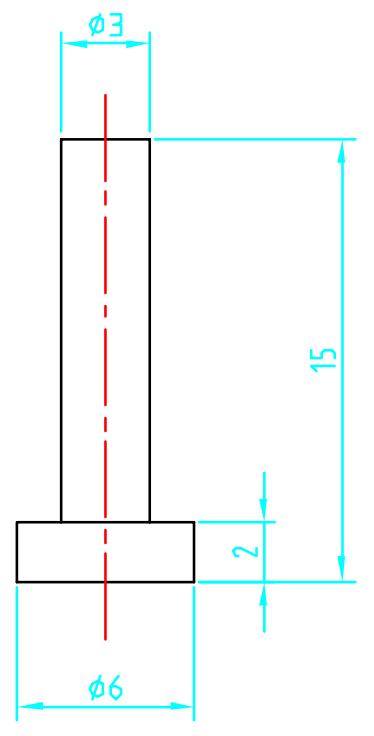

\begin{tabular}{|c|c|c|c|c|c|}
\hline MATERIAL & BITOLA & PESO B. & PESO L. & QUANT & ESCALA \\
\hline$A c ̧ D \ln D x$ & & & & & $3: 1$ \\
\hline \multirow{2}{*}{\multicolumn{3}{|c|}{ DISCRIMINAČ̃̃O: Pino 1}} & \multirow{2}{*}{\multicolumn{2}{|c|}{$\begin{array}{l}\text { TOL. NÃO ESP. } \\
\pm 1,2 \text { ÂNG. } 30^{\prime}\end{array}$}} & \\
\hline & & & & & \\
\hline \multirow[t]{3}{*}{ OBSERVACÃO: } & & DESENHADO & \multicolumn{2}{|l|}{ DATA } & \\
\hline & & Eng. Legendre & \multicolumn{2}{|l|}{$14 / 03 / 2002$} & \\
\hline & & APROVADO & \multicolumn{2}{|l|}{ DATA } & \\
\hline \multicolumn{2}{|l|}{ MODIFICAÇĀO: } & Eng. Агоп & \multicolumn{2}{|l|}{$14 / 03 / 2002$} & \multirow[b]{2}{*}{$\mathrm{N}^{\circ}$ DESENHO } \\
\hline & & \multicolumn{3}{|c|}{ ACABAMENTO ESPECIAL } & \\
\hline & & & & 06 \\
\hline
\end{tabular}




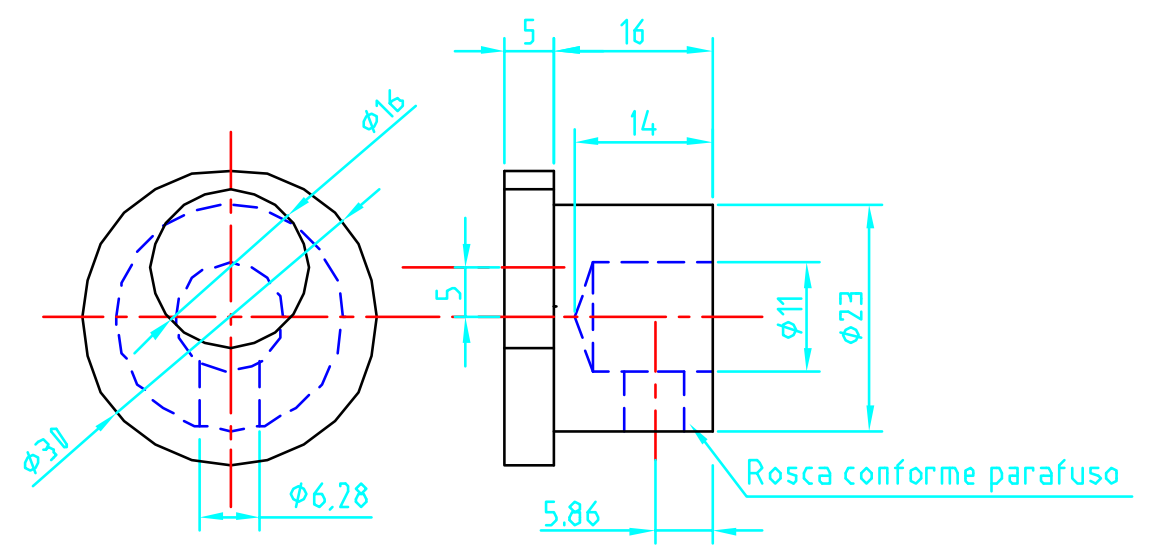

\begin{tabular}{|c|c|c|c|c|c|}
\hline MATERIAL & BITOLA & PESO B. & PESO L. & QUAN & ESCALA \\
\hline Latão & & & & & 1:1 \\
\hline \multirow{2}{*}{\multicolumn{3}{|c|}{ DISCRIMINAČ̃̃O: Disco Excêntrico }} & \multirow{2}{*}{\multicolumn{2}{|c|}{$\begin{array}{l}\text { TOL. NÃO ESP. } \\
\pm 1,2 \text { ÂNG. } 30^{\prime}\end{array}$}} & \\
\hline & & & & & \\
\hline \multirow[t]{3}{*}{ OBSERVAÇÃO: } & & DESENHADO & \multicolumn{2}{|l|}{ DATA } & \\
\hline & & Eng. Legendre & \multicolumn{2}{|l|}{$14 / 03 / 2002$} & \\
\hline & & APROVADO & \multicolumn{2}{|l|}{ DATA } & \\
\hline \multicolumn{2}{|l|}{ MODIFICAÇĀO: } & Eng. Агоп & $14 / 03 / 2002$ & & \\
\hline & & \multicolumn{3}{|c|}{ ACABAMENTO ESPECIAL } & $V^{\circ}$ DESENHO \\
\hline & & & & & 07 \\
\hline
\end{tabular}




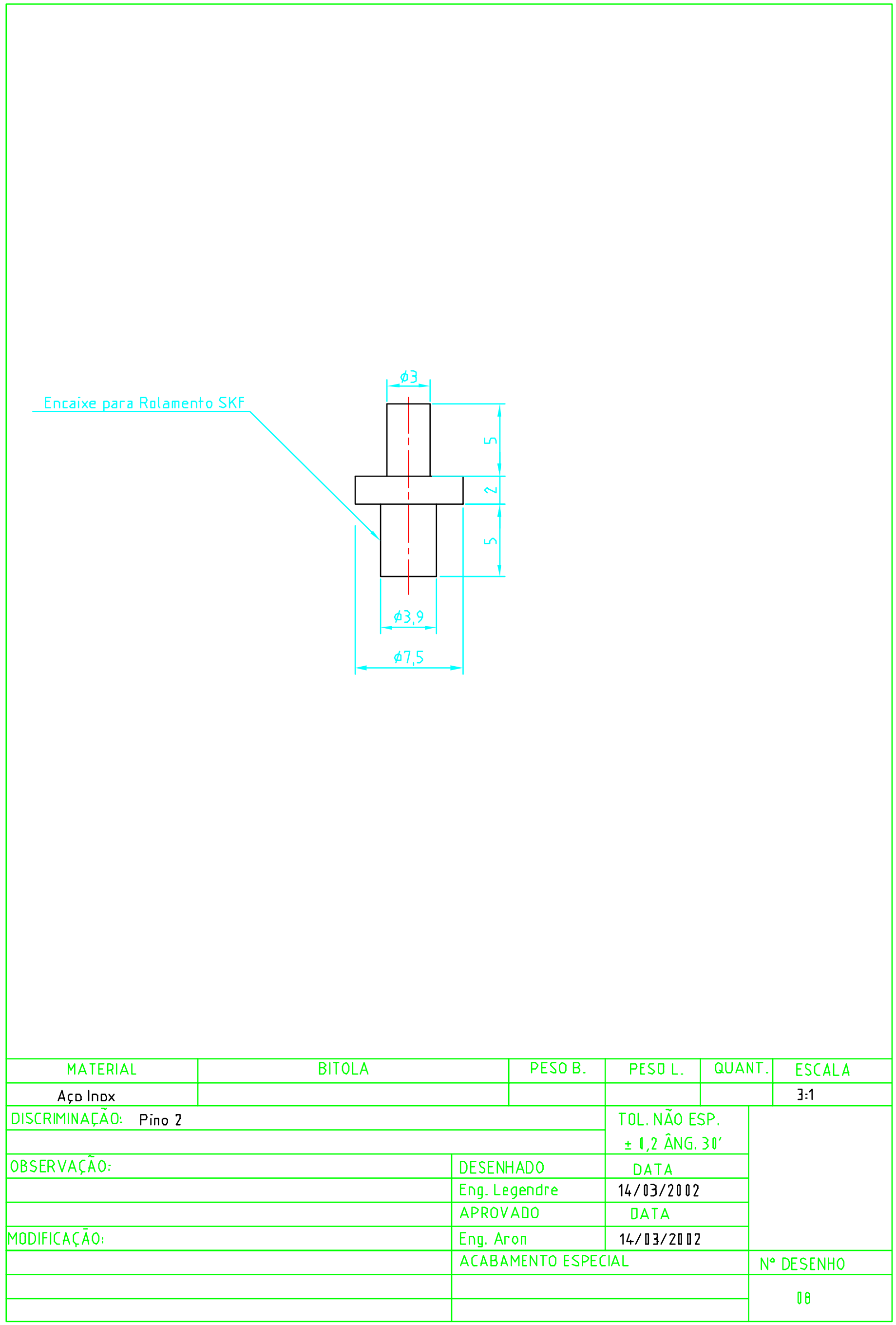




\section{Molde para Diafragma Esquerdo}

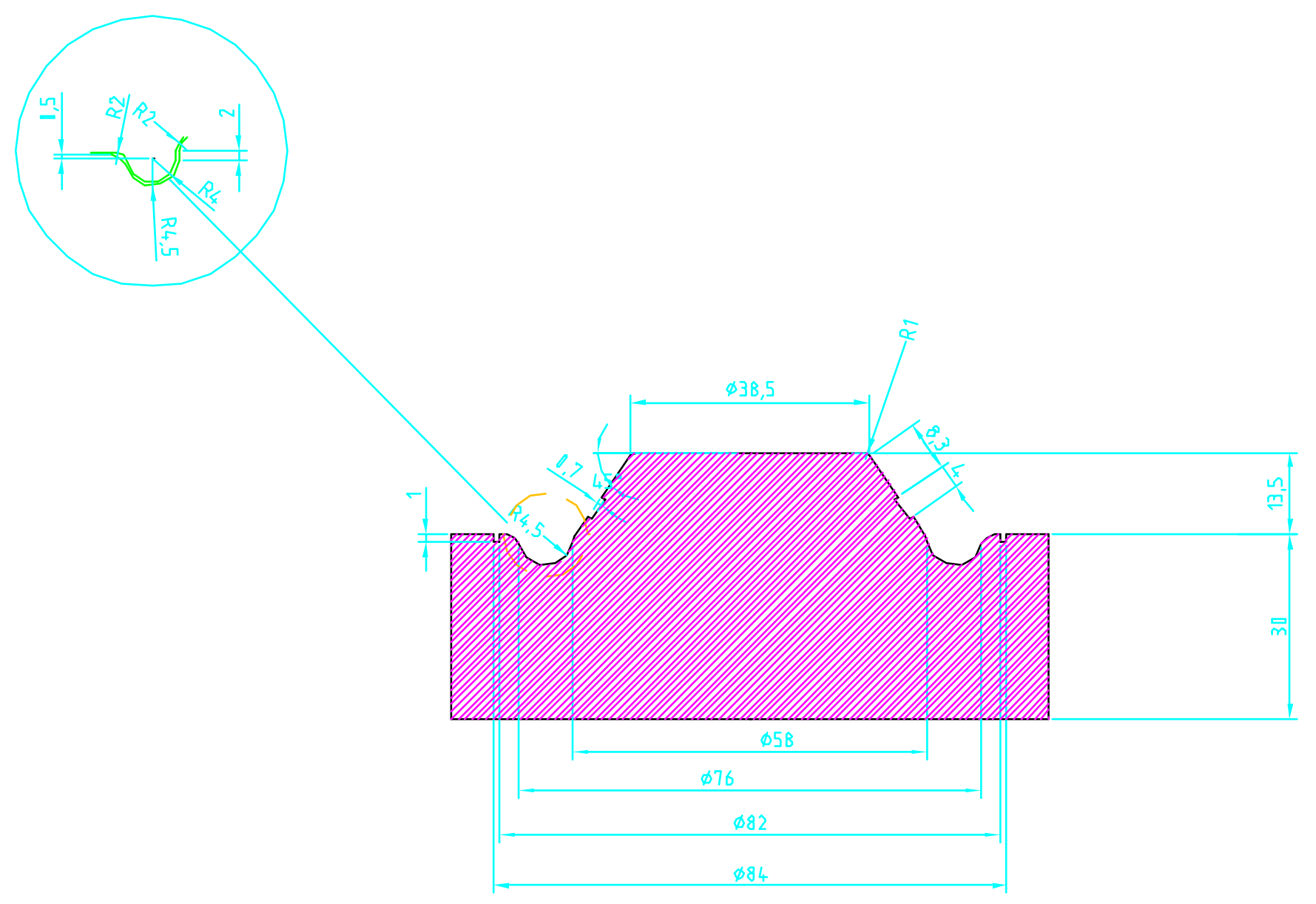




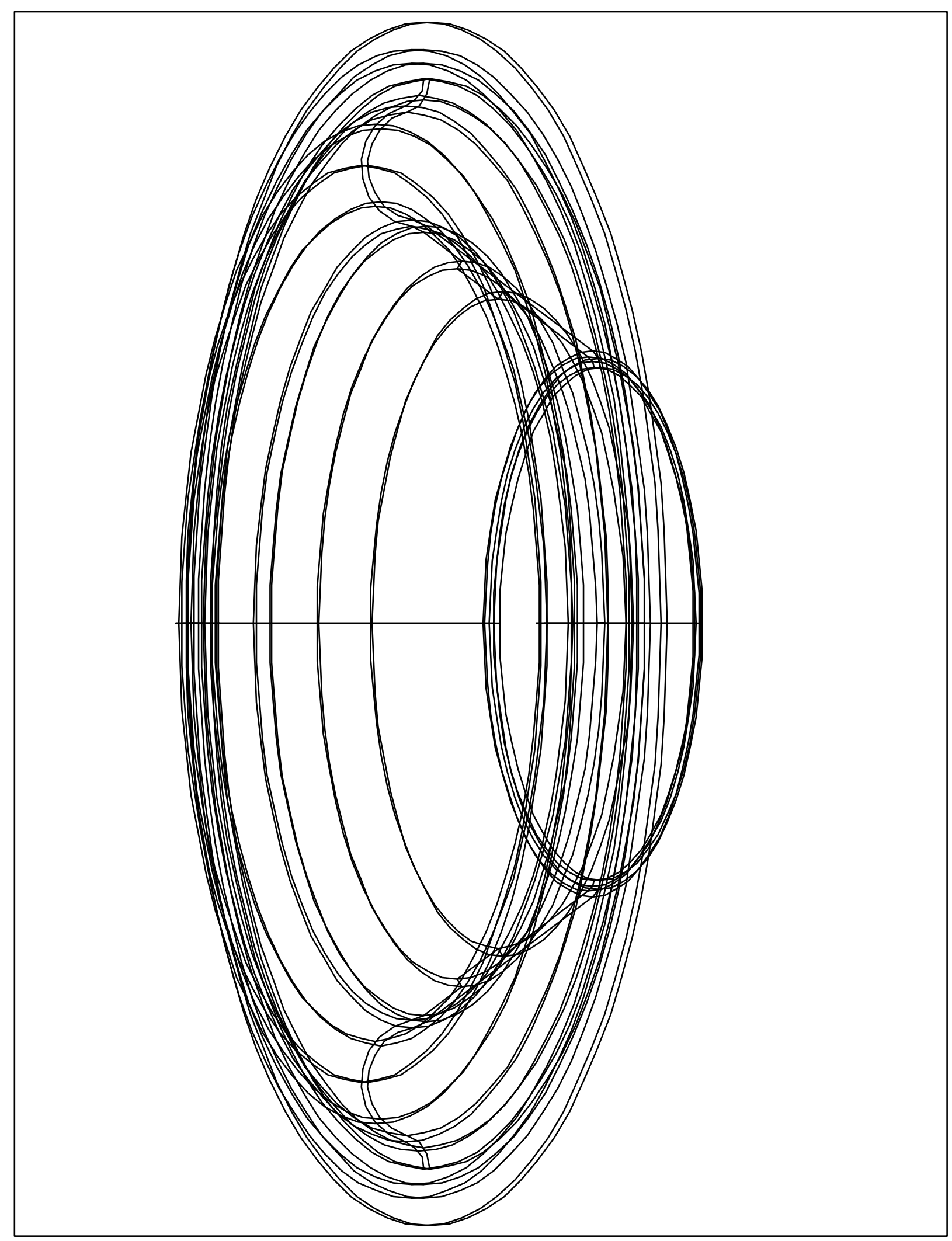


APÊNDICE C - Artigo 


\title{
Endurance Test on a Textured Diaphragm for the Auxiliary Total Artificial Heart (ATAH)
}

\author{
$* \dagger$ Daniel Legendre, †Orivaldo Lopes da Silva, *Aron Andrade, *Jeison Fonseca, \\ *Denys Nicolosi, and *Jose Biscegli \\ *Institute “Dante Pazzanese” of Cardiology, Department of Bioengineering, Sao Paulo, SP, and †University of Sao Paulo, \\ Department of Bioengineering, Sao Carlos, SP_Brazil
}

\begin{abstract}
We performed an endurance test on a textured diaphragm made of polyurethane $\left(\right.$ BioSpan $^{\circledR}$, The Polymer Technology Group, San Francisco, U.S.A.) to be used in the Auxiliary Total Artificial Heart (ATAH), an electromechanical device that can be totally implantable without removing the natural heart due to the device's reduced dimension. The objective of this endurance test was to predict whether this diaphragm would be capable of resisting in vivo tests with the ATAH implanted for fifteen days in calves. In this study, a mock loop system simulating the
\end{abstract}

human circulatory system was used. The test protocol was elaborated to reproduce extreme physiological conditions. The technique to produce the textured diaphragms made of polyurethane is shown. The textured surface is used as basis to fix a layer of calf-skin gelatin. The technique used to make the diaphragm guaranteed a totally textured surface without cracking. The diaphragm demonstrated enough resistance to be used at the 15 day in vivo experiments. Key Words: Artificial heart-BiomaterialPolyurethane-Durability-Endurance test.
Heart transplantation is considered appropriate for many patients in the end stage of cardiac disease. However, a heart donor must be a patient who developed encephalic death because of intracerebral hemorrhage or an accident. In developed countries, it is possible to obtain from 20 to 40 donors per million inhabitants per year. However, in developing countries, the rate is 3 to 4 donors per million inhabitants per year. Several factors and difficulties lead to a small utilization of potential donors, and consequently there are a huge number of registered deaths of patients waiting for a transplant due to an insufficient quantity of available organs (1).

A new auxiliary total artificial heart (ATAH) has been developed and tested. The ATAH is a reduced dimension, totally implantable electromechanical device that can be implanted without the removal of the patient's natural heart (2).

Received December 2002.

Presented in part at the $2^{\text {nd }}$ Latin American Congress for Artificial Organs and Biomaterials, held December 2001, in Brazil.

Address correspondence and reprint requests to Daniel Legendre, Department of Bioengineering, Institute "Dante Pazzanese" of Cardiology, Av. Dr. Dante Pazzanese, 500 Sao Paulo, Brazil-04012-180. Phone: +55 115085 4010. E-mail: legendre@cte.dante.br
According to previous studies, to avoid blood coagulation inside cardiac devices, such factors as geometry, appropriate flow, surface finishing, appropriate cleanliness of the blood contact surface, and junction between different materials must be considered $(3,4,5)$.

Blood pumps with different surfaces have been studied, showing relevant improvement in devices' biocompatibility with textured surface and with protein outer layer. Polymers with biological coating elements such as calf-skin gelatin were proved to be hemocompatible $(6,7)$. This thin layer of glutaraldehyde-treated calf-skin gelatin is applied over a textured diaphragm surface to improve longterm blood compatibility, creating a neo interface between the material and blood $(8,9,10)$.

The design of a pulsatile electromechanical blood pump such as the ATAH requires the utilization of a high lifetime and biocompatible diaphragm.

\section{MATERIALS AND METHODS}

\section{Diaphragm}

Some special conditions are required to make a polyurethane diaphragm (BioSpan ${ }^{\circledR}$, The Polymer Technology Group, San Francisco, U.S.A.). The use 
of high efficiency particulate air (HEPA)-filtered air and adequate ventilation avoid particle contamination, and the immediate work area temperature must be from 30 to $35^{\circ} \mathrm{C}$ because N,N dimethylacetamide (DMAc) is a hygroscopic solvent and will pick up moisture at room temperature.

The diaphragm mold is made of Delrin in order to achieve a small friction coefficient as well as temperature resistance. The diaphragm has $0.5 \mathrm{~mm}$ of thickness and the outer layer has a special treatment to become textured. The textured surface is produced to guarantee an efficient fixation of the calf-skin gelatin over the diaphragm.

The procedure to make the diaphragm starts by diluting the polyurethane in DMAc solvent to a concentration of $18.75 \%$. After dipping, the diaphragm is kept in a controlled temperature from 30 to $35^{\circ} \mathrm{C}$ for 20 to 60 minutes. Then, the diaphragm is dried in an oven at $60^{\circ} \mathrm{C}$ for 60 to 120 minutes. This first step is repeated until the diaphragm obtains $0.5 \mathrm{~mm}$ of thickness. The diaphragm quality is verified with $\mathrm{x}$-ray, which can detect small particles, contaminants, bubbles, and cracks in the material. After the last dipping, the diaphragm is completely coated with polysaccharide to get a textured surface. A final water extraction may remove trace DMAc by keeping the diaphragm in an oven at $60^{\circ} \mathrm{C}$ for 24 hours. In the last step, the diaphragm must be boiled in water for 60 minutes, dried, and checked.

All ATAH inner surfaces including the textured diaphragm will receive a cross-linked calf-skin gelatin coating. This creates a neo-interface between the polymeric surface and the blood. The coat is fixed over the textured surface by vacuum impregnation, filling up every porous surface. The glutaraldehyde treatment stabilizes the gelatin by cross-linking its proteins (11).

\section{In vitro test}

Performing an in vitro test allows verifying some variables without the device implantation (12). According to Graham and collaborators (13), to be an elective biomaterial for a long-term assistance device flexible part, it must resist at least 40 million cycles per year.

A mock system circuit (Fig. 1) to evaluate the diaphragm was built. This system reproduces some extreme human physiological characteristics.

The mechanical device has the same functional characteristics of the ATAH, and it is used exclusively to perform this in vitro test. The system evaluates the diaphragm mechanical characteristics and its

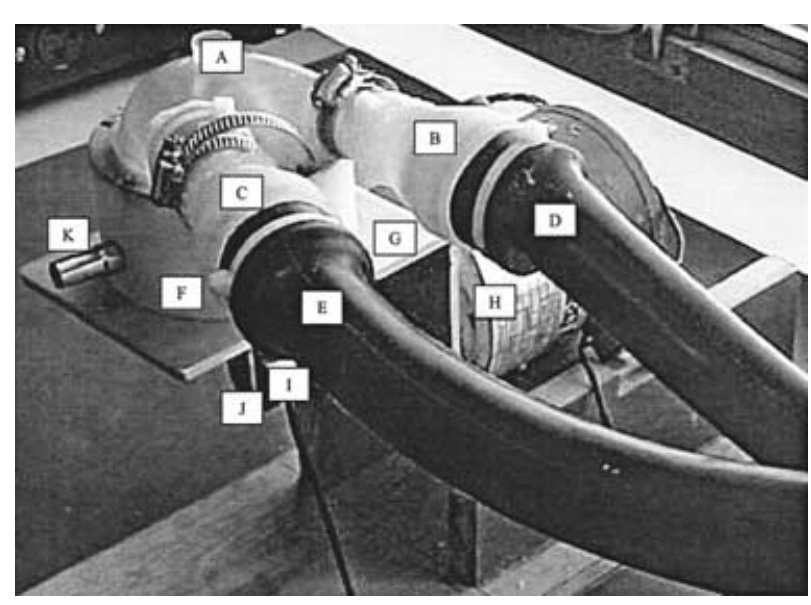

FIG. 1. A Mock Loop System used to the endurance test of the textured diaphragm is illustrated, showing: Pump chamber (A); Aortic valve housing (B); Venous valve housing (C); Aortic compliance tube (D); Venous compliance tube (E); Pump chamber base $(F)$; Motor fixation base $(\mathrm{G})$; $\mathrm{DC}$ motor $(\mathrm{H})$; Eccentric (I); Articulated arm (J); Anti chamber connector (K).

potential failure points. Figure 2 shows schematically the test circuit to reproduce the human circulatory system.

The objective of the in vitro test with mock loop system is to confirm and validate the diaphragm design project, and also to verify the diaphragm performance under a variety of physiological and extra physiological conditions occurring in steady state and transitory mode, and to determine the diaphragm lifetime.

\section{Mechanical system description}

The mock loop circuit (Fig. 1) utilizes a DC (direct current) motor $(\mathrm{H})$ (Supertorq, Supergauss, Sao Paulo, Brazil) fixed in an aluminum base $(\mathrm{G})$, with an eccentric (I) coupled in its shaft. The eccentric is connected to an articulated arm $(\mathrm{J})$, which is connected to a pin. That pin has a linear movement, and pushes the diaphragm, ejecting all liquid through the outlet (B) of the pump chamber (A). The pump chamber base $(\mathrm{F})$ avoids the pin trepidation. The anti-chamber connector $(\mathrm{K})$ is used to compensate for the volume variation inside the device.

In the other end of the motor shaft a tachometer (an indented disc with an optical sensor) is coupled. An oscilloscope (7613 Tektronix, Beaverton, EUA) is used to count the pulses and give the average motor speed.

The aortic valve housing (B) and the venous valve housing (C) are used to accommodate the outflow and the inflow valve disks, and they are connected to the natural rubber tubes (D and E). 


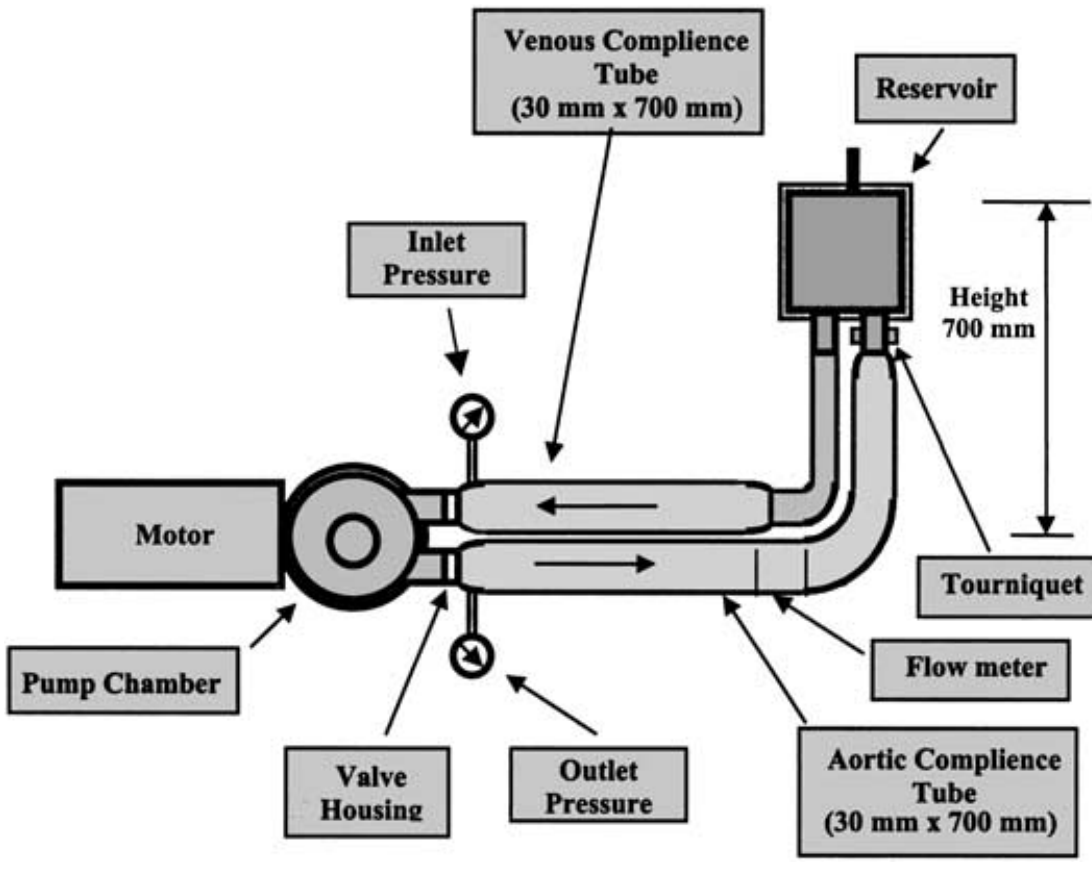

FIG. 2. The schematic drawing shows all parts of the Mock Loop System.

\section{Mock loop system}

The protocol sets 200 beats per minute, preload of $50 \mathrm{~mm} \mathrm{Hg}$, average afterload of $110 \mathrm{~mm} \mathrm{Hg}$ (higher $150 \mathrm{~mm} \mathrm{Hg}$ and smaller $80 \mathrm{~mm} \mathrm{Hg}$ ), flow of 8 liters per minute, and 70 days' duration.

The beat rate is accelerated up to three times the human normal rate to reduce the experiment duration. It is estimated that under normal conditions this 70 -day accelerated test is equivalent to a 6-month test $(12,14)$.

Water is used as a fluid test instead of a $37 \%$ glycerin-water solution, which has the same density and viscosity as blood (15). A glycerin-water solution is not used for a long- term test because of putrefaction.

The preload pressure is adjusted to $50 \mathrm{~mm} \mathrm{Hg}$, and the mean afterload pressure to $110 \mathrm{~mm} \mathrm{Hg}$ in order to provoke higher mechanical exigencies for the diaphragm.

Two $70 \mathrm{~cm}$ length tubes made of natural rubber are used to simulate aortic and venous compliance (Fig. 2).

The reservoir height and the tourniquet allow the preload and the afterload pressure regulation. Two mechanical valves $(23 \mathrm{~mm}$ one leaflet, Adib Jatene Fundation, Sao Paulo, Brazil) are used to command the flow direction. A flow meter (D74653, Gemü Gebr Muller, Ingelfingen, Germany) is used to measure the flow, and the pressure is measured with a differential manometer (Adib Jatene Fundation, Sao Paulo, Brazil).

\section{RESULTS}

Figure 3 shows a textured diaphragm made by a dipping process. The surface is totally textured, and no cracks are found in the diaphragm after the endurance test.

The in vitro test was interrupted after the stipulated period of 70 days, according to the protocol. That time means approximately 20 million cycles. At the end of the in vitro test, the mechanical device was totally taken apart, and all components were ana-

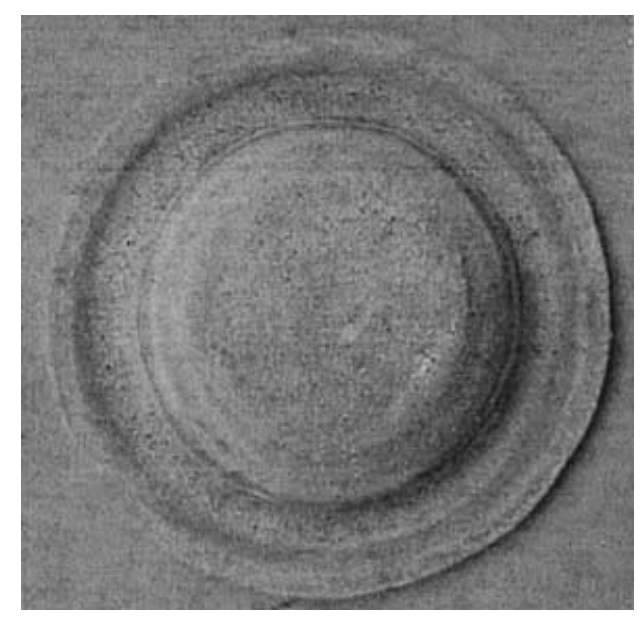

FIG. 3. The textured diaphragm made of polyurethane (BioSpan $\AA$, The Polymer Technology Group, San Francisco, USA) is illustrated. 
lyzed. To verify the occurrence of failure, the pump chamber and the diaphragm were carefully analyzed.

\section{DISCUSSION AND CONCLUSION}

The applied technique to make a polyurethane textured diaphragm has shown efficient results since a porous surface was obtained to fix the calf-skin gelatin coating. New tests are required in order to verify the gelatin coating stability.

The endurance test showed that the polyurethane textured diaphragm has sufficient mechanical resistance to be used in 15-day in vivo experiments. Additional in vitro tests will evaluate the textured diaphragm lifetime prior to any in vivo long-term study.

Acknowledgments: The authors would like to thank the technical staff (Mr. Pérsio Anibal and Mr. Wilson Tropico) for their valuable contribution to the project. In addition, the authors wish to express their gratitude to the Institute "Dante Pazzanese" of Cardiology and Adib Jatene Fundation for their financial support and contribution.

\section{REFERENCES}

1. Electronic publishing at ABTO 〈http://www.abto.com.br/doa org/doa_org.htm $\rangle$ March, 18 of 2002.

2. Andrade A, Nicolosi D, Lucchi J, Biscegli J, Arruda ACF, Ohashi Y, Mueller J, Tayama E, Glueck J, and Nosé Y. The Auxiliary Total Artificial Heart (ATAH) - A compact electromechanical artificial heart working simultaneously with the natural heart. Artif Organs 1999;23(9):876-80.
3. Nosé Y. Blood clotting problems in the artificial heart devices. J Biomed Mater Res 1967(a);1:151.

4. Nosé Y, Kwan-Gett CS, Hino K, Kolff WJ, Effler DB. Clot formation inside the artificial heart device. $J$ Thorac Cardiovasc Surg 1967(b);54:697.

5. Kwan-Gett CS, Oros R, Nosé Y. Detection of thrombogenic areas in artificial heart. Trans Am Soc Artif Intern Organs 1967;13:313.

6. Kambic H, Picha G, Kiraly R, Koshino T, Nosé Y. Application of aldehyde treatments to cardiovascular devices. Trans Am Soc Artif Intern Organs 1976;22:664.

7. Kambic H, Barenberg S, Harasaki H, Gibbons D, Kiraly R, Nosé Y. Glutaraldehyde-protein complexes as blood compatible coatings. Trans Am Soc Artif Intern Organs 1978;24:426.

8. Nosé Y, Kiraly R, Ozawa K, Sukalac R, Snow J, Harasaki H, Jacobs G, Murabayashi S, Golding L, Hillegass D, Castle C. Development and evaluation of cardiac prostheses. Annual Report N01-HV-4-2960-6, December 1980.

9. Kiraly R, Murabayashi S, Pepoy M, Field A, Kambic H, Hillegass D, Nosé Y. Cross-linked gelatin as a blood contacting surface. Artif Organs 1979;3:216.

10. Imai Y, Von Bally K, Nosé Y. New elastic materials for the artificial heart. Trans Am Soc Artif Intern Organs 1970;16-17.

11. Blass J, Verriest C, Leau A, Weiss M. Monomeric glutaraldehyde as an effective cross-linking reagent for proteins. J Am Leath Chem Assoc 1976;71-121.

12. Orime Y, Takatani S, Tasai K, Ohara Y, Naito K, Mizuguchi K, Makinouchi K, Matsuda Y, Shimono T, Glueck J, Noon GP, Nosé Y. In vitro and in vivo validation tests for total artificial heart. Artif Organs 1994;18(1):54-72.

13. Graham TR, Dasse K, Coumbe A, Salih V, Marrinan MT, Frazier OH, Lewis CT. Evaluation of textured biomaterial surfaces during clinical use of an implantable left ventricle assist device. Artif Organs 1990;14:135-43.

14. Ohashi Y, Andrade A, Nakata K, Müller J, Nosé Y. An augmented destruction test with an eletromechanical pulsatile total artificial heart. Artif Organs 1999;23(9):884-7.

15. Andrade A, Biscegli J, Dinkhuysen J, Sousa JE, Ohashi Y, Hemmings S, Glueck J, Kawahito K, Nosé Y. Characteristics of a blood pump combining the centrifugal and axial pumping principles: the spiral pump. Artif Organs 1996;20(6):60512 
ANEXO A - Informações Técnicas do BioSpan ${ }^{\circledR}$ 


\title{
'BioSpan ${ }^{\circledR}$ Segmented Polyurethane
}

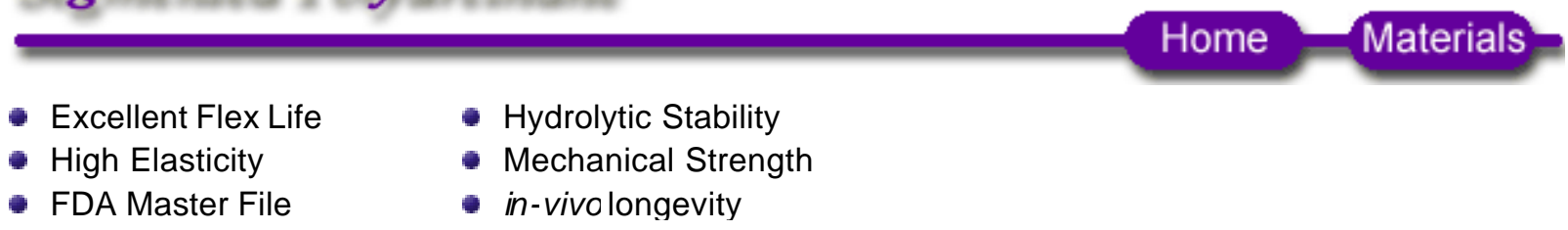

\author{
Introduction \\ Chemistry \\ Applications \\ Properties \\ Biological Test Results \\ Processing \\ Safety
}

\section{Introduction}

BioSpan ${ }^{\circledR}$ segmented polyurethane (SPU) is the critical biomaterial used in the majority of clinical ventricular assist devices and artificial heart cases worldwide. It is one of the most extensively tested biomaterials on the market, backed by a comprehensive FDA Master File. BioSpan is the most elastomeric biomaterial available that simultaneously exhibits an impressive combination of physical and mechanical properties together with biological compatibility.

SPUs have been used as biomaterials (e.g., in heart assist devices) since the late 1960s, when it was shown by Boretos and Pierce that Lycra ${ }^{\circledR}$ spandex, the SPU manufactured by DuPont (as textile fiber), has flex-fatigue resistance superior to silicone rubber. Ethicon, a Johnson and Johnson subsidiary, licensed the technology from DuPont for medical applications. Ethicon introduced a batchsynthesized version of Lycra spandex under the tradename Biomer ${ }^{\mathrm{TM}}$ SPU. For 20 years, Biomer was used to fabricate a variety of experimental blood pumps, such as ventricular assist devices and artificial hearts, including the well-known "Jarvik Heart," implanted in Dr. Barney Clark. Although Biomer performed well in most of these early applications, it was used in relatively few clinical cases. Product liability concerns eventually lead to Ethicon's decision to terminate the manufacture and sale Biomer in the late 1980s.

The Polymer Technology Group, Inc. (PTG) developed BioSpan ${ }^{\circledR}$ segmented polyurethane in response to the crisis created by the withdrawal of Biomer. Although designed as a direct replacement for Biomer, PTG made several improvements to the manufacturing process of BioSpan, including scaling up the reaction from 5 to 100 gallons, using glass-lined reaction vessels and depth filters that minimize contamination, and implementing rigorous quality control and documentation of the manufacturing procedures. As a result, PTG consistently produces BioSpan batches of precise molecular structure. This consistency, combined with an extensive FDA Master File, has facilitated the approval process for clinical applications of BioSpan. In its first eight years on the market, the total number of clinical VAD and artificial heart cases utilizing BioSpan, under branded and private label, has surpassed that of Biomer by thousands of cases.

For device components that require high strength, flexibility, and fatigue resistance, BioSpan should be considered as a candidate biomaterial. Whereas typical urethanes lose stability with increasing soft segment concentration, BioSpan SPU has excellent physical properties at nominal 65A Shore hardness. In the absence of (cobalt) corrosion products, BioSpan not only resists degradation, but actually increases in molecular weight in vivo in certain applications. Thus, BioSpan is the most elastomeric biomaterial available today with a proven combination of biocompatibility, biostability, and flex life in many critical applications.

In addition to the proven BioSpan polymer (i.e., the original Biomer replacement), PTG also offers experimental grades and variations of BioSpan with a variety of bulk and surface properties to satisfy specific requirements. For example, BioSpan ${ }^{\circledR} \mathrm{C}$ has an aliphatic polycarbonate soft segment that 
may impart additional oxidative stability to long-term implants, such as pacemaker leads, catheters, and stents, where metal oxide-induced oxidation (MIO) is a potential degradation mechanism.

Variations of BioSpan and BioSpan C are also available with surface properties similar to silicone, fluorocarbon, polyethylene oxide, or hydrocarbon polymers. By incorporating PTG's proprietary Surface-Modifying End Groups ${ }^{\mathrm{TM}}$, desirable surface properties may be obtained, including reduced coefficient of friction, improved abrasion resistance, thromboresistance, and control of wettability. PTG has also developed and patented a new generation of BioSpan that incorporates silicone into the soft segment, thus delivering the biocompatibility and stability of silicone to an extremely soft biomaterial with unique bulk properties.

Certain BioSpan materials are available unconfigured in a dimethylacetamide (DMAc) solution, suitable for fabrication processes such as casting, dipping, spinning, and spraying. Alternatively, PTG has the GMP/cleanroom facilities to fabricate devices and device components from BioSpan, according to your specifications.

\section{Chemistry}

BioSpan SPU is similar in chemistry to DuPont's Lycra Spandex. This series of solvent-based elastomers is based on an aromatic polyetherurethaneurea with a soft segment of polytetramethyleneoxide (PTMO) and a hard segment of diphenylmethane diisocyanate and mixed diamines. It contains an additive package consisting of an antioxidant and a copolymer of decyl methacrylate and diisopropylaminothyl methacrylate. Surface properties can be tailored to your specifications with surface modifying endgroups.

\section{Applications}

Numerous medical devices and technologies have benefited from the combination of softness, excellent mechanical properties, stability, and good biocompatibility of BioSpan segmented polyurethane. This section presents several clinical applications where BioSpan is used with continued success.

\section{Vascular Prostheses}

Synthetic vascular grafts are used to replace damaged vessels in the body, or to by-pass blocked arteries and veins. Large-diameter vascular grafts fabricated from BioSpan have been shown to retain their elastic characteristics long after repeated immersion in hot water, and also exhibit better thromboresistance than materials such as PET and e-PTFE.

\section{Left Ventricular Assist Devices (LVADs)}

The left ventricle accounts for 80 percent of heart functions, making bypass of the left side of the heart one of the most common methods of heart assist. BioSpan is used in this application to fabricate blood pump diaphragms because of its excellent flexure and wear properties. A blood sac of a totally implantable LVAD fabricated from BioSpan was implanted for 244 days with no thromboembolic complications.

\section{Total Artificial Hearts (TAH)}

Development of a totally implantable artificial heart remains one of the greatest challenges in biomedical engineering. BioSpan is currently being used as a bladder material in a number of different artificial heart programs, showing a good degree of blood compatibility and physical stability. BioSpan also displays low lipid absorption, a distinct advantage of over similar devices manufactured from silicone rubber. 


\section{Properties}

\begin{tabular}{|lll|}
\hline Property & Procedure ASTM & Value \\
\hline Initial Modulus (psi) & D-1708 & 850 \\
\hline Tensile Strength (psi) & D-1708 & 6000 \\
\hline Ultimate Elongation (\%) & D-1708 & 850 \\
\hline Hardness & D-2240 & $70 \mathrm{~A}$ \\
\hline Glass Transition Temperature $\left({ }^{\circ} \mathrm{C}\right)$ & D-3418 & -65 \\
\hline Water Absorption $(\%)$ & D-570 & 1.5 \\
\hline Weight Average MW (daltons) & D-3593 & 180,000 \\
\hline Appearance & NA & Translucent \\
\hline Solution Concentration & NA & $<25 \%$ (wt/wt) \\
\hline
\end{tabular}

$\boldsymbol{\Delta}$ Top

Biological Test Results

Tripartite Requirement

\begin{tabular}{|c|c|}
\hline Irritation & $\begin{array}{l}* \text { Primary Skin } \\
\approx \text { Primary Mucosal }\end{array}$ \\
\hline Sensitation & $\begin{array}{l}\text { * Kligman's Maximization: } \\
* \text { CSO Extract } \\
* \mathrm{NaCl} \text { Extract }\end{array}$ \\
\hline Cytotoxicity & * USP Cytotoxicity (MEM Elution) \\
\hline $\begin{array}{l}\text { Acute Systemic } \\
\text { Toxicity }\end{array}$ & $\begin{array}{l}* \quad \text { USP Acute Systemic } \\
* \quad \text { Intracutaneous Injection }\end{array}$ \\
\hline $\begin{array}{l}\text { Hemocompatibility } \\
\text { and Hemolysis }\end{array}$ & $\begin{array}{l}* \text { Hemolysis } \\
\approx \quad \text { Lee White Clotting }\end{array}$ \\
\hline Pyrogenicity & * USP Pyrogen \\
\hline Implantation & * USP Muscle Implantation: 14 Days in Rats \\
\hline $\begin{array}{l}\text { Mutagenicity } \\
\text { and Carcinogenicity }\end{array}$ & $\begin{array}{l}* \text { Ames Mutagenicity } \\
\approx \text { Chromosome Aberration } \\
\approx \text { Balb/c-3T3 Cell Transformation }\end{array}$ \\
\hline Subchronic Toxicity & * Repeat Dose Intravenous Study \\
\hline
\end{tabular}


To prepare films or components from BioSpan solution, PTG recommends the following protocol:

Note: the only materials that should ever come into contact with BioSpan solution are glass, stainless steel, or Teflon ${ }^{\circledR}$.

- Heat the immediate work area to $30-35^{\circ} \mathrm{C}\left(86-95{ }^{\circ} \mathrm{F}\right)$

- Provide HEPA-filtered air and adequate ventilation

- Dry the film or component (part) in the temperature controlled area. The elevated temperature is required because dimethylacetamide (DMAc) is a hygroscopic solvent and will pick up moisture at room temperature, resulting in a poor quality part.

- After the bulk of the solvent has evaporated (20-60 minutes), dry the part in an oven at $60^{\circ} \mathrm{C}$ $\left(140^{\circ} \mathrm{F}\right)$ to remove the remaining solvent. Please note that if too much solvent remains when the part is placed in the oven, bubbles may form. The oven time will vary depending on the dimensions of the part.

- A final water extraction may remove trace DMAc. Perform this water extraction at $60^{\circ} \mathrm{C}$ for 24 hours or longer, depending on sample thickness.

\section{$\mathbf{\Delta}$ Top}

\section{Safety}

- Store the material in a moisture-free environment

- Re-seal the jar with a nitrogen purge after each use

- Avoid contact with skin, eyes and clothing

- Provide adequate ventilation

- Keep away from excessive heat, sparks or open flame

- Biospan MSDS

$\boldsymbol{\Delta}$ Top 


\section{ANEXO B - Resultado dos Exames}

\section{Laboratoriais}

